Manoel Ângelo Gomes Palácio

\title{
Glicemia na ressuscitação cardiopulmonar
}

Tese apresentada ao Instituto Dante Pazzanese,

Entidade Associada à Universidade de São Paulo, para obtenção do título de Doutor em Ciências

Área de concentração: Medicina, Tecnologia e Intervenção em Cardiologia

Orientador: Dr. Ari Timerman

São Paulo

2011 
Manoel Ângelo Gomes Palácio

\section{Glicemia na ressuscitação cardiopulmonar}

Tese apresentada ao Instituto Dante Pazzanese,

Entidade Associada à Universidade de São Paulo, para obtenção do título de Doutor em Ciências

Área de concentração: Medicina, Tecnologia e Intervenção em Cardiologia

Orientador: Dr. Ari Timerman

São Paulo

2011 
Dados Internacionais de Catalogação na Publicação (CIP)

Preparada pela Biblioteca do Instituto Dante Pazzanese de Cardiologia

Oreprodução autorizada pelo autor

Palácio, Manoel Ângelo Gomes

Glicemia na ressuscitação cardiopulmonar / Manoel Ângelo Gomes Palácio. -- São Paulo, 2011.

Tese(doutorado)--Instituto Dante Pazzanese de Cardiologia

Área de Concentração: Medicina, Tecnologia e Intervenção em Cardiologia

Orientador: Dr. Ari Timerman

Descritores: 1.HIPERGLICEMIA. 2.PARADA CARDÍACA.

3.RESSUSCITAÇÃO. 4.GLICOSE. 5.METABOLISMO

USP/IDPC/Biblioteca/003/11 


\section{DEDICATÓRIA}

À minha querida irmã

Carmen Lúcia Gomes Palácio,

que acalentou o menino em seu sonho

até o despertar:

Médico

À minha amada família

Vânia Pomin Bechtlufft e Natan Bechtlufft Palácio,

que de tanto amor, carinho e felicidade o médico

voltou a ser menino e a

Sonhar... 


\section{AGRADECIMENTOS}

As palavras escritas podem ser ricas de significado, mas não podem expressar os meus sinceros agradecimentos:

\section{Muito obrigado!}

Ao meu orientador, Dr. Ari Timerman, pela oportunidade do trabalho e da pesquisa, pelo exemplo de humildade e compreensão, e por ter conduzido este doutorando de forma calma, eficaz e amigável.

Ao meu co-orientador informal, Dr. Edison Paiva, pelo companheirismo, pela generosidade nos ensinamentos e na lapidação dos resultados, propiciando um brilho pelo verdadeiro trabalho de equipe, e por ser bom amigo em todos os momentos.

Ao Dr. Luciano de Azevedo, pelos ensinamentos, participação científica e tecnológica e pelo trabalho de equipe no Laboratório de Medicina Intensiva e Anestesiologia (CT2), Instituto de Ensino e Pesquisa do Hospital SírioLibanês (IEP-HSL).

A Dra. Vet. Andreza Patara (IEP-HSL), pelo trabalho de equipe, guarda do sigilo da randomização e conhecimentos de anestesia aplicados. 
Aos auxiliares de biotério do CT2, Sr. Ernande Xavier dos Santos, Sr. Flávio Silva de Novaes e Sr. Renato Serapião, pelo apoio no preparo dos animais e durante os experimentos.

Ao Dr. Fausto Feres, pelo treinamento na Cardiologia Intervencionista, sob sua indicação e, algumas preciosas vezes, sob o toque de suas mãos na arte da intervenção percutânea. Pelos cateteres e introdutores gentilmente cedidos e adequadamente re-esterilizados que, junto com a técnica assimilada, foram importantes para este estudo.

Ao Dr. Sérgio Braga, pelo apoio e treinamento básico recebidos na Cardiologia Intervencionista.

A Enf. Maria Helena de Almeida e ao Sr. Lauro de Aro Filho, pelo apoio recebido na separação de material e re-esterilização adequada.

A Dra. Elizabete Silva dos Santos, pelo aprendizado de Emergências, especialmente Síndrome Coronária Aguda, pelo incentivo à pesquisa e ao trabalho, pela participação em importantes e singelos estudos que embasaram esta pesquisa.

Ao Dr. Vet. Paulo Valente pelo apoio e treinamento recebidos.

Ao Dr. Eng. Aron de Andrade, pelo apoio e incentivo recebidos.

A Sra. Rika Kishi e ao Sr. Celso Trigo pelo apoio e incentivo e ao Dr. Luís Bento, Pres. da Fundação Adib Jatene, pelo financiamento de material permanente e de consumo. 
Ao Pres. do Instituto de Ensino e Pesquisa do Hospital Sírio-Libanês, Dr. Luiz Fernando Lima Reis, pela cooperação e pelo oferecimento de suas instalações e facilidades para a pesquisa.

A Profa. Dra. Amanda G.M.R. Sousa, pelo incentivo às Ciências.

A Pres. da Comissão de Pós-Graduação, Profa. Dra. Amanda G. M. R. Sousa, e aos llustres Membros da Comissão de Pós-Graduação, pelo financiamento de material de consumo por meio do Programa de Apoio à Pós-Graduação (PROAP - CAPES).

A Sra. Janeide Alves dos Santos, Sra. Michelle Putnoki Oliveira, Sra. Rita de Cássia Lopes Oliveira e Sra. Valquíria Cristina S. Dias, pelo apoio nas questões formais e regulamentares do doutoramento.

Aos amigos da $1^{a}$ turma de

Medicina, Tecnologia e Intervenção em

Cardiologia:

Foi um prazer e uma honra estudar com vocês!

Manoel 


\section{NORMALIZAÇÃO}

Esta tese está de acordo com as seguintes normas, em vigor no momento desta publicação:

- Referências: adaptado de International Committee of Medical Journals Editors (Vancouver).

- Universidade de São Paulo. Faculdade de Medicina. Serviço de Biblioteca e Documentação. Guia de apresentação de dissertações, teses e monografias. Elaborado por Anneliese Carneiro da Cunha, Maria Julia de A. L. Freddi, Maria F. Crestana, Marinalva de Souza Aragão, Suely Campos Cardoso, Valéria Vilhena. 2a ed. São Paulo: Serviço de Biblioteca e Documentação; 2005.

- Abreviaturas dos títulos dos periódicos de acordo com List of Journals Indexed in Index Medicus. 


\section{SUMÁRIO}

\section{LISTA DE ABREVIATURAS \\ LISTA DE SÍMBOLOS \\ LISTA DE TABELAS \\ LISTA DE FIGURAS \\ RESUMO \\ SUMMARY}

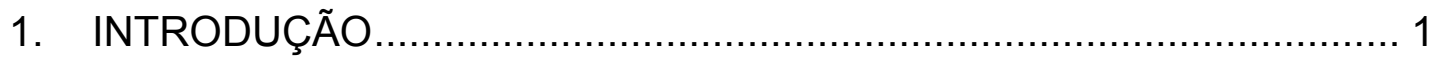

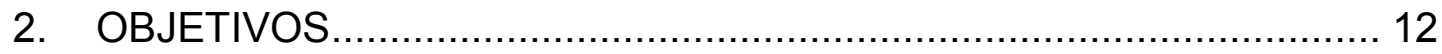

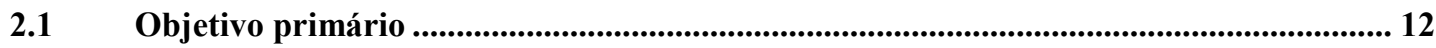

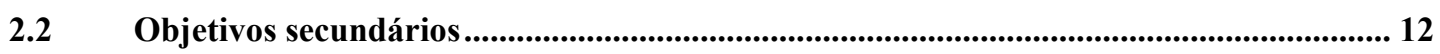

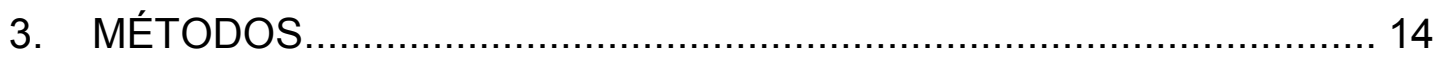

3.1 Aprovação dos comitês de ética .......................................................................................... 14

3.2 Descrição dos animais que foram utilizados ......................................................... 14

3.3 Descrição dos Procedimentos........................................................................................... 14

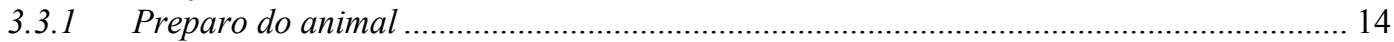

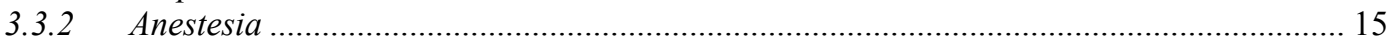

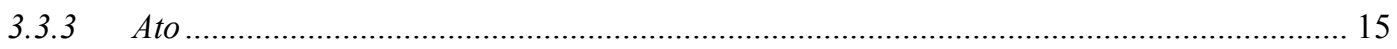

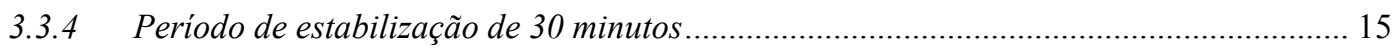

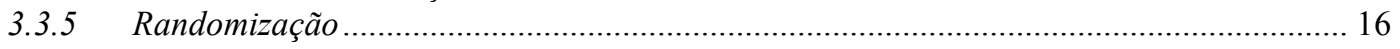

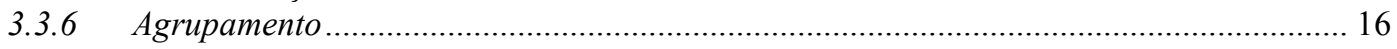

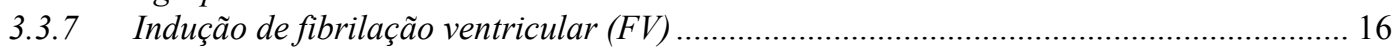

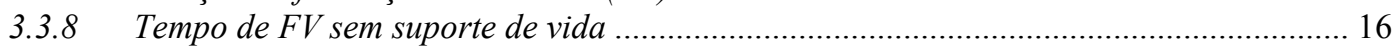

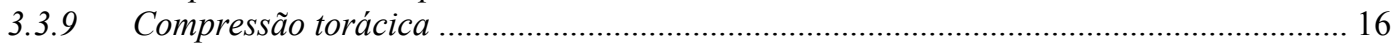

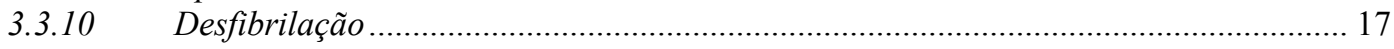

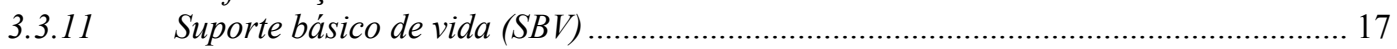

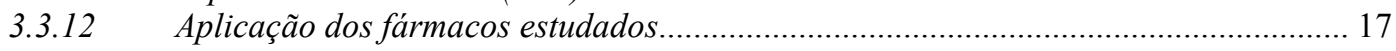

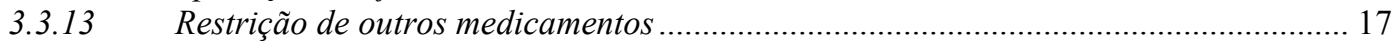

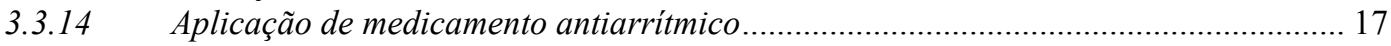

3.3.15 Suporte básico e avançado de vida de acordo com o padrão atual ............................. 17

3.3.16 Retorno da circulação espontânea e período pós-parada............................................ 18

3.3.17 Coletas de sangue para dosagem imediata e para congelamento............................... 18

3.3.18 Coletas de sangue para cálculos de oferta e de consumo de oxigênio......................... 18

3.3.19 Variáveis anotados em formulário .............................................................................. 19

3.3.20 Variáveis anotados em duplicata durante o experimento ........................................... 19

3.3.21 Variáveis monitorados e gravadas continuamente ..................................................... 19

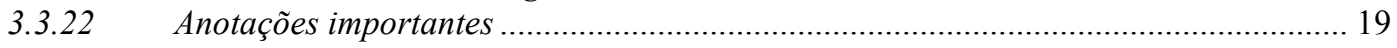

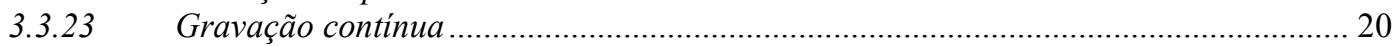

3.3.24 Preparo prévio das seringas com os fármacos em estudo......................................... 20

3.3.25 Preparo prévio das seringas para coleta de sangue e imediata dosagem................... 20

3.3.26 Preparo prévio dos tubos de coleta de sangue para congelamento ............................. 20 


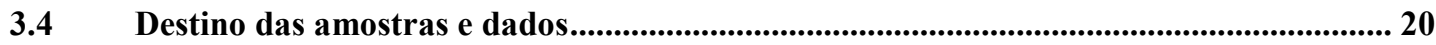

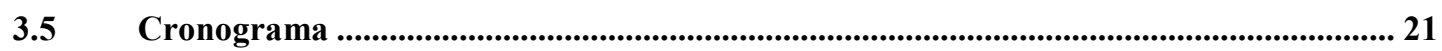

3.6 Participantes do projeto e auxiliares ........................................................................................ 21

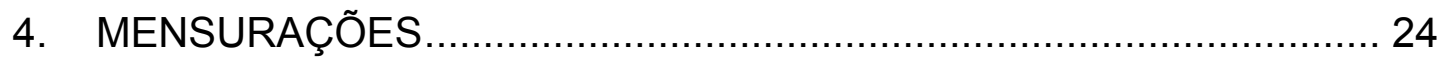

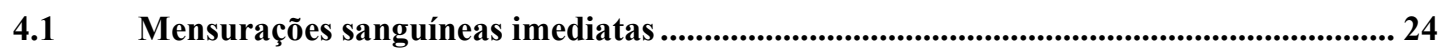

4.2 Mensuração no sangue congelado ……………................................................................... 24

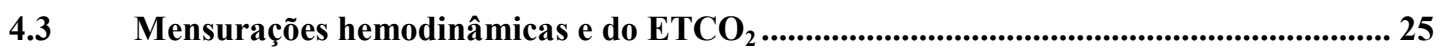

4.3.1 Sistematização das mensurações ............................................................................ 25

4.4 Mensurações derivadas das hemodinâmicas e sanguíneas ...................................................... 26

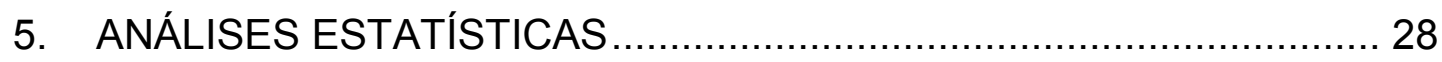

$5.1 \quad$ Cálculo prévio do tamanho da amostra ........................................................................... 28

5.2 Testes estatísticos .................................................................................................................... 29

$5.3 \quad$ Precisão das mensurações ........................................................................................................ 30

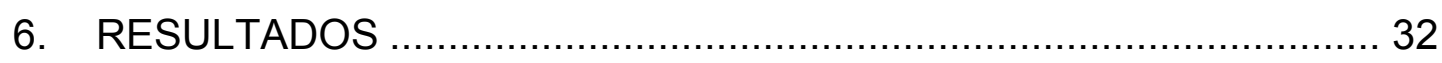

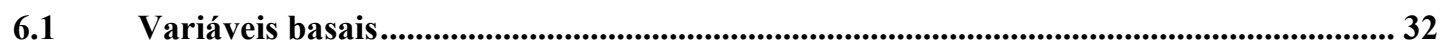

6.2 Retorno da circulação espontânea ........................................................................................... 38

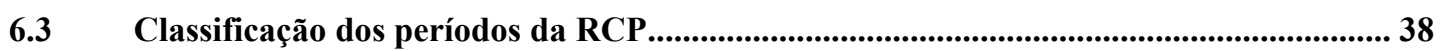

6.4 Períodos da RCP em cada animal ........................................................................................ 39

6.5 A seqüência de RCE.................................................................................................................... 40

6.6 A compilação das curvas de glicemia dos 32 animais ............................................................ 41

6.7 Perfis glicêmicos extremos podem influenciar o RCE ......................................................... 42

6.8 As análises das médias correspondem aos 29 animais típicos ............................................ 42

6.9 A evolução típica da glicemia na RCP ocorreu em 91\% dos animais ................................ 43

6.10 Sinopse das variáveis até 35 min.................................................................................44

6.10.1 Variáveis do sangue venoso misto ...................................................................... 44

6.10.2 Pressão, ETCO $\mathrm{CH}_{2}$ e freqüência das manobras de suporte .......................................... 46

6.11 A glicemia e a PPC se associaram com o RCE ..................................................................4 46

6.11.1 A glicemia se associou com o RCE, independente do fármaco .................................. 46

6.11.2 A PPC se associou com o RCE, mas dependeu do fármaco ....................................... 48

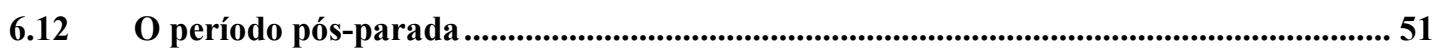

6.13 A concentração de epinefrina basal e após o suporte de vida ..................................... 51 


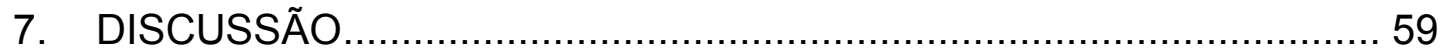

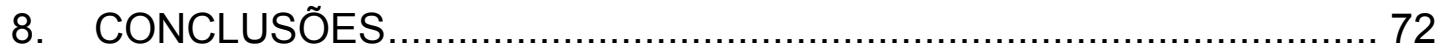

ANEXOS

Anexo A - Documento da Comissão de Pós-Graduação ao diretor do Instituto de Ensino e Pesquisa do Hospital Sírio-Libanês e ao Comitê de Ética local.

Anexo B - Documento de aprovação do Comitê de Ética no Uso de Animais do Instituto de Ensino e Pesquisa do Hospital Sírio-Libanês.

Anexo C - Documento de aprovação do Comitê de Ética no Uso de Animais do Instituto Dante Pazzanese de Cardiologia. .......................................... 76

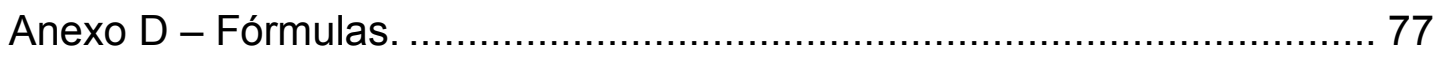

Anexo E - Gráfico para cálculo do tamanho da amostra............................ 78

Anexo $\mathrm{F}$ - Evolução de variáveis do sangue venoso misto conforme o retorno da circulação espontânea (RCE)................................................... 79

Anexo G - Evolução de variáveis do sangue venoso misto de acordo com o

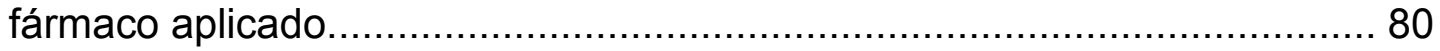

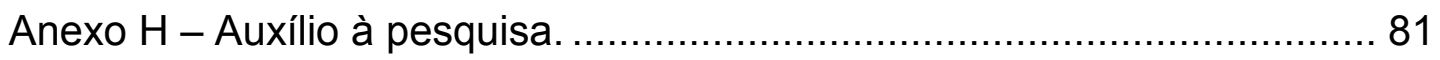

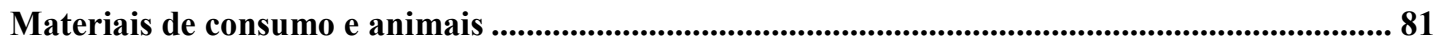

Laboratório de Pesquisa de Medicina Intensiva (CT2) ..............................................................8 81

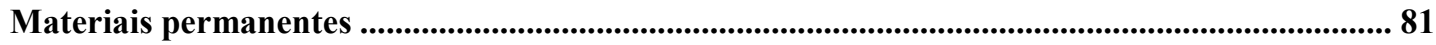

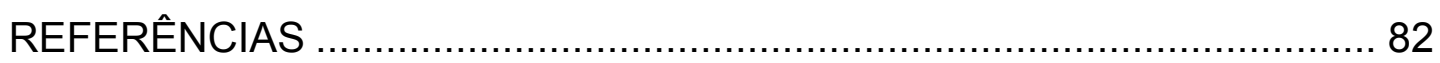




\section{LISTA DE ABREVIATURAS}

\begin{tabular}{ll} 
ADP & Adenosina Difosfato \\
ATP & Adenosina Trifosfato \\
CAPES & Coordenação de Aperfeiçoamento de Pessoal \\
& de Nível Superior \\
EV & Endovenoso \\
FV & Fibrilação Ventricular \\
GLUT & Transportador de Glicose \\
HSL & Hospital Sírio-Libanês \\
IDPC & Instituto Dante Pazzanese de Cardiologia \\
IEP & Instituto de Ensino e Pesquisa \\
IM & Intramuscular \\
PCR & Parada Cardiorrespiratória \\
PPC & Pressão de Perfusão Coronária \\
PROAP & Programa de Apoio à Pós-Graduação \\
RCE & Retorno da Circulação Espontânea \\
RCP & Ressuscitação Cardiopulmonar \\
RNA & Acido Ribonucléico \\
RNAm & RNA mensageiro \\
SBV & Suporte Básico de Vida \\
SNC & Sistema Nervoso Central \\
\hline
\end{tabular}




\section{LISTA DE SÍMBOLOS}

$\begin{array}{ll}\Delta & \text { Delta (Diferença) } \\ \mathrm{g} & \text { grama } \\ { }^{\circ} \mathrm{C} & \text { Grau Celsius } \\ \mathrm{J} & \text { Joule } \\ \mu & \text { micro } \\ \mathrm{min} & \text { minuto } \\ \mathrm{n} & \text { nano } \\ \mathrm{kg} & \text { quilograma } \\ \mathrm{s} & \text { segundo }\end{array}$




\section{LISTA DE TABELAS}

Tabela 1 - Variáveis do período basal de 32 animais agrupados conforme a evolução da parada cardíaca: sem diferenças significantes entre os grupos.

Tabela 2 - Variáveis séricas basais de 32 animais agrupados conforme a evolução da parada cardíaca: sem diferenças significantes entre os grupos.

Tabela 3 - Variáveis do período basal de 32 animais agrupados pelo fármaco da parada cardíaca: sem diferenças significantes entre os grupos.

Tabela 4 - Variáveis venosas basais de 32 animais de acordo com o fármaco da parada cardíaca: sem diferenças significantes entre os grupos.

Tabela 5 - Variáveis arteriais basais de 32 animais de acordo com o fármaco da parada cardíaca: sem diferenças significantes entre os grupos.

Tabela 6 - Evolução da parada cardíaca de acordo com o fármaco aplicado.

Tabela 7 - Classificação da parada cardíaca em períodos de tempo.

Tabela 8 - Tempo transcorrido desde a indução da fibrilação ventricular e número de animais com RCE de acordo com o fármaco aplicado.

Tabela 9 - Evolução da glicemia de acordo com o RCE.

Tabela 10 - Evolução da glicemia de acordo com o fármaco aplicado.

Tabela 11 - Variáveis basais e após $2 \mathrm{~h}$ de RCE. Sem diferenças ao se compararem os grupos em cada período.

Tabela 12 - Variáveis venosas no basal e após $2 \mathrm{~h}$ de RCE: sem diferenças ao sem compararem os grupos em cada período.

Tabela 13 - Variáveis arteriais no basal e após 2 h de RCE: sem diferenças ao se compararem os grupos em cada período. 


\section{LISTA DE FIGURAS}

Figura 1 - Glicemia média de 29 animais típicos (símbolos cheios) e com 3 animais atípicos, de acordo com o retorno da circulação espontânea (RCE).--

Figura 2 - Glicemia conforme o retorno da circulação espontânea (RCE). ------------------- 43

Figura 3 - Glicemia de acordo com o fármaco aplicado

Figura 4 - Evolução do lactato durante a ressuscitação cardiopulmonar.

Figura 5 - Pressão de perfusão coronária (PPC) durante o suporte de vida com fármaco (Fárm) aplicado aos 9 min. Em cima, de acordo com o retorno da circulação espontânea $(\mathrm{RCE})$. Em baixo, de acordo com o fármaco aplicado Epinefrina (Ep), Vasopressina (Vp) ou

Salina (Sal). Símbolo e barras (média \pm 2 erro-padrão).

Figura 6 - Glicemia durante o suporte de vida com fármaco (Fárm) aplicado aos 9 min. Em cima, conforme o retorno da circulação espontânea (RCE). Em baixo, de acordo com o fármaco Epinefrina (Ep), Vasopressina (Vp) ou Salina (Sal). Símbolo e barras (média \pm 2 erro-padrão).

Figura 7 - Epinefrina sérica basal e após o óbito ou após 10 min de retorno da circulação espontânea (RCE 10'). Em cima, conforme o retorno da circulação (RCE) ou não. Em baixo, de acordo com o fármaco aplicado Epinefrina (Ep), Vasopressina (Vp) ou Salina (Sal).

Símbolo e barras (média \pm 2 erro-padrão).

Figura 8 - Evolução do débito cardíaco basal (0) até $2 \mathrm{~h}$ após o retorno da circulação espontânea (RCE) conforme os grupos Epinefrina (Ep), Vasopressina (Vp) ou Salina (Sal).

Figura 9 - Evolução da extração de oxigênio basal (0) até $2 \mathrm{~h}$ após o retorno da circulação espontânea (RCE) conforme os grupos Epinefrina (Ep), Vasopressina (Vp) ou Salina (Sal).

Figura 10 - Evolução do consumo de oxigênio basal ( 0 ) até $2 \mathrm{~h}$ após o retorno da circulação espontânea (RCE) conforme os grupos Epinefrina (Ep), Vasopressina (Vp) ou Salina (Sal).

Figura 11 - Evolução da oferta de oxigênio basal (0) até $2 \mathrm{~h}$ após o retorno da circulação espontânea (RCE) conforme os grupos Epinefrina (Ep), Vasopressina (Vp) ou Salina (Sal). 


\section{RESUMO}

Palácio, MAG. Glicemia na ressuscitação cardiopulmonar [tese]. São Paulo: Instituto Dante Pazzanese de Cardiologia, Universidade de São Paulo; 2011. $115 p$.

FUNDAMENTO: Hiperglicemia está associada a mau prognóstico nas doenças crônicas e agudas, mas poucos estudos abordaram a glicemia durante a ressuscitação cardiopulmonar. OBJETIVO: Avaliar a evolução da glicemia em modelo de parada cardíaca similar ao atendimento atual dos casos de morte súbita extra-hospitalar. MÉTODOS: Em estudo prospectivo, randomizado e cego, fibrilação ventricular foi induzida em 32 animais. Após 7 min, suporte de vida padrão foi iniciado e mantido até o retorno da circulação espontânea ou por $30 \mathrm{~min}$ no máximo. Os animais foram randomizados em três grupos, de acordo com o fármaco aplicado: Epinefrina $(n=12)$, Vasopressina $(n=12)$ ou Salina $(n=8)$. A glicemia basal foi mensurada e novamente aos $4 \mathrm{~min}, 8 \mathrm{~min}$, após o primeiro choque aos 9 min (coincidindo com a $1^{\text {a }}$ dose de fármaco) e a cada 5 min. RESULTADOS: O retorno da circulação espontânea ocorreu em 19 animais: grupo Epinefrina 10/12, Vasopressina 7/12 e Salina 2/8, diferença significante somente entre Epinefrina e Salina $(p=0,019)$. A evolução foi típica ao longo do suporte de vida em todos os grupos, com grande aumento da glicemia ocorrendo também no grupo controle. A cada instante, com apenas 2 min de suporte de vida, a glicemia dos animais que sobreviveram à parada cardíaca foi maior do que a glicemia dos animais que não sobreviveram $(229 \pm 15 \mathrm{mg} / \mathrm{dL} v s$. $182 \pm 15 \mathrm{mg} / \mathrm{dL} ; \mathrm{p}=0,041)$. Esta diferença foi notada aos $9 \mathrm{~min}$, antes da $1^{\mathrm{a}}$ dose de fármaco e se manteve ao longo de todo o experimento, com pico aos $14 \mathrm{~min}(263 \pm 20 \mathrm{mg} / \mathrm{dL}$ vs. $178 \pm 16 \mathrm{mg} / \mathrm{dL} ; p=0,006)$. CONCLUSÕES: Houve uma evolução típica, com hiperglicemia durante a ressuscitação cardiopulmonar e concentrações maiores de glicose se associaram à sobrevivência da parada cardíaca.

\section{Descritores:}

Glicemia, Hiperglicemia, Ressuscitação, Parada Cardíaca, Metabolismo. 


\section{SUMMARY}

Palácio, MAG. Serum Glucose During Cardiopulmonary Resuscitation: A Predictor of Outcome [Thesis]. São Paulo: Instituto Dante Pazzanese de Cardiologia, Universidade de São Paulo; 2011. 115p.

Background: Although hyperglycemia is associated with poor outcomes in emergency conditions, limited data exist regarding the effects of serum glucose on cardiopulmonary resuscitation (CPR). Methods and Results: In a prospective, blinded animal study, ventricular fibrillation was induced in 32 pigs. Standard CPR was initiated at $7 \mathrm{~min}$ and continued for up to $30 \mathrm{~min}$ or until the return of spontaneous circulation (ROSC). The animals were randomly assigned into three groups according to the medication administered: epinephrine $(n=12)$, vasopressin $(n=12)$, and saline $(n=8)$. The serum glucose was measured at baseline, $4 \mathrm{~min}, 8 \mathrm{~min}, 9 \mathrm{~min}$ (immediately after the first shock), with the first dose of medication, and then every 5 min. ROSC occurred in 19 pigs: in 10/12 of the epinephrine group, 7/12 of the vasopressin group, and $2 / 8$ of the saline group. A significant difference in the ROSC rate was found only between the epinephrine and saline groups $(p=0.019)$. The serum glucose presented a typical pattern; hyperglycemia was present in all the groups and was higher in those animals that achieved ROSC, independent of the drug administered $(229 \pm 15 \mathrm{mg} / \mathrm{dL}$ vs. $182 \pm 15$ $\mathrm{mg} / \mathrm{dL} ; \mathrm{p}=0,041)$. This difference was first noticed at $9 \mathrm{~min}$ and the largest difference occurred at $14 \mathrm{~min}$, after $7 \mathrm{~min}$ of CPR, and $5 \mathrm{~min}$ after the first medication (263 $\pm 20 \mathrm{mg} / \mathrm{dL}$ vs. $178 \pm 16 \mathrm{mg} / \mathrm{dL} ; \mathrm{p}=0,006)$. Conclusions: In an experimental VF study, there was a typical hyperglycemic response pattern during CPR, and higher glucose levels were associated with ROSC.

\section{Key Words}

Glucose, Hyperglycemia, Resuscitation, Heart Arrest, Metabolism. 


\section{INTRODUÇÃO}

A hiperglicemia verificada na admissão hospitalar por motivo de doença aguda é denominada "hiperglicemia de estresse" ou "da admissão" hospitalar e está associada a pior prognóstico, ocorrendo em pacientes diabéticos e em pacientes que comprovadamente não são diabéticos. ${ }^{1-30} \mathrm{~A}$ glicemia foi pouco estudada em modelos animais da espécie suína, dentro da pesquisa experimental sobre RCP*. Em humanos, a hiperglicemia de estresse tem sido estudada na síndrome coronária aguda, no acidente vascular encefálico, em outras doenças agudas e no trauma, nos casos clínicos e cirúrgicos sob terapia intensiva, mas não tanto na PCR e RCP..$^{31-45}$ Com exceção do benefício comprovado no pós-operatório principalmente de cirurgia cardíaca, o controle glicêmico rigoroso com insulina intensiva está em destaque como forma de melhorar o prognóstico de diversas doenças agudas, mas há controvérsias. ${ }^{46-49}$ Os estudos clínicos são poucos e houve um aumento na incidência de hipoglicemia grave e na mortalidade associada ao controle glicêmico mais rigoroso. ${ }^{46,50-54}$ Já a PCR tem como causa freqüente a isquemia, mas, qualquer que seja a causa, a conseqüência é a isquemia global com o predomínio do metabolismo anaeróbico sustentando a vida celular por alguns minutos. ${ }^{55-57} \mathrm{~A}$ possibilidade terapêutica associada ao o metabolismo da glicose motivou este estudo da evolução da glicemia durante a RCP.

\footnotetext{
*Após extensa pesquisa na literatura científica (Bireme, Medline e Resuscitation), encontraram-se poucos artigos que relataram a glicemia em algum momento da RCP em animais.
} 
A isquemia global decorrente da PCR causa lesões sistêmicas, principalmente neurológicas e cardíacas, conhecidas como síndrome pósparada. ${ }^{58-63}$ As lesões não se limitam ao período de isquemia, na realidade se estendem e se acentuam com a reperfusão, refletindo-se clinicamente no coma e na disfunção cardíaca. ${ }^{58-64} \mathrm{O}$ retorno da circulação espontânea (RCE) está associado com a pressão de perfusão coronária (PPC), gradiente entre a pressão da aorta e do átrio direito ao final da descompressão torácica durante o suporte básico de vida (SBV). ${ }^{65-69}$ Medicamentos vasoconstritores são utilizados na RCP porque aumentam a PPC ao elevarem a pressão "diastólica" da aorta devido à vasoconstrição periférica. ${ }^{56,70-72}$ Epinefrina contrai os vasos pelo estímulo dos receptores $\alpha$ 2, aumentando a PPC. ${ }^{56,70-79}$ Contudo, ao estimular também os receptores $\alpha-1$ e $\beta-1$, aumenta o inotropismo e o cronotropismo causando maior consumo de oxigênio e maior depleção energética do miócito. ${ }^{56,71,73}$ Esses efeitos deletérios estão implicados com a disfunção miocárdica pósparada. ${ }^{56,70,73,80-88}$ A vasopressina é um potente vasoconstritor que age através de seus receptores $\mathrm{V} 1_{\mathrm{a}}$ localizados no músculo liso vascular. ${ }^{70-73,83-}$ 87, 89-95 Aumenta a PPC e não aumenta o cronotropismo e o consumo de oxigênio miocárdico acentuadamente como a epinefrina. ${ }^{70,72,73,83-87}$ Ao contrário das catecolaminas, preserva o efeito vasoconstritor mesmo durante hipóxia e acidose prolongada. Seu efeito é maior nos vasos musculares, cutâneos e esplâncnicos. ${ }^{70,72,73,83-87}$ Contudo, vasodilatação dose dependente paradoxalmente foi descrita nos leitos coronário, pulmonar e vertebrobasilar. $^{70,73,83-87}$ 
Devido ao potente efeito vasoconstritor de ambas e aos efeitos deletérios da epinefrina em contraponto com a vasopressina quanto à disfunção miocárdica pós-parada, as duas medicações têm sido muito estudadas em animais e em humanos. ${ }^{72,74,75,77,81,82,85,89-92,96-103}$ Apesar da superioridade da vasopressina em animais quanto a PPC e quanto aos menores efeitos deletérios, em humanos restam dúvidas sobre a ampliação de sua utilização, atualmente indicada para os casos de assistolia ou atividade elétrica sem pulso, PCR prolongada e em uso combinado com a epinefrina. ${ }^{71,72,98,99,102,104}$ Diversos outros medicamentos foram associados com ambas visando à proteção da lesão de reperfusão e da disfunção miocárdica pós-parada, além da proteção cerebral. ${ }^{58-61,64,82,105-117}$

Apesar da extensa pesquisa experimental sobre a proteção da lesão de isquemia e de reperfusão, poucos estudos reverteram para a aplicação clínica, como ocorreu com a hipotermia recentemente. ${ }^{118-121}$ Isto se deve em parte aos modelos de estudo que não reproduzem a complexa condição do ser humano acometido da síndrome isquêmica. ${ }^{118}$ Existe a necessidade de se pesquisar medicamentos mais eficazes e que protejam da lesão da isquemia e da reperfusão, além da pesquisa dos processos metabólicos relacionados. ${ }^{120} \mathrm{O}$ conhecimento da glicemia ao longo da RCP é um passo importante para o estudo de possíveis intervenções aplicadas antes da reperfusão visando à proteção celular.

O conhecimento do metabolismo da glicose por meio de sua curva sanguínea abre a possibilidade de intervenção preventiva para as conseqüências deletérias da PCR observadas no período pós-parada. Toda 
a vida se mantém com a homeostase energética ubíqua. ${ }^{122}$ A glicose transporta a energia que nos mantém vivos. A todo o momento, mesmo durante a PCR sem suporte e sem circulação sanguínea, é o metabolismo anaeróbico da glicose, a glicólise que mantém a célula viva por alguns minutos. ${ }^{122}$ Com o SBV, a glicose da reserva hepática chega à célula pela circulação sanguínea, junto com pouco oxigênio. ${ }^{87,121,123-128}$ A maior importância da compressão torácica é primordialmente a oferta de glicose para os tecidos, corroborando com a recomendação atual de se priorizar a compressão torácica de qualidade. ${ }^{121,129-133}$

A escolha do modelo suíno de experimentação foi por motivos de semelhança cardiovascular anatômica e fisiológica com o ser humano, principalmente para tentar reproduzir o evento real do ser humano vítima de morte súbita e socorrido de forma adequada. ${ }^{65,134}$ As alterações hemodinâmicas e funcionais são semelhantes e também as características do tórax durante as compressões. ${ }^{65,134}$ O modelo suíno tem sido largamente utilizado e permite a aplicação adequada do suporte básico e avançado de vida. ${ }^{65,134-168}$ Certas alterações metabólicas devem ser idênticas, pois as vias metabólicas básicas são as mesmas em todas as espécies. ${ }^{122} \mathrm{~A}$ glicólise e o ciclo do ácido cítrico são reações químicas que compartilham dos mesmos substratos e metabólitos pertencentes não só à espécie mas também ao reino animal. ${ }^{122}$ Metabólitos como piruvato e acetil-coenzima $\mathrm{A}$ são moléculas que participam das mesmas vias metabólicas da bactéria, da planta, do ser humano ou do suíno. ${ }^{122}$ 
A glicólise é uma reação química que ocorre no citoplasma de todas as células sem utilizar o oxigênio, consome duas moléculas de adenosina trifosfato (ATP) e gera quatro. Portanto, cada mol de glicose gera dois mols de ATP. ${ }^{122}$

O ciclo de Krebs é outra reação química que ocorre no interior da mitocôndria junto com a cadeia de transporte de elétrons que ocorre na membrana interna da mitocôndria, gerando 36 ATP por molécula de glicose, mas estas reações só ocorrem se houver oxigênio. ${ }^{122}$

A maioria das espécies de vertebrados possui reserva de glicose, como a reserva hepática de glicogênio dos mamíferos. ${ }^{122}$ Estoques de glicogênio existem no fígado e nos músculos, mas o fígado possui a enzima glicose 6fosfatase para a conversão da glicose-6-fosfato em glicose, forma de transporte da energia e que pode sair do citoplasma para a circulação sanguínea. ${ }^{122}$ A veia porta e veia hepática conduzem a glicose para a veia cava inferior. O sangue venoso misto das duas cavas pode ser coletado na artéria pulmonar. ${ }^{169,170}$

A glicose-6-fosfato é a molécula que participa do cruzamento das diversas vias metabólicas de catabolismo ou anabolismo. ${ }^{122}$ A energia que mantém os processos estruturais, funcionais, o equilíbrio iônico e toda a bioquímica celular vêm da molécula de ATP que é constantemente formada e constantemente utilizada, num equilíbrio finamente ajustado por mecanismos intrínsecos (auto-regulação) e extrínsecos (hormônios). ${ }^{122} \mathrm{O}$ pâncreas libera os hormônios insulina e glucagon que agem no fígado para diminuir ou aumentar a glicemia respectivamente, na verdade mantendo a 
concentração sanguínea finamente ajustada. ${ }^{122} \mathrm{~A}$ adrenalina sobrepõe seus efeitos aos dos hormônios nas situações de estresse e aumenta a glicemia, a hidrólise do glicogênio e a glicólise, aumentando rapidamente a produção de energia demandada. Na condição globalmente isquêmica da parada cardíaca os hormônios exógenos como a adrenalina e também a vasopressina têm efeito sobre o metabolismo da glicose no sentido de

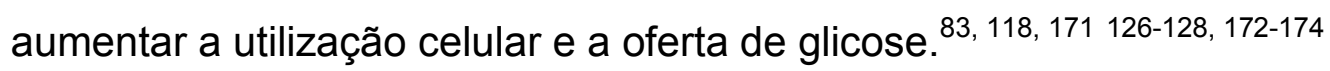
Na condição de isquemia, rapidamente várias alterações ocorrem, como o aumento da glicólise, da glicogenólise, aumento da expressão dos transportadores de glicose (GLUT) na membrana plasmática e da atividade das hexoquinases. A captação de glicose pode ser aumentada e a função celular, preservada por meio de maior oferta de glicose, graças à difusão facilitada pelos GLUT. ${ }^{175-188}$ A expressão dos GLUT é específica de cada tecido ou sistema celular. ${ }^{189}$ GLUT1 é expresso em todas as células junto com outros transportadores que predominam conforme o tecido. GLUT1 predomina nos eritrócitos e nas células endoteliais. GLUT2 predomina nos hepatócitos e células beta pancreáticas. GLUT3 não é regulado pela insulina e predomina nos neurônios e plaquetas. GLUT4 é expresso nos tecidos sensíveis à insulina e nos cardiócitos. No coração existem dois tipos principais de transportadores, GLUT1 e GLUT4. Em modelos in vitro e in vivo, a isquemia desencadeia o aumento da glicólise, da glicogenólise, da atividade das hexoquinases e da expressão ou afinidade de GLUT1 nos cardiócitos. A velocidade de transporte de glicose aumenta proporcionalmente com a concentração extracelular. ${ }^{175}$ No fígado, GLUT2 
permanece na membrana (sem translocação) e é tão eficiente que as concentrações intra e extracelulares de glicose são quase instantaneamente iguais devido ao $\mathrm{K}_{\mathrm{m}}=10 \mathrm{mM}$. Nos mamíferos é difícil estudar as constantes e velocidades máximas individuais dos GLUT1 e GLUT4 porque essas isoformas estão juntas nas células sensíveis à insulina, como no coração. Por meio de inoculação de RNAm de GLUT de rato em oócitos de rã, induziu-se a expressão isolada de GLUT1 ou GLUT4 e se mensuraram as respectivas constantes e velocidades, separadamente. ${ }^{190}$ GLUT1 apresentou $\mathrm{K}_{\mathrm{m}}=26,2 \pm 4.9$ e Vmax $=3491 \pm 448 \mathrm{pmol} / \mathrm{min} /$ célula $(\mathrm{n}=3)$. GLUT4 apresentou $\mathrm{K}_{\mathrm{m}}=4,3 \pm 0,6 \mathrm{mM}$ e Vmax=667 $\pm 87 \mathrm{pmol} / \mathrm{min} /$ célula $(\mathrm{n}=3) .{ }^{190}$ No cardiócito as proporções de isoformas de GLUT expressas variam constantemente sob o efeito dos hormônios, a depender da condição funcional. Sob a influência de adrenalina há aumento de GLUT1 e GLUT4 na membrana plasmática do cardiócito. ${ }^{175,177-188}$

É interessante notar que os conceitos médicos predominantes sobre a glicemia se devem aos conhecimentos e aos tratamentos relativos a doenças crônicas como o diabetes mellitus ou, mais recentemente, a doenças agudas cursando com hiperglicemia de estresse. Nos dois casos a hiperglicemia é tida como deletéria. ${ }^{31-45}$ Os mesmos conceitos têm sido referidos para o tratamento da disfunção pós-parada, extrapolando-se certos conhecimentos estabelecidos principalmente sobre a síndrome coronária aguda e o subseqüente miocárdio atordoado. ${ }^{1,61,70,118,191-193}$ A própria condição de PCR e RCP é difícil de estudar além do comparativo observacional histórico. ${ }^{118} \mathrm{O}$ prognóstico reservado dos pacientes 
recuperados da parada cardíaca, principalmente o neurológico, torna impraticáveis os estudos de superioridade de medicamentos ou de condutas de controle metabólico aplicadas após a recuperação, com alterações muitas vezes já irreversíveis. Da mesma forma, historicamente o suporte básico e avançado de vida foi se aprimorando e se padronizando. ${ }^{118}$ Mesmo assim, é difícil a aplicação de estudo observacional, quanto mais experimental no ser humano durante o atendimento de emergência. Mesmo com todos os avanços e padronizações conquistados a mortalidade e a morbidade permanecem elevadas. ${ }^{118,119}$ A própria adrenalina tem seu uso estabelecido sem a devida comprovação de eficácia por meio de estudos clínicos adequados. Também os estudos com animais inicialmente se voltaram para o aumento do RCE, depois, para a melhora do prognóstico neurológico. ${ }^{118}$

Os exames laboratoriais habitualmente utilizados em medicina intensiva, como gasometria arterial e venosa, bicarbonato, potássio, lactato, foram bastante pesquisados e há muitos artigos relatando essas variáveis no período de suporte de vida e no período pós-parada. Esses exames habitualmente vêm acompanhados da glicemia no mesmo relatório pelo motivo do temor da hipoglicemia, não devido a algum temor da glicemia elevada e conceitualmente dentro do esperado para uma situação de estresse. ${ }^{194,195}$ A natural e conhecida "reação de luta ou de fuga" associada à adrenalina foi e tem sido a explicação empírica para a hiperglicemia aguda. A "reação de fuga" veio como explicação natural para a hiperglicemia que se observa, eventualmente, no cotidiano do trabalho médico nas emergências, além de outras explicações como diabetes ainda não 
diagnosticado ou mesmo intolerância à glicose e generalizações como “distúrbios metabólicos”. Portanto, além dessas circunstâncias e desses conceitos estabelecidos, nunca se deu muita atenção à glicose nem sequer se relatou sua dosagem prolificamente como se relataram as outras variáveis laboratoriais no estudo da parada cardíaca.

A clássica reação de fuga associada à adrenalina se refere às respostas dos seres vivos para as situações de ataque ou de dor com grande demanda de energia para a luta ou para a fuga. Ao se observar a hiperglicemia no paciente recuperado após poucos minutos de PCR, inconsciente e sem dor, vítima de síncope de arritmia, cabe a seguinte pergunta: existe reação de fuga na morte súbita? A adrenalina associada pode atuar sem a circulação sanguínea? Um estudo dosou a adrenalina intersticial do músculo cardíaco durante os minutos de fibrilação ventricular sem suporte de vida em modelo suíno de PCR e RCP. ${ }^{82}$ As terminações nervosas liberaram adrenalina e noradrenalina no interstício muscular, aumentando a concentração de adrenalina com significância frente à concentração basal. ${ }^{82}$ A concentração sérica de adrenalina também aumentou, mas foi aferida no período basal e durante o suporte de vida, não durante a fibrilação sem suporte. ${ }^{82}$ Note-se a complexidade da questão sobre adrenalina e reação de fuga. No entanto, esse estudo não relatou a glicemia. $^{82}$

Antes dos conhecimentos sobre a hiperglicemia de estresse, o médico nas emergências e nas unidades de terapia intensiva não tinha a preocupação de tratar a hiperglicemia moderada. ${ }^{194,195}$ Por outro lado, no 
atendimento da PCR em que se observasse eventualmente a hipoglicemia, soro glicosado seria aplicado em bolo. No entanto, nada seria feito durante a RCP caso se observasse a hiperglicemia moderada, mesmo nos pacientes diabéticos. Dosar a glicose sanguínea sequer faz parte das atenções rotineiras durante a RCP e sim no período pós-parada. ${ }^{196}$ Os estudos com animais se focaram na busca de conhecimentos por meio de dosagens de $\mathrm{pH}$, de bicarbonato, de lactato, de eletrólitos ou de hormônios. A glicemia, no entanto, não foi estudada com a mesma intensidade e nem com a mesma associação com a lesão celular ou com alterações metabólicas de importância ou passíveis de intervenção no período prévio ao RCE. É curioso, já que a dosagem de glicose é um exame barato e acessível. $\mathrm{O}$ desenvolvimento tecnológico laboratorial facilitou ainda mais, com dosagens rápidas e automatizadas. Atualmente é possível ter em mãos o relatório com os resultados das dosagens a cada 2 min.

O estudo realizado tentou demonstrar a evolução dos variáveis de uso rotineiro e avançado em terapia intensiva paralelamente, mas com destaque para a glicemia durante o suporte de vida. Espera-se que o conhecimento da glicemia na parada cardíaca possa trazer subsídios para novas pesquisas sobre proteção celular. Buscou-se apresentar o estudo de forma coerente, didática, resumida e embasada nos resultados obtidos e analisados sob a luz da biologia, da bioquímica, da fisiologia e da estatística. 
OBJETIVOS 


\section{OBJETIVOS}

\subsection{Objetivo primário}

Avaliar a evolução da glicemia associada ao prognóstico e à farmacoterapia recomendada na ressuscitação cardiopulmonar.

\subsection{Objetivos secundários}

Comparar o efeito da epinefrina e da vasopressina com o grupo controle de solução salina quanto às variáveis hemodinâmicas, funcionais, laboratoriais sanguíneas e metabólicas, e quanto à freqüência de retorno da circulação espontânea. 


\section{MÉTODOS}

\subsection{Aprovação dos comitês de ética}

O projeto foi realizado no Laboratório de Pesquisa de Medicina Intensiva e Anestesiologia (CT2) do Instituto de Ensino e Pesquisa do Hospital Sírio-Libanês, mediante cooperação interinstitucional com o Instituto Dante Pazzanese de Cardiologia / Fundação Adib Jatene (Anexo A). Os comitês de ética de ambos os Institutos aprovaram o projeto, como se pode observar nos documentos do Anexo B e Anexo C.

\subsection{Descrição dos animais que foram utilizados}

- Espécie: Suína.

- Raça: Landrace com Large-White.

- Gênero: fêmea

- Peso: 36 kg.

\subsection{Descrição dos Procedimentos}

\subsubsection{Preparo do animal}

O animal permaneceu em jejum por $12 \mathrm{~h}$, porém com livre acesso à água. Recebeu medicação pré-anestésica composta de midazolan $(0,5$ $\mathrm{mg} / \mathrm{kg} \mathrm{IM}$ ) e cloridrato de cetamina (5 mg/kg IM). 


\subsubsection{Anestesia}

Após 10 min, a veia marginal da orelha foi puncionada e mantida com soro fisiológico $0,9 \%$ (SF 0,9\%) em gotejamento. A anestésica foi induzida com tiopental sódico (12,5 mg/kg EV) e foi mantida com midazolan, fentanil e pancurônio em infusão contínua sem diluição, conforme o necessário para a sedação, analgesia e paralisia muscular adequadas, respectivamente.

\subsubsection{Ato}

Em decúbito dorsal, o animal foi intubado e permaneceu em ventilação mecânica. Seguiram-se a tricotomia das regiões inguinais e cervicais e a dissecção dos feixes arteriovenosos. As artérias femorais direita e esquerda receberam introdutores de 6 french $(F)$. As veias cervicais direita e esquerda receberam introdutores de 8,5 F. Cateter pigtail de $6 \mathrm{~F}$ foi introduzido pela artéria femoral direita e posicionado na aorta ascendente. Cateter de SwanGanz com débito contínuo foi introduzido pela veia cervical esquerda e posicionado na artéria pulmonar. O posicionamento dos cateteres foi confirmado pelas curvas de pressão características. Cabo de marca-passo de $5 \mathrm{~F}$ foi introduzido pela veia cervical direita e posicionado na parede do ventrículo direito, confirmado pelo aparecimento de extra-sístoles características.

\subsubsection{Período de estabilização de 30 minutos}

O animal permaneceu em estabilização de 30 min com sedação, analgesia e paralisia muscular contínuas e ventilação mecânica com volume corrente de $10 \mathrm{ml} / \mathrm{kg}$, fração inspirada de oxigênio de $40 \%$ e freqüência 
ventilatória adequada para dióxido de carbono final expirado (ETCO2) de 40 a $45 \mathrm{~mm} \mathrm{Hg}$. Recebeu SF 0,9\% neste período.

\subsubsection{Randomização}

A alocação dos animais nos respectivos grupos de fármacos estudados ocorreu por sorteio simples sem reposição. Os investigadores não souberam a qual grupo pertencia o animal até três meses de encerradas as experimentações e com as planilhas de dados prontas, com todas as mensurações realizadas, com exceção da dosagem de adrenalina

\subsubsection{Agrupamento}

Grupo solução Salina (0,2 mL/kg de SF 0,9\%): 08 animais.

Grupo Epinefrina (20 $\mu \mathrm{g} / \mathrm{kg}$ ou 0,2 mL/kg da diluição): 12 animais.

Grupo Vasopressina (0,4 U/kg ou 0,2 mL/kg da diluição): 12 animais.

\subsubsection{Indução de fibrilação ventricular (FV)}

Foi induzida com pilha comum de nove volts conectada aos pólos do cabo de marca-passo, durante dois segundos.

\subsubsection{Tempo de FV sem suporte de vida}

Sete minutos sem compressão torácica, sem infusão de medicamentos e sem ventilação mecânica.

\subsubsection{Compressão torácica}

Iniciada aos 7 min exatos e executada sempre pelo mesmo investigador. 


\subsubsection{Desfibrilação}

Por meio de desfibrilador automático externo com descarga única monofásica de $150 \mathrm{~J}$ aos 9 min de experimento e a cada 2 min, se necessário, até no máximo 30 min de RCP.

\subsubsection{Suporte básico de vida (SBV)}

O SBV foi manual (compressão torácica e ventilação com Ambu) iniciado aos 7 min de FV e mantido até se obter RCE ou até $30 \mathrm{~min}$, no máximo. Compressão com incursão de $5 \mathrm{~cm}$ e freqüência de 100 por minuto. Ventilação com freqüência de 10 por minuto.

\subsubsection{Aplicação dos fármacos estudados}

Primeira aplicação imediatamente após a $1^{\text {a }}$ tentativa de desfibrilação e a cada 5 min até o RCE ou até 30 min de SBV.

\subsubsection{Restrição de outros medicamentos}

Outros medicamentos não foram utilizados, como atropina para os casos de assistolia, por exemplo.

\subsubsection{Aplicação de medicamento antiarrítmico}

Amiodarona foi aplicada imediatamente após a $2^{\mathrm{a}}$ tentativa de desfibrilação na dose de $5 \mathrm{mg} / \mathrm{kg}$ e foi repetida uma única vez após $5 \mathrm{~min}$, se necessário, na dose de $2,5 \mathrm{mg} / \mathrm{kg}$.

3.3.15 Suporte básico e avançado de vida de acordo com o padrão atual

Exceto pelo que foi descrito nos itens 3.3.12 e 3.3.13, todo o suporte básico e avançado de vida foi de acordo com o padrão internacional atual. 


\subsubsection{Retorno da circulação espontânea e período pós-parada}

A RCE foi declarada na ocorrência de ritmo cardíaco adequado e pressão sistólica da aorta maior do que $50 \mathrm{~mm} \mathrm{Hg}$. O período de observação após o RCE ou período pós-parada foi de $120 \mathrm{~min}$. A RCP foi reiniciada somente quando necessária antes dos 20 min iniciais de RCE.

\subsubsection{Coletas de sangue para dosagem imediata e para congelamento}

Por meio de analisador sanguíneo Radiometer $A B L 730$, pequenos volumes de sangue da artéria pulmonar foram analisados imediatamente no local. As coletas ocorreram antes da indução da fibrilação ventricular, depois aos 4 min, sob fibrilação sem suporte de vida. A seguir, aos $8 \mathrm{~min}, 9 \mathrm{~min}$ e imediatamente após a aplicação do fármaco, ou seja, a cada 5 min. Após o RCE as coletas ocorreram imediatamente, aos $5 \mathrm{~min}, 10 \mathrm{~min}, 15 \mathrm{~min}, 20$ min, 30 min, 60 min, 90 min e antes da eutanásia, aos 120 min. Coletas simultâneas da artéria femoral esquerda ocorreram nos períodos basal e pós-parada, mas não durante a RCP.

Para congelamento, amostras com $20 \mathrm{~mL}$ de sangue foram coletadas da artéria femoral esquerda no período basal, imediatamente após o fim dos esforços de ressuscitação ou aos 10 min após o RCE e aos 60 min.

\subsubsection{Coletas de sangue para cálculos de oferta e de consumo de oxigênio}

No período basal e no período pós-parada as coletas de sangue para dosagens imediatas foram venosas mistas e artérias para cálculos de oferta e de consumo de oxigênio, juntamente com as mensurações hemodinâmicas adequadas simultâneas. No período de RCP as coletas foram venosas mistas apenas. 
3.3.19 Variáveis anotados em formulário

- Peso;

- Área de superfície corpórea;

- Hora local e dos equipamentos para sincronização;

- Hora exata das coletas de sangue, das tentativas de desfibrilação ou verificações de ritmo, da aplicação dos fármacos em estudo ou de antiarrítmico;

- Volume total de soro fisiológico aplicado;

- Volume total de heparina aplicada (heparina $500 \mathrm{UI} / \mathrm{ml}$ );

- Hora e descrição de ocorrências ou de condutas gerais.

3.3.20 Variáveis anotados em duplicata durante o experimento

- Pressão da artéria pulmonar;

- Pressão da artéria pulmonar ocluída, equivalente à pressão do átrio esquerdo;

- Temperatura central basal e no período pós-parada.

3.3.21 Variáveis monitorados e gravadas continuamente

- ECG de uma derivação / freqüência cardíaca derivada;

- Pressão da aorta;

- Pressão do átrio direito;

- Débito cardíaco;

- Gás carbônico (ETCO2) / freqüência ventilatória derivada.

\subsubsection{Anotações importantes}

- Em formulário impresso. 


\subsubsection{Gravação contínua}

- Sistema de aquisição de dados Biopac a 250 amostras por segundo.

\subsubsection{Preparo prévio das seringas com os fármacos em estudo}

As seringas para a injeção dos medicamentos estudados ou de solução salina foram preparadas previamente na quantidade adequada e com volume final igual de $0,2 \mathrm{~mL} / \mathrm{kg}$ da diluição ou de solução salina a $0,9 \%$. Todas as seringas foram identificadas apenas como "fármaco".

\subsubsection{Preparo prévio das seringas para coleta de sangue e imediata} dosagem

As seringas foram lavadas com heparina previamente.

\subsubsection{Preparo prévio dos tubos de coleta de sangue para congelamento}

Os tubos de coleta com heparina foram identificados previamente como A, B e C, para as amostras respectivas dos períodos basal, após o óbito ou aos 10 min e 60 min após o RCE.

\subsubsection{Eutanásia}

Uma injeção venosa de $10 \mathrm{~mL}$ de cloreto de potássio $19,1 \%$ foi aplicada e a ventilação mecânica foi cessada aos 120 min pós-parada.

\subsection{Destino das amostras e dados}

As amostras de sangue A, B e C permaneceram imersas em gelo e foram centrifugadas (3000 rotações por minuto durante 10 min a $4{ }^{\circ} \mathrm{C}$ ) e os sobrenadantes permaneceram congelados a $80^{\circ} \mathrm{C}$ negativos até seu encaminhamento para análise, no final do projeto. 
As variáveis gravadas continuamente foram arquivadas em harddrive, pendrive e mídia de DVD.

As dosagens sanguíneas foram exportadas diretamente do equipamento Radiometer $A B L 730$ para a planilha do programa de estatística, bem como as mensurações realizadas por meio do programa "AcqKnowledge" que acompanha o equipamento Biopac de aquisição de dados. Apenas os dados anotados em formulário foram digitados na planilha, como as pressões da artéria pulmonar, bem como as raras correções de dados oriundos de falhas de mensuração.

\subsection{Cronograma}

De abril a outubro de 2010, geralmente nas segundas-feiras e nas quartas-feiras no período comercial, um animal foi estudado até se completarem os 32 animais do projeto.

\subsection{Participantes do projeto e auxiliares}

- Dr. Ari Timerman (IDPC): orientador.

- Manoel Palácio (IDPC): doutorando. Intubações, atos cirúrgicos, posicionamento dos cateteres, cuidados de medicina intensiva e atenção geral ao projeto, bem como as compressões torácicas.

- Dr. Edison Paiva (IEP-HSL): co-orientador informal. Anotação, coordenação e cronometragem das manobras, dos medicamentos e das verificações de ritmo durante o período de RCP, bem como das mensurações de pressão da artéria pulmonar e temperatura. 
- Dr. Luciano de Azevedo (IEP-HSL): participação científica e tecnológica de medicina intensiva, aplicação dos medicamentos e coletas de sangue durante o período de RCP.

- Dra. Veterinária Andreza Patara (IEP-HSL): guarda do sigilo da amostra aleatória por sorteio simples sem reposição e preparo das seringas com o fármaco em estudo.

- Auxiliares do IEP-HSL: intubações, dissecções, inserções de introdutores, auxílios gerais e ventilação com Ambu. 


\section{MENSURAÇÕES}




\section{MENSURAÇÕES}

\subsection{Mensurações sanguíneas imediatas}

O equipamento Radiometer $\mathrm{ABL} 730$ analisa pequenos volumes de sangue rapidamente e grava os resultados. Os itens número um a 11 são medidos e os itens 12 e 13 são calculados:

1. Concentração de glicose (Glicemia - mg/dL);

2. Concentração de lactato (Lactato $-\mathrm{mg} / \mathrm{dL})$;

3. Logaritmo da concentração de íons hidrogênio $(\mathrm{pH})$;

4. Pressão parcial de oxigênio $\left(\mathrm{pO}_{2}-\mathrm{mm} \mathrm{Hg}\right)$;

5. Pressão parcial de dióxido de carbono $\left(\mathrm{pCO}_{2}-\mathrm{mm} \mathrm{Hg}\right)$;

6. Saturação de oxi-hemoglobina $\left(\mathrm{sO}_{2}-\%\right)$;

7. Concentração de íons potássio (Potássio - mmol/L);

8. Concentração de íons sódio (Sódio - mmol/L);

9. Concentração de íons cloro (Cloro - mmol/L);

10. Concentração de íons cálcio (Cálcio - mmol/L);

11. Concentração de hemoglobina (Hemoglobina - g/dL);

12. Concentração de bicarbonato (Bicarbonato $-\mathrm{mmol} / \mathrm{L}$ );

13. Hematócrito (Hematócrito - \%).

\subsection{Mensuração no sangue congelado}

A concentração de epinefrina (ELISA BA 5100 Labor Diagnostika Nord) foi dosada no período basal, imediatamente após o óbito aos 35 min ou aos 
10 min e 60 min após o RCE. Essas dosagens ocorreram simultaneamente após o término das experimentações e após a análise dos resultados que indicaram a dosagem desse hormônio.

\subsection{Mensurações hemodinâmicas e do $\mathrm{ETCO}_{2}$}

O equipamento Biopac de aquisição de dados possui o programa AcqKnowledge por meio do qual se realizaram centenas de mensurações sobre as variáveis gravadas:

- Pressão da aorta (mm Hg);

- Pressão do átrio direito $(\mathrm{mm} \mathrm{Hg})$;

- Gás carbônico expirado final $\left(\mathrm{ETCO}_{2}\right)$;

- Pressão da aorta menos a pressão do átrio na "diástole" ou Pressão de perfusão coronária (PPC - mm Hg);

- Freqüência cardíaca (ciclos/min);

- Freqüência de compressão (ciclos/min);

- Freqüência ventilatória (ciclos/min);

- Freqüência ventilatória com Ambu (ciclos/min);

- Débito cardíaco (L/min).

\subsubsection{Sistematização das mensurações}

Ao longo do gráfico na linha do tempo das curvas simultâneas de ECG, pressões da aorta e do átrio, $\mathrm{PPC}$ e $\mathrm{ETCO}_{2}$ se inseriram marcadores no início da FV, nas paradas de compressão para verificação do ritmo e assim por diante nos pontos protocolados. A partir de cada marcador, regrediramse 20 s até o ponto de início do pulso sistólico da pressão de aorta. A partir 
deste ponto, selecionaram-se os 0,05 s prévios e extraíram-se as médias das curvas neste intervalo, seguido da média dos 0,10 s prévios, depois dos 0,20 s prévios, de um ciclo de pulso, de um ciclo ventilatório e de 7 s. Nos períodos de SBV, observou-se a equivalência da mensuração de até 0,20 s (platô de descompressão) com a mensuração de $7 \mathrm{~s}$, portanto este intervalo de tempo foi escolhido para as mensurações e equivaleu a 15 ciclos de compressão torácica ou mais ciclos conforme a freqüência cardíaca. A média das variáveis no intervalo de $7 \mathrm{~s}$ foi utilizada como medida e não a máxima ou a mínima do intervalo, com exceção do $\mathrm{ETCO}_{2}$ que utilizou a máxima do ciclo ventilatório. No período de SBV, utilizou-se a mediana das pressões no intervalo, ainda mais similares do que a média em relação à mensuração de até $0,20 \mathrm{~s}$, pois ocorreu um longo platô de "diástole" e a compressão em si foi rápida. As mensurações foram realizadas após os experimentos e foram exportadas no formato ASCII (American Standard Code for Information Interchange) para o programa de estatística. Depois de concluídas as planilhas, a randomização foi revelada.

\subsection{Mensurações derivadas das hemodinâmicas e sanguíneas}

As fórmulas para cálculo das variáveis encontram-se no Anexo D.

- Conteúdo arterial de oxigênio;

- Conteúdo venoso de oxigênio;

- Diferença de conteúdo arteriovenoso de oxigênio;

- Razão de extração de oxigênio;

- Oferta de oxigênio;

- Consumo de oxigênio. 


\section{ANÁLISES ESTATÍSTICAS}

\subsection{Cálculo prévio do tamanho da amostra}

Utilizou-se o programa Power Analysis and Sample Size (PASS) para calcular o tamanho da amostra (n) de cada grupo (Anexo E).

Foi calculado o $\mathrm{n}$ de 12 animais para os grupos Epinefrina e Vasopressina e o $\mathrm{n}$ de oito animais para o grupo controle Salina. O $\mathrm{n}$ de 12 animais foi calculado para Teste t significante com alfa de 0,05 e poder de 90\%, supondo-se uma diferença mínima de $50 \mathrm{mg} / \mathrm{dL}$ entre as médias das glicemias de dois grupos, com desvio-padrão estimado de $40 \mathrm{mg} / \mathrm{dL}$. Quanto ao grupo controle Salina o $\mathrm{n}$ de oito animais foi suficiente, supondo-se que a diferença entre as médias da glicemia seria maior.

A variância da glicemia foi estimada de estudo clínico prévio realizado no pronto-socorro do Instituto Dante Pazzanese sobre a glicemia da admissão de pacientes diabéticos internados por síndrome coronária aguda. ${ }^{197}$ Neste estudo, os pacientes foram agrupados conforme o tratamento prévio do diabetes com sulfoniluréia, apenas com metformina ou apenas com dieta. Neste último grupo, a média da glicemia foi de $146 \mathrm{mg} / \mathrm{dl}$, com desvio-padrão de $45 \mathrm{mg} / \mathrm{dL}$. A elevação da glicemia pode ser atribuída ao estresse e não ao diabetes, pois nos demais grupos a glicemia e o desvio-padrão foram bem maiores. Como na PCR haveria estresse semelhante mas com isquemia global, a variância de 40 foi escolhida para o 
cálculo do tamanho da amostra, supondo-se que a resposta glicêmica seria também semelhante nos animais.

\subsection{Testes estatísticos}

Foi utilizado o programa de estatística Number Cruncher Statistical System (NCSS 2007) para a análise dos dados nas séries temporais.

Um agrupamento para as comparações das médias das variáveis foi entre recuperados e não-recuperados da parada cardíaca. Outro agrupamento foi conforme o medicamento em estudo ou solução salina. $O$ agrupamento conforme os três fármacos e conforme a recuperação ou não (seis grupos) foi apenas para demonstrar as estatísticas das variáveis, sem aplicar o teste t porque os tamanhos de amostra ficaram pequenos demais.

As comparações foram analisadas a cada série temporal de mensurações. Somente os valores de p significantes foram relatados.

- Aplicou-se o teste t de Student independente. Todas as variáveis foram comparadas da mesma forma que a glicemia e os valores de $p$ significantes menores que 0,05 se referiram sempre aos animais e não ao número de exames, com os graus de liberdade apropriados para tal. Os testes de normalidade das variáveis e igualdade ou não das variâncias foram sempre analisados e considerados para a escolha do valor de $p$.

- O valor de $p$ do teste Mann-Whitney $U$ foi utilizado nos casos de quebra da premissa de normalidade nos grupos.

- O teste qui-quadrado e o teste exato de Fisher foram utilizados para a análise da freqüência de recuperação entre os grupos de fármacos. 


\subsection{Precisão das mensurações}

As mensurações realizadas foram exportadas dos equipamentos de dosagens sanguíneas e de aquisição de dados fisiológicos com precisão simples de sete dígitos, assim analisadas mas apresentadas com a precisão apropriada a cada variável e com a aproximação fornecida pelo programa de estatística. $\mathrm{O}$ valor de $\mathrm{p}$ foi apresentado com precisão de três dígitos e sem aproximação. 
RESULTADOS 


\section{RESULTADOS}

\subsection{Variáveis basais}

As variáveis basais foram mensuradas após o preparo e após 30 min de estabilização. Os volumes totais de SF 0,9\% e de heparina utilizados foram semelhantes, mas os 19 animais que alcançaram RCE receberam anestésicos por mais tempo, cerca de $10 \mathrm{~mL}$ a mais de midazolan, fentanil e pancurônio. As principais variáveis mensuradas no período basal podem ser observadas nas Tabelas 1 a 5.

Comparando-se os 19 animais que alcançaram o RCE com os 13 animais que não alcançaram, no período basal não ocorreram diferenças significantes das variáveis fisiológicas (Tabela 1) ou sanguíneas venosas e arteriais (Tabela 2). Aos 4 min após a indução de fibrilação ventricular e antes de se iniciar o suporte de vida, sangue venoso misto foi coletado e as variáveis foram semelhantes ao basal. No mesmo instante a PPC teórica é zero.

Comparando-se os animais de acordo com o fármaco aplicado, no período basal não ocorreram diferenças significantes das variáveis fisiológicas (Tabela 3), do sangue venoso misto (Tabela 4) ou do sangue arterial (Tabela 5). 
Tabela 1 - Variáveis do período basal de 32 animais agrupados conforme a evolução da parada cardíaca: sem diferenças significantes entre os grupos. VARIÁVEL BASAL $\mathrm{RCE}=\mathrm{NÃO} \quad \mathrm{RCE}=\mathrm{SIM}$ $n=13 \quad n=19$

Peso $(\mathrm{kg})$

Temperatura $\left({ }^{\circ} \mathrm{C}\right)$

Débito Cardíaco (L/min)

Oferta de Oxigênio $(\mathrm{mL} / \mathrm{min})$

Consumo de Oxigênio ( $\mathrm{mL} / \mathrm{min})$

$\mathrm{ETCO}_{2}(\mathrm{~mm} \mathrm{Hg})$

Freqüência Ventilatória (ciclos/min)

Freqüência Cardíaca (ciclos/min)

Pressão Média da Aorta (mm Hg)

Pressão do Átrio D (mm Hg)
$35 \pm 0,6$

$37,9 \pm 0,3 \quad 37,7 \pm 0,3$

$6,1 \pm 0,3$

$6,2 \pm 0,3$

$760 \pm 35$

$248 \pm 11$

$43 \pm 0,6$

$21 \pm 0,8$

$133 \pm 7$

$134 \pm 4$

$6 \pm 0,5$
$816 \pm 34$

$242 \pm 9$

$41 \pm 0,5$

$23 \pm 0,9$

$136 \pm 6$

$142 \pm 4$

$4 \pm 0,3$

Média \pm erro-padrão;

$\mathrm{ETCO}_{2}$ : Gás carbônico expirado;

RCE: Retorno da Circulação Espontânea. 
Tabela 2 - Variáveis séricas basais de 32 animais agrupados conforme a evolução da parada cardíaca: sem diferenças significantes entre os grupos.

\begin{tabular}{|c|c|c|c|c|}
\hline VARIÁVEL BASAL & $\begin{array}{c}\text { RCE }=N \tilde{A O} \\
n=13\end{array}$ & $\begin{array}{c}\text { RCE }=\text { SIM } \\
n=19\end{array}$ & $\begin{array}{c}\text { RCE }=N \tilde{N O} \\
n=13\end{array}$ & $\begin{array}{c}\text { RCE }=\text { SIM } \\
n=19\end{array}$ \\
\hline Sangue & Venoso & Venoso & Arterial & Arterial \\
\hline Glicemia (mg/dL) & $97 \pm 4$ & $105 \pm 4$ & $98 \pm 3$ & $105 \pm 5$ \\
\hline Lactato (mg/dL) & $6 \pm 1$ & $8 \pm 2$ & $7 \pm 1$ & $8 \pm 2$ \\
\hline $\mathrm{pH}$ & $7,39 \pm 0,01$ & $7,39 \pm 0,01$ & $7,43 \pm 0,01$ & $7,42 \pm 0,01$ \\
\hline Saturação de $\mathrm{O}_{2}(\%)$ & $66 \pm 1,8$ & $68 \pm 1,4$ & $97 \pm 0,8$ & $98 \pm 0,6$ \\
\hline $\mathrm{pO}_{2}(\mathrm{~mm} \mathrm{Hg})$ & $61 \pm 5,9$ & $67 \pm 4,9$ & $134 \pm 8$ & $140 \pm 6$ \\
\hline $\mathrm{pCO}_{2}(\mathrm{~mm} \mathrm{Hg})$ & $48 \pm 1,7$ & $48 \pm 1,6$ & $42 \pm 1,0$ & $43 \pm 2$ \\
\hline Bicarbonato (mmol/L) & $28 \pm 0,5$ & $28 \pm 0,5$ & $27 \pm 0,5$ & $27 \pm 0,4$ \\
\hline Sódio (mmol/L) & $140 \pm 0,9$ & $139 \pm 0,3$ & $139 \pm 0,9$ & $138 \pm 0,4$ \\
\hline Potássio (mmol/L) & $3,6 \pm 0,1$ & $3,6 \pm 0,1$ & $3,5 \pm 0,1$ & $3,6 \pm 0,1$ \\
\hline Hemoglobina (g/dL) & $9,1 \pm 0,2$ & $9,6 \pm 0,2$ & $9,0 \pm 0,2$ & $9,5 \pm 0,2$ \\
\hline Epinefrina (ng/dL) & & & $0,90 \pm 0,17$ & $1,25 \pm 0,27$ \\
\hline
\end{tabular}

Média \pm erro-padrão;

$\mathrm{pO}_{2} / \mathrm{pCO}$ : Pressão parcial de oxigênio / gás carbônico;

RCE: Retorno da Circulação Espontânea. 
Tabela 3 - Variáveis do período basal de 32 animais agrupados pelo fármaco da parada cardíaca: sem diferenças significantes entre os grupos.

\begin{tabular}{lccc}
\hline VARIÁVEL BASAL & SALINA & VASOPRESSINA & EPINEFRINA \\
& $\mathrm{n}=8$ & $\mathrm{n}=12$ & $\mathrm{n}=12$ \\
\hline Peso $(\mathrm{kg})$ & $36 \pm 0,9$ & $35 \pm 0,6$ & $36 \pm 0,5$ \\
Temperatura ( $\left.{ }^{\circ} \mathrm{C}\right)$ & $37,7 \pm 0,3$ & $38,0 \pm 0,4$ & $37,6 \pm 0,3$ \\
Débito Cardíaco (L/min) & $6,1 \pm 0,4$ & $6,1 \pm 0,3$ & $6,1 \pm 0,3$ \\
Oferta de Oxigênio (mL/min) & $827 \pm 53$ & $775 \pm 45$ & $789 \pm 36$ \\
Consumo de Oxigênio (mL/min) & $238 \pm 16$ & $249 \pm 11$ & $243 \pm 10$ \\
ETCO ${ }_{2}$ (mm Hg) & $42 \pm 0,7$ & $42 \pm 0,6$ & $41 \pm 0,5$ \\
Freq Ventilatória (ciclos/min) & $21 \pm 0,5$ & $23 \pm 1,2$ & $24 \pm 1,1$ \\
Freq Cardíaca (ciclos/min) & $141 \pm 9$ & $127 \pm 8$ & $139 \pm 7$ \\
Pressão da Aorta (mm Hg) & $134 \pm 9$ & $141 \pm 4$ & $141 \pm 4$ \\
Pressão do Átrio D (mm Hg) & $5 \pm 0,7$ & $5 \pm 0,6$ & $5 \pm 0,4$ \\
\hline Média \pm erro-padrão; & & & \\
ETCO ${ }_{2}$ Gás carbônico expirado. & & & \\
\hline
\end{tabular}


Tabela 4 - Variáveis venosas basais de 32 animais de acordo com o fármaco da parada cardíaca: sem diferenças significantes entre os grupos.

\begin{tabular}{lccc}
\hline VARIÁVEL BASAL & SALINA & VASOPRESSINA & EPINEFRINA \\
& $\mathrm{n}=8$ & $\mathrm{n}=12$ & $\mathrm{n}=12$ \\
\hline Sangue venoso misto & $102 \pm 4$ & $100 \pm 6$ & $104 \pm 5$ \\
Glicemia (mg/dL) & $6 \pm 1$ & $8 \pm 2$ & $7 \pm 2$ \\
Lactato (mg/dL) & $7,40 \pm 0,02$ & $7,38 \pm 0,01$ & $7,39 \pm 0,02$ \\
pH & $69 \pm 2,5$ & $66 \pm 1,7$ & $67 \pm 1,9$ \\
Saturação de O ${ }_{2}(\%)$ & $56 \pm 5,7$ & $68 \pm 6,9$ & $66 \pm 6,4$ \\
$\mathrm{pO}_{2}(\mathrm{~mm} \mathrm{Hg})$ & $48 \pm 2,1$ & $48 \pm 1,5$ & $50 \pm 2,4$ \\
$\mathrm{pCO}_{2}(\mathrm{~mm} \mathrm{Hg})$ & $29 \pm 0,7$ & $28 \pm 0,7$ & $29 \pm 0,5$ \\
Bicarbonato (mmol/L) & $139 \pm 1,0$ & $139 \pm 0,8$ & $139 \pm 0,6$ \\
Sódio (mmol/L) & $3,5 \pm 0,1$ & $3,7 \pm 0,1$ & $3,6 \pm 0,1$ \\
Potássio (mmol/L) $_{\text {Hemoglobina (g/dL) }}$ & $9,9 \pm 0,5$ & $9,1 \pm 0,2$ & $9,4 \pm 0,2$ \\
& & & \\
\hline
\end{tabular}

Média \pm erro-padrão;

$\mathrm{pO}_{2} / \mathrm{pCO}_{2}$ : Pressão parcial de oxigênio / gás carbônico. 
Tabela 5 - Variáveis arteriais basais de 32 animais de acordo com o fármaco da parada cardíaca: sem diferenças significantes entre os grupos.

\begin{tabular}{|c|c|c|c|}
\hline VARIÁVEL BASAL & SALINA & VASOPRESSINA & EPINEFRINA \\
\hline & $n=8$ & $n=12$ & $n=12$ \\
\hline Sangue arterial & & & \\
\hline Glicemia (mg/dL) & $102 \pm 3$ & $100 \pm 6$ & $104 \pm 5$ \\
\hline Lactato (mg/dL) & $7 \pm 1$ & $8 \pm 2$ & $8 \pm 2$ \\
\hline $\mathrm{pH}$ & $7,43 \pm 0,01$ & $7,42 \pm 0,01$ & $7,43 \pm 0,02$ \\
\hline Saturação de $\mathrm{O}_{2}(\%)$ & $98 \pm 0,9$ & $98 \pm 0,8$ & $98 \pm 0,9$ \\
\hline $\mathrm{pO}_{2}(\mathrm{~mm} \mathrm{Hg})$ & $131 \pm 9,4$ & $139 \pm 8,2$ & $140 \pm 7,6$ \\
\hline $\mathrm{pCO}_{2}(\mathrm{~mm} \mathrm{Hg})$ & $42 \pm 1,4$ & $42 \pm 1,0$ & $44 \pm 2,3$ \\
\hline Bicarbonato (mmol/L) & $27 \pm 0,6$ & $26 \pm 0,6$ & $28 \pm 0,4$ \\
\hline Sódio (mmol/L) & $139 \pm 1,0$ & $139 \pm 0,7$ & $139 \pm 0,6$ \\
\hline Potássio (mmol/L) & $3,5 \pm 0,1$ & $3,7 \pm 0,1$ & $3,5 \pm 0,1$ \\
\hline Hemoglobina (g/dL) & $9,8 \pm 0,5$ & $9,1 \pm 0,2$ & $9,3 \pm 0,2$ \\
\hline Epinefrina (ng/dL) & $1,24 \pm 0,38$ & $1,11 \pm 0,36$ & $1,01 \pm 0,21$ \\
\hline
\end{tabular}

Média \pm erro-padrão;

$\mathrm{pO}_{2} / \mathrm{pCO}_{2}$ : Pressão parcial de oxigênio / gás carbônico. 


\subsection{Retorno da circulação espontânea}

Dezenove animais alcançaram o RCE e sobreviveram por 2 h, mas 13 animais não sobreviveram após 30 min de tentativas de desfibrilação. $\mathrm{Na}$ maioria dos sobreviventes, o RCE ocorreu entre 13 min e 17 min de experimento, com 6 min de suporte de vida e uma dose do fármaco testado. A freqüência de RCE foi maior no grupo Epinefrina, mas a diferença, por pouco, não foi significante no grupo Vasopressina (Tabela 6).

Tabela 6 - Evolução da parada cardíaca de acordo com o fármaco aplicado.

\begin{tabular}{lcccc}
\hline EVOLUÇÃO & EPINEFRINA & VASOPRESSINA & SALINA & $X^{2}$ \\
& $\mathrm{n}=12$ & $\mathrm{n}=12$ & $\mathrm{n}=8$ & $\mathrm{p}$ \\
\hline RCE & $10^{*}$ & 7 & 2 & 0,032 \\
Sobrevida de $2 \mathrm{~h}$ & $83 \%$ & $58 \%$ & $25 \%$ & 0,032
\end{tabular}

RCE: Retorno da Circulação Espontânea;

$\left.{ }^{*}\right)$ : Epinefrina vs. Salina $p=0,019$ no teste exato de Fisher.

\subsection{Classificação dos períodos da RCP}

Para destacar condições subjacentes relevantes, principalmente a aplicação de fármaco aos 9 min, o experimento pode ser classificado em períodos conforme a Tabela 7. 
Tabela 7 - Classificação da parada cardíaca em períodos de tempo.

\begin{tabular}{lc}
\hline PERÍODO & MINUTOS \\
\hline Basal & 0 \\
PCR sem suporte de vida & $0-7$ \\
PCR com suporte e sem fármaco & $7-9$ \\
PCR com suporte e com fármaco & $9-35$ \\
Pós-parada* & $0-120$
\end{tabular}

PCR: Parada Cardiorrespiratória;

(*): Intervalo desde o retorno da circulação espontânea.

\subsection{Períodos da RCP em cada animal}

O período de RCP com suporte farmacológico variou de acordo com o tempo decorrido até o RCE. Na maior parte, o RCE ocorreu com diferença de tempo de até 15 min. Portanto, foi possível aproximar as mensurações efetuadas no período pós-parada para o tempo médio de experimento. Somando-se os 7 min de fibrilação ventricular sem suporte de vida aos 28 min efetivos de suporte (sem as pausas para verificação de ritmo), os animais que não alcançaram o RCE foram representados nos gráficos até 35 min de experimento. Somando-se os 120 min de observação aos 15 min médios até o RCE, os sobreviventes foram representados até $135 \mathrm{~min}$. Na maioria das vezes, os sobreviventes estavam sob efeito de uma dose do fármaco testado quando ocorreu o RCE. 


\subsection{A seqüência de RCE}

Nenhum RCE ocorreu aos $9 \mathrm{~min}$, quando se aplicou o $1^{\circ}$ choque e a $1^{\mathrm{a}}$ dose de fármaco, o que foi verificado aos $11 \mathrm{~min}$. Aos $13 \mathrm{~min}$, declarou-se o RCE de oito animais. A seqüência de RCE ao longo do tempo e de acordo com o fármaco aplicado pode ser observada na Tabela 8. Na maioria, o RCE ocorreu após o $2^{\circ}$ ou $3^{\circ}$ choques.

Tabela 8 - Tempo transcorrido desde a indução da fibrilação ventricular e número de animais com RCE de acordo com o fármaco aplicado.

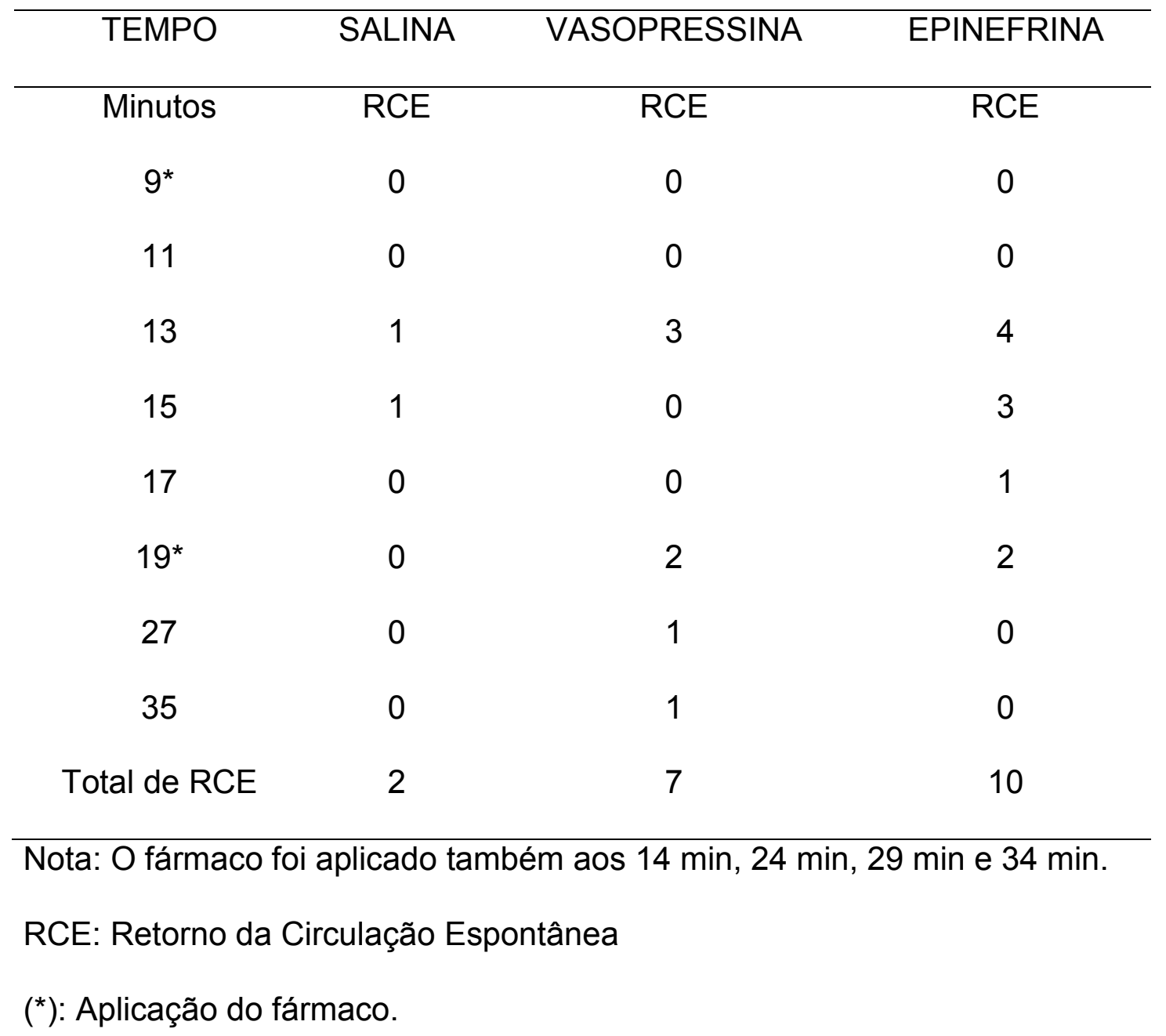




\subsection{A compilação das curvas de glicemia dos 32 animais}

Em análise por meio de gráficos de dispersão, a curva glicêmica de cada animal foi posicionada frente à curva média do respectivo grupo, conforme o RCE ou não. Percebeu-se que apenas três animais não apresentaram curvas semelhantes às curvas médias, com elevação rápida seguida de diminuição rápida da glicemia.

Na Figura 1 está representada a compilação de todas as curvas de glicemia dos 32 animais, pois se destacam três animais com perfis diferentes da curva típica de 29 animais.

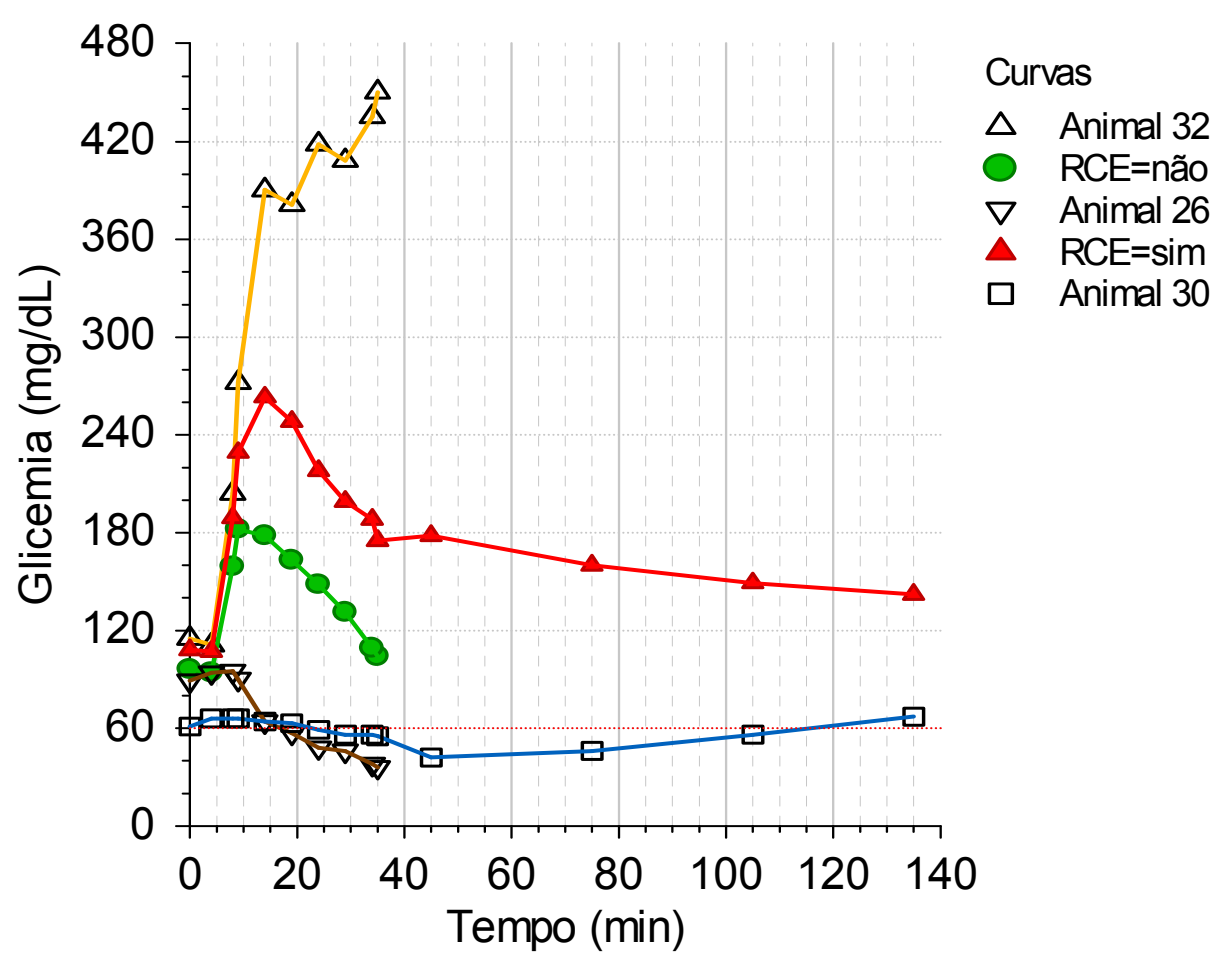

Figura 1 - Glicemia média de 29 animais típicos (símbolos cheios) e com 3 animais atípicos, de acordo com o retorno da circulação espontânea (RCE). 


\subsection{Perfis glicêmicos extremos podem influenciar o RCE}

Analisando-se a pressão da aorta do animal 30 (Figura 1) que apresentou hipoglicemia desde o início e que alcançou o RCE tardiamente, aos 35 min, por motivo funcional e não do ritmo cardíaco, percebeu-se que ocorreu dissociação eletromecânica. Desde 13 min havia onda de pulso em vários instantes, mas abaixo de $50 \mathrm{~mm} \mathrm{Hg}$ de pressão sistólica, portanto acarretando a continuação do suporte de vida. Este animal recebeu vasopressina e cursou com hipoglicemia desde o início, chegando a 47 $\mathrm{mg} / \mathrm{dL}$. Havia atividade elétrica compatível com recuperação do ritmo, onda de pulso tênue ou dissociada e concentração baixa de glicose. $\mathrm{O}$ animal 26 também cursou com hipoglicemia a partir de 15 min e recebeu epinefrina, mas cursou com fibrilação e depois com assistolia e não alcançou o RCE. O animal 32 recebeu epinefrina e cursou com hiperglicemia, mas a glicemia continuou a se elevar até o fim dos esforços de ressuscitação aos 35 min.

Apesar dos casos de curvas atípicas representarem menos de $10 \%$ dos animais, demonstra que pode haver diferentes perfis glicêmicos na RCP e que isso pode influenciar o RCE.

\subsection{As análises das médias correspondem aos 29 animais típicos}

Foram distintas as condições metabólicas dos animais que apresentaram hiperglicemia acentuada ou hipoglicemia. Além dos aspectos biológicos da íntima relação entre metabolismo e função celular, sob o aspecto estatístico as concentrações elevadas foram extremas a partir de 24 min. Os casos foram reportados mas suas exclusões da análise não modificaram o sentido da significância que já existia, apenas a acentuaram. 


\subsection{A evolução típica da glicemia na RCP ocorreu em $91 \%$ dos animais}

A evolução da glicemia ao longo da ressuscitação cardiopulmonar foi típica em $91 \%$ dos animais, independente de se ter aplicado medicamento vasoativo - e hormonal - ou solução salina. Com o início das compressões torácicas a glicemia aumentou rapidamente em todos os animais, atingiu o pico por volta de 15 min e diminuiu rapidamente até $30 \mathrm{~min}$, aproximando-se do basal nos animais que não alcançaram o RCE. Mas, após o RCE, a glicemia diminuiu lentamente por $2 \mathrm{~h}$ (Figura 2). O mesmo perfil típico da glicemia ocorreu nos animais agrupados de acordo com o fármaco aplicado. Neste caso, após os 35 min, a curva média representa apenas os 19 animais que sobreviveram à parada cardíaca (Figura 3).

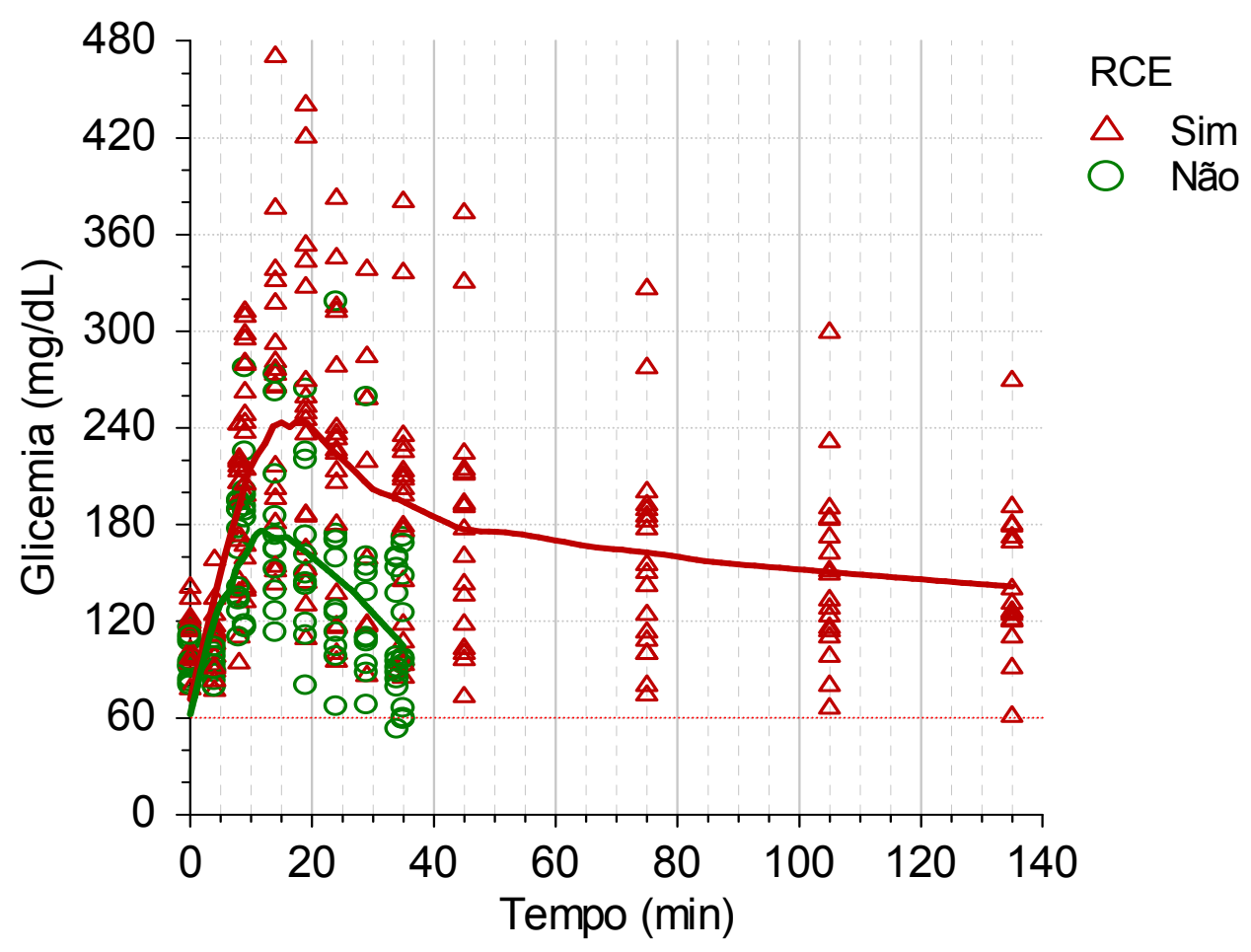

Figura 2 - Glicemia conforme o retorno da circulação espontânea (RCE). 


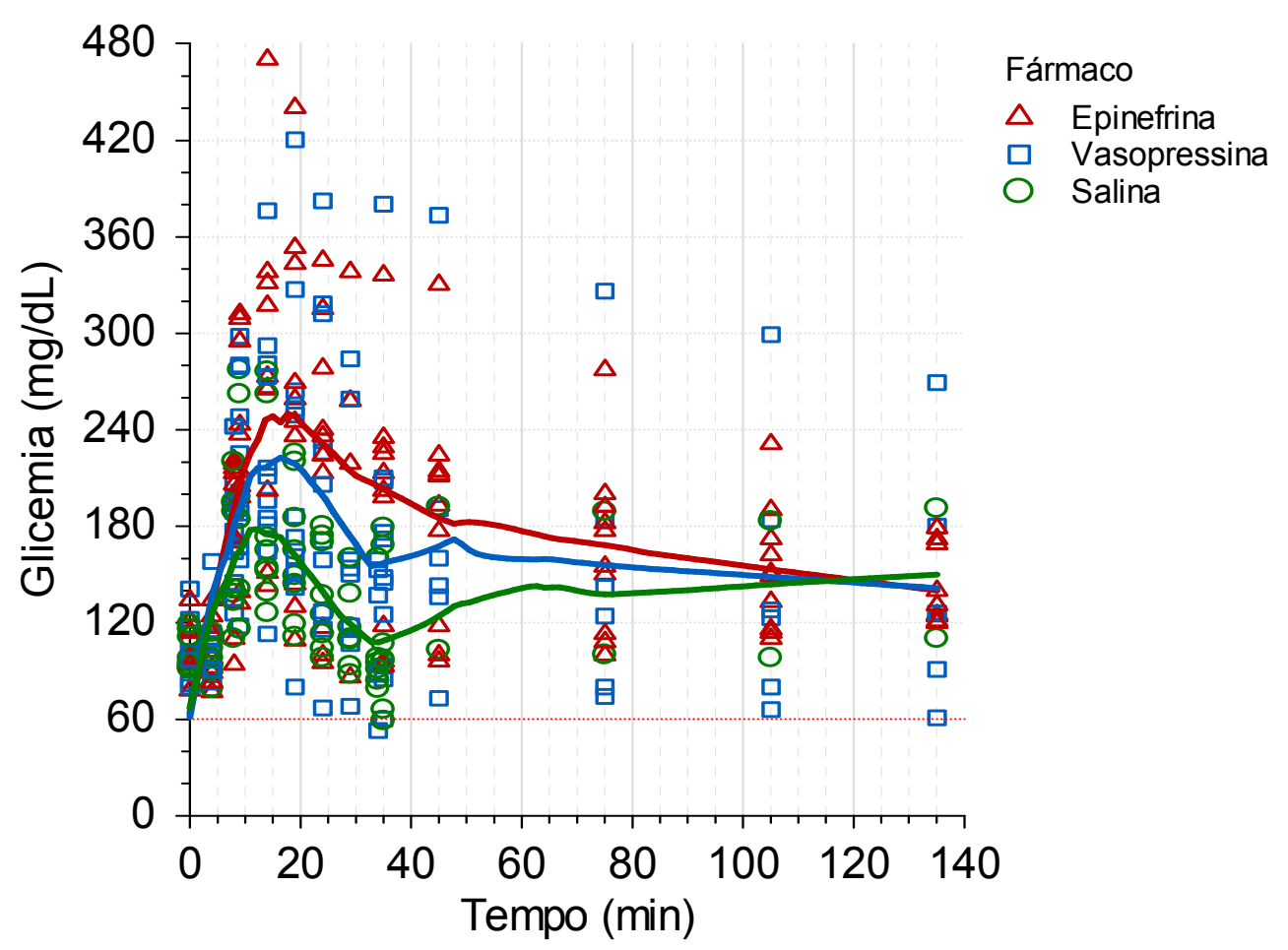

Figura 3 - Glicemia de acordo com o fármaco aplicado.

\subsection{Sinopse das variáveis até 35 min}

\subsubsection{Variáveis do sangue venoso misto}

Quanto aos animais sobreviventes à parada cardíaca ou não, as evoluções das variáveis do sangue venoso misto podem ser observadas no Anexo F e no Anexo G. Pode-se resumir dizendo que não ocorreram diferenças relevantes e significantes entre os grupos, com exceção da glicemia. No entanto, cabe notar o aumento do lactato em todos os grupos (Figura 4). 

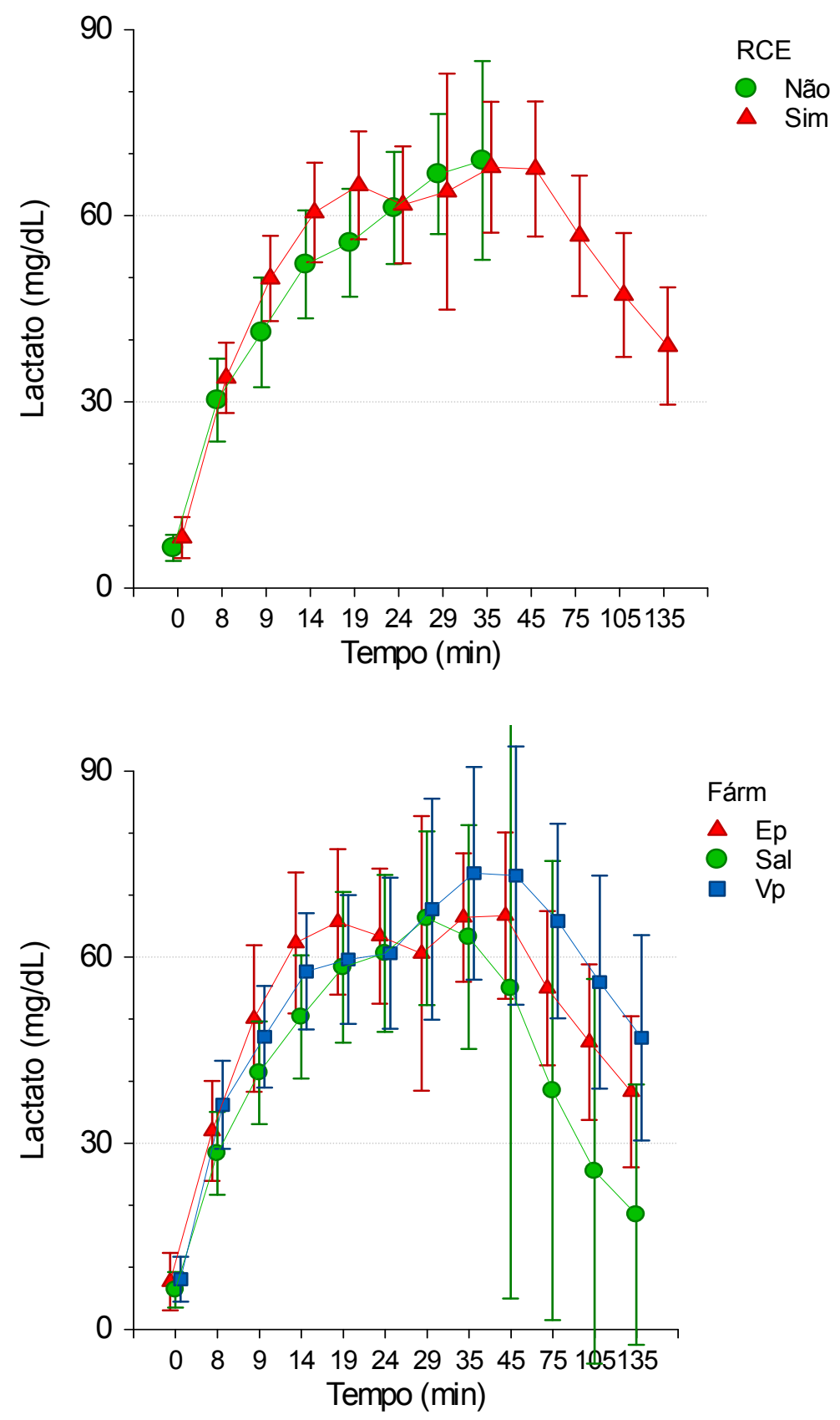

Figura 4 - Evolução do lactato durante a ressuscitação cardiopulmonar.

Em cima, de acordo com o retorno da circulação espontânea (RCE) ou não.

Em baixo, de acordo com o fármaco (Fárm) aplicado. Símbolo e barras (média \pm 2 erro-padrão). 
6.10.2 Pressão, $\mathrm{ETCO}_{2}$ e freqüência das manobras de suporte

Essas variáveis foram avaliadas quanto a diferenças entre os grupos somente antes de qualquer animal alcançar o RCE, pois se elevam claramente após. Até 13 min, nenhuma dessas variáveis diferiu com relevância entre os grupos, com exceção da PPC. A freqüência mensurada de compressão torácica foi cerca de 100/min. A freqüência de ventilação com Ambu variou mas foi cerca de 10/min.

\subsection{A glicemia e a PPC se associaram com o RCE}

6.11.1 A glicemia se associou com o RCE, independente do fármaco

A glicemia média basal foi cerca de $100 \mathrm{mg} / \mathrm{dL}$ e não diferiu entre os grupos. Aos 4 min de fibrilação ventricular sem suporte de vida, sangue venoso misto foi coletado e a glicemia foi semelhante ao basal. No entanto, um aumento da glicemia foi notado após 1 min apenas de suporte, em todos os grupos e na maioria dos animais. A partir de 9 min de experimento e 2 min de suporte, ocorreu uma diferença significante entre as glicemias dos animais conforme o RCE ou não: a glicemia foi maior nos animais que sobreviveram (Tabela 9). Note-se que a diferença surgiu aos $9 \mathrm{~min}$, antes da aplicação do fármaco e antes de qualquer animal alcançar o RCE, o que ocorreu somente a partir de $13 \mathrm{~min}$.

Comparando-se os animais por grupos de fármaco, a diferença entre as glicemias foi significante mais tardiamente, aos $14 \mathrm{~min}$, e se manteve até 35 min. Sempre maior no grupo Epinefrina. No grupo Vasopressina a glicemia se elevou mais do que no grupo Salina, mas não alcançou diferença significante, apenas uma vez aos 24 min (Tabela 10). 
Tabela 9 - Evolução da glicemia de acordo com o RCE.

\begin{tabular}{ccccc}
\hline TEMPO & RCE=NÃO & RCE=SIM & DIFERENÇA & TESTE T \\
& $\mathrm{n}=11$ & $\mathrm{n}=18$ & $\mathrm{p}$ \\
\hline Minutos & Glu & Glu & Glu & NS \\
4 & 97 & 105 & 8 & $\mathrm{NS}$ \\
8 & 95 & 105 & 10 & $\mathrm{NS}$ \\
9 & 159 & 189 & 30 & 0,041 \\
14 & 182 & 229 & 47 & 0,006 \\
19 & 178 & 263 & 85 & 0,013 \\
24 & 163 & 248 & 85 & 0,026 \\
35 & 148 & 220 & 72 & 0,002 \\
\hline
\end{tabular}

RCE: Retorno da Circulação Espontânea;

Glu: Glicemia (mg/dL);

NS: Não Significante. 
Tabela 10 - Evolução da glicemia de acordo com o fármaco aplicado.

\begin{tabular}{ccccc}
\hline TEMPO & SALINA & VASOPRESSINA & EPINEFRINA & TESTE T \\
& $\mathrm{n}=8$ & $\mathrm{n}=11$ & $\mathrm{n}=10$ & $\mathrm{p}$ \\
\hline Minutos & Glu & Glu & Glu & \\
4 & 102 & 100 & 104 & $\mathrm{NS}$ \\
8 & 97 & 100 & 104 & $\mathrm{NS}$ \\
9 & 165 & 183 & 182 & $\mathrm{NS}$ \\
14 & 185 & 214 & 228 & $\mathrm{NS}$ \\
19 & 181 & 226 & 276 & $0,026^{*}$ \\
24 & 165 & 219 & 253 & $0,043^{*}$ \\
35 & 138 & 211 & 216 & $0,029^{*} \dagger$ \\
\hline
\end{tabular}

Glu: Glicemia (mg/dL);

NS: Não Significante;

$\left(^{*}\right)$ : Epinefrina vs. Salina;

$(\dagger)$ : Vasopressina vs. Salina $p=0,036$

6.11.2 A PPC se associou com o RCE, mas dependeu do fármaco

A PPC se elevou pouco em todos os animais com o início do SBV e não diferiu entre os grupos de RCE ou de fármaco até $9 \mathrm{~min}$, quando foi de aproximadamente $18 \mathrm{~mm} \mathrm{Hg}$. Após a aplicação do fármaco e previamente a qualquer RCE, aos 11 min a PPC claramente se elevou, sendo maior no grupo de animais que alcançaram o RCE bem como nos grupos Epinefrina e Vasopressina em comparação com o controle. Essa diferença ocorreu somente sob o efeito dos medicamentos vasoativos (Figura 5), ao contrário da glicemia (Figura 6). 

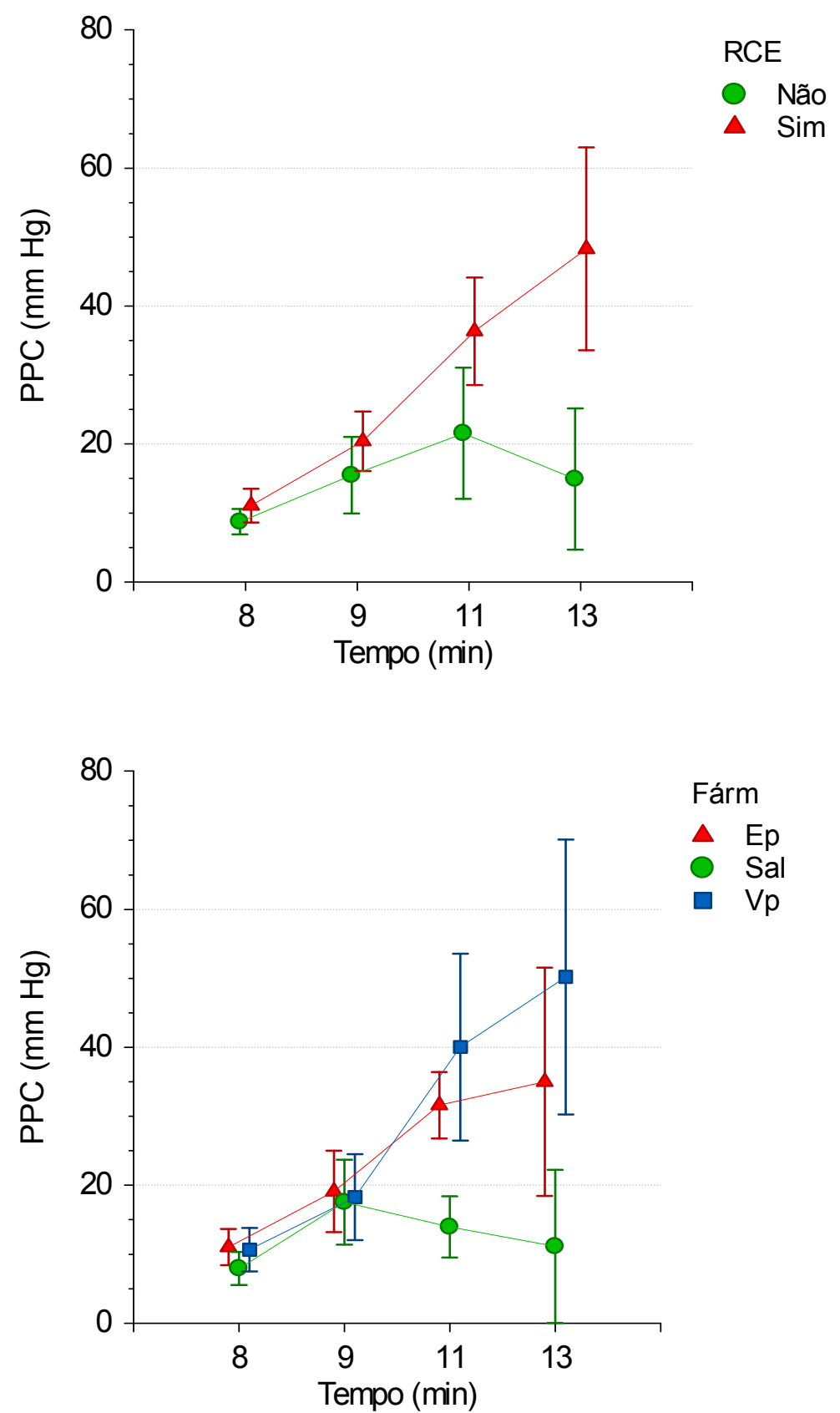

Figura 5 - Pressão de perfusão coronária (PPC) durante o suporte de vida com fármaco (Fárm) aplicado aos $9 \mathrm{~min}$. Em cima, de acordo com o retorno da circulação espontânea (RCE). Em baixo, de acordo com o fármaco aplicado Epinefrina (Ep), Vasopressina (Vp) ou Salina (Sal). Símbolo e barras (média \pm 2 erro-padrão). 

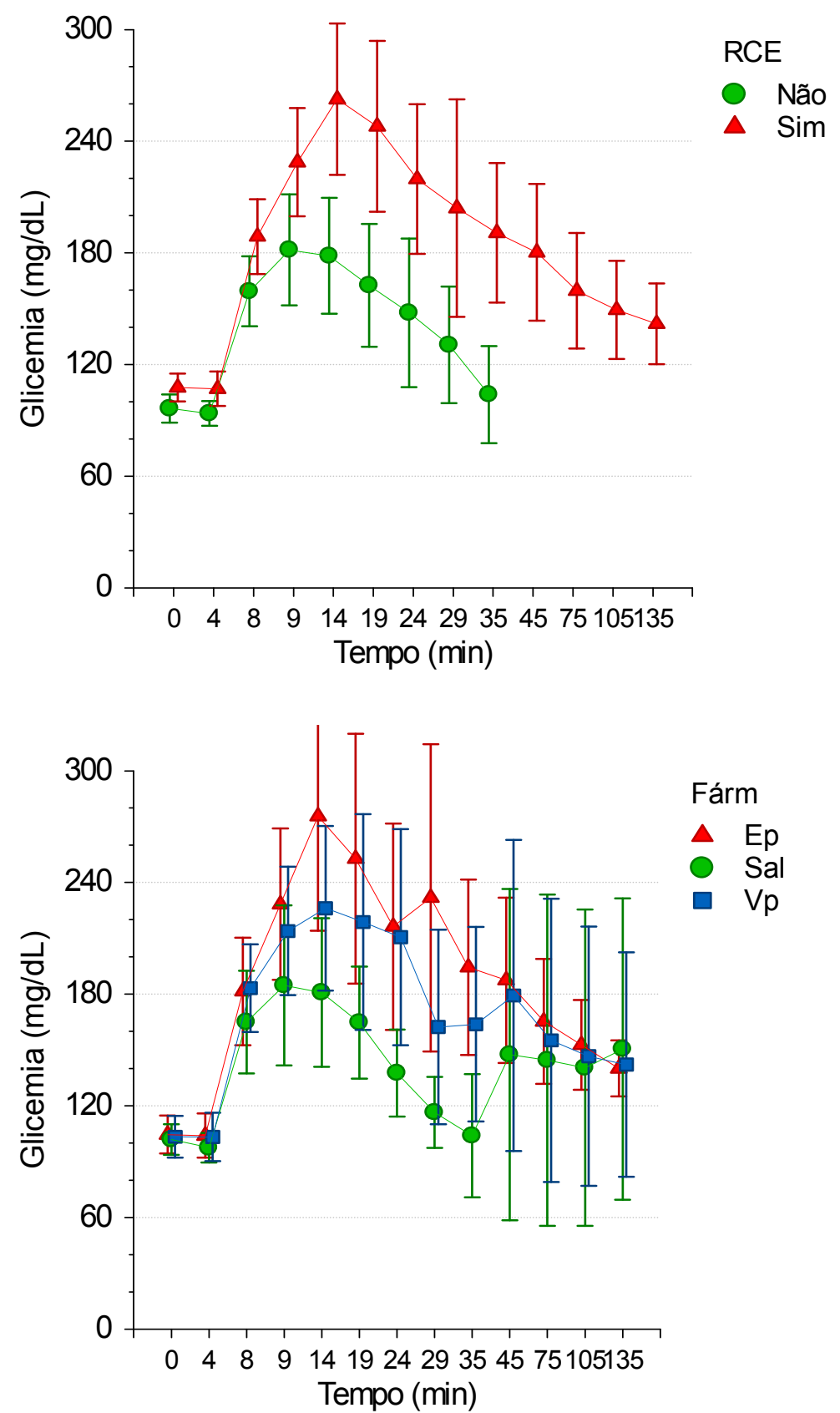

Figura 6 - Glicemia durante o suporte de vida com fármaco (Fárm) aplicado aos 9 min. Em cima, conforme o retorno da circulação espontânea (RCE). Em baixo, de acordo com o fármaco Epinefrina (Ep), Vasopressina (Vp) ou Salina (Sal). Símbolo e barras (média \pm 2 erro-padrão). 


\subsection{O período pós-parada}

O período pós-parada se caracterizou pela diferença das variáveis em relação ao basal, mas não ocorreram diferenças relevantes entre os grupos de fármacos, inclusive em relação à glicemia. Note-se que o tamanho da amostra foi pequeno e com apenas dois animais sobreviventes do grupo Salina. Isto reduz o poder para as comparações entre os grupos em cada período, mas, pode-se ter uma idéia das conseqüências da PCR sobre as variáveis basais ao se observar as Tabelas 11 a 13. Poucas variáveis não diferiram, após o RCE, das respectivas variáveis basais. No entanto, comparando-se as variáveis entre os grupos dos animais sobreviventes, quase nenhuma diferença significante ou relevante ocorreu.

No geral, pode-se resumir dizendo que, em relação ao período basal, o débito cardíaco caiu para 2/3, a extração de oxigênio aumentou 2/3 e o consumo de oxigênio aumentou $10 \%$ aos 120 min (Figuras 8 a 11).

\subsection{A concentração de epinefrina basal e após o suporte de vida}

A concentração de epinefrina basal não diferiu entre os grupos, cerca de $1 \mathrm{ng} / \mathrm{dL}$. Mas se elevou dezenas de vezes em todos os grupos, inclusive no grupo Salina, o que foi verificado imediatamente após o óbito ou aos 10 min após o RCE (Figura 7). Os dois animais do grupo Epinefrina que não alcançaram o RCE apresentaram concentração acima de 450 ng/dL. Mesmo excluindo esses dois casos, a concentração de epinefrina foi maior após o óbito do que aos $10 \mathrm{~min}$ de RCE $(58 \pm 12 \mathrm{ng} / \mathrm{dL}$ vs. $23 \pm 4 \mathrm{ng} / \mathrm{dL} ; \mathrm{p}=0,013)$. 

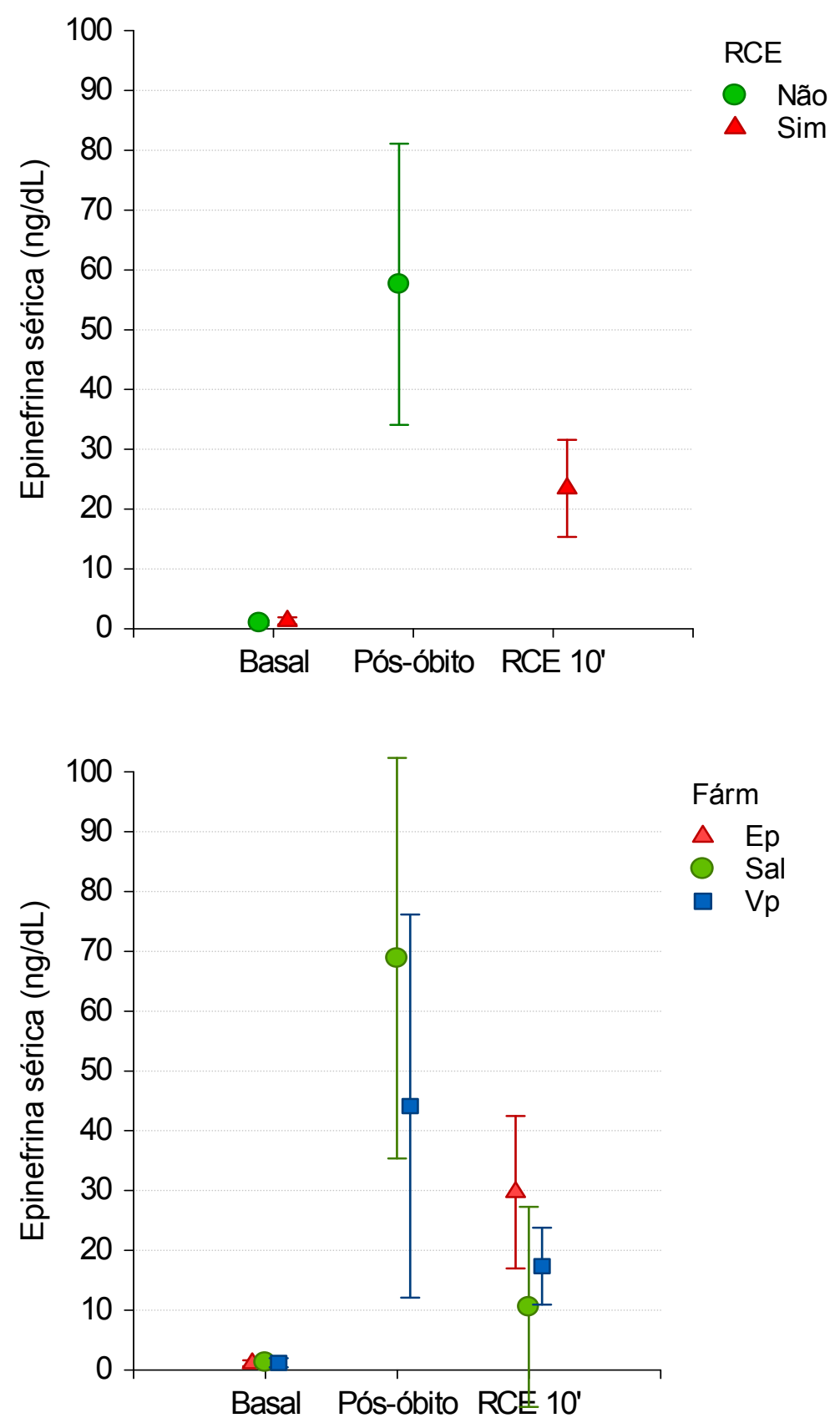

Figura 7 - Epinefrina sérica basal e após o óbito ou após 10 min de retorno da circulação espontânea (RCE 10'). Em cima, conforme o retorno da circulação (RCE) ou não. Em baixo, de acordo com o fármaco aplicado Epinefrina (Ep), Vasopressina (Vp) ou Salina (Sal). Símbolo e barras (média \pm 2 erro-padrão). 
Tabela 11 - Variáveis basais e após 2 h de RCE. Sem diferenças ao se compararem os grupos em cada período.

\begin{tabular}{lccccccc}
\hline VARIÁVEL & Sal & Sal 2 h & Vp & Vp 2 h & Ep & Ep 2 h \\
& $\mathrm{n}=8$ & $\mathrm{n}=2$ & $\mathrm{n}=12$ & $\mathrm{n}=6$ & $\mathrm{n}=12$ & $\mathrm{n}=10$ \\
\hline Temperatura ( $\left.{ }^{\circ} \mathrm{C}\right)$ & 37,7 & 39,4 & 38,0 & 39,9 & 37,6 & 38,9 \\
Débito Cardíaco (L/min) & 6,1 & 4,0 & 6,1 & 3,6 & 6,1 & 3,5 \\
Oferta de Oxigênio (mL/min) & 827 & 651 & 775 & 537 & 789 & 512 \\
Consumo de Oxigênio (mL/min) & 238 & 271 & 249 & 298 & 243 & 262 \\
ETCO 2 (mm Hg) & 42 & 41 & 42 & 42 & 41 & 43 \\
Freq Ventilatória (ciclos/min) & 21 & 21 & 23 & 26 & 24 & 24 \\
Freq Cardíaca (ciclos/min) & 141 & 130 & 127 & 159 & 139 & 143 \\
Pressão da Aorta (mm Hg) & 134 & 132 & 141 & 97 & 141 & 112 \\
Pressão do Átrio D (mm Hg) & 5 & 4 & 5 & 7 & 5 & $6 *$ \\
\hline
\end{tabular}

RCE: Retorno da Circulação Espontânea;

Grupos: Salina (Sal), Vasopressina (Vp), Epinefrina (Ep) no basal;

Grupos 2 h: Respectivos grupos 2 h após o RCE;

$\left(^{*}\right): p=0,041$ vs. Sal $2 h$. 
Tabela 12 - Variáveis venosas no basal e após 2 h de RCE: sem diferenças ao sem compararem os grupos em cada período.

\begin{tabular}{|c|c|c|c|c|c|c|}
\hline VARIÁVEL & $\begin{array}{l}\text { Sal } \\
n=8\end{array}$ & $\begin{array}{c}\text { Sal } 2 \mathrm{~h} \\
n=2\end{array}$ & $\begin{array}{c}\mathrm{Vp} \\
\mathrm{n}=12\end{array}$ & $\begin{array}{c}\text { Vp } 2 \text { h } \\
n=6\end{array}$ & $\begin{array}{c}E p \\
n=12\end{array}$ & $\begin{array}{l}\text { Ep } 2 \mathrm{~h} \\
\mathrm{n}=10\end{array}$ \\
\hline \multicolumn{7}{|l|}{ Sangue venoso misto } \\
\hline Glicemia (mg/dL) & 102 & 151 & 100 & 142 & 104 & 140 \\
\hline Lactato (mg/dL) & 6 & 19 & 8 & 47 & 7 & 38 \\
\hline $\mathrm{pH}$ & 7,40 & 7,35 & 7,38 & 7,21 & 7,39 & 7,26 \\
\hline Saturação de $\mathrm{O}_{2}(\%)$ & 69 & 55 & 66 & 42 & 67 & 43 \\
\hline $\mathrm{pO}_{2}(\mathrm{~mm} \mathrm{Hg})$ & 56 & 58 & 68 & 62 & 66 & 60 \\
\hline $\mathrm{pCO}_{2}(\mathrm{~mm} \mathrm{Hg})$ & 48 & 54 & 48 & 61 & 50 & 60 \\
\hline Bicarbonato (mmol/L) & 29 & 28 & 28 & 22 & 29 & 25 \\
\hline Sódio (mmol/L) & 139 & 137 & 139 & 138 & 139 & 138 \\
\hline Potássio (mmol/L) & 3,5 & 4,8 & 3,7 & $5,6^{*}$ & 3,6 & 4.5 \\
\hline Hemoglobina (g/dL) & 9,9 & 12,3 & 9,1 & 11,1 & 9,4 & 11,0 \\
\hline \multicolumn{7}{|c|}{$\mathrm{pO}_{2} / \mathrm{pCO}_{2}$ : Pressão parcial de oxigênio / gás carbônico } \\
\hline \multicolumn{7}{|c|}{ RCE: Retorno da Circulação Espontânea; } \\
\hline \multicolumn{7}{|c|}{ Grupos: Salina (Sal), Vasopressina (Vp), Epinefrina (Ep) no basal; } \\
\hline \multicolumn{7}{|c|}{ Grupos 2 h: Respectivos grupos 2 h após o RCE; } \\
\hline$\left(^{*}\right): p=0,038$ vs. Ep. & & & & & & \\
\hline
\end{tabular}


Tabela 13 - Variáveis arteriais no basal e após 2 h de RCE: sem diferenças ao se compararem os grupos em cada período.

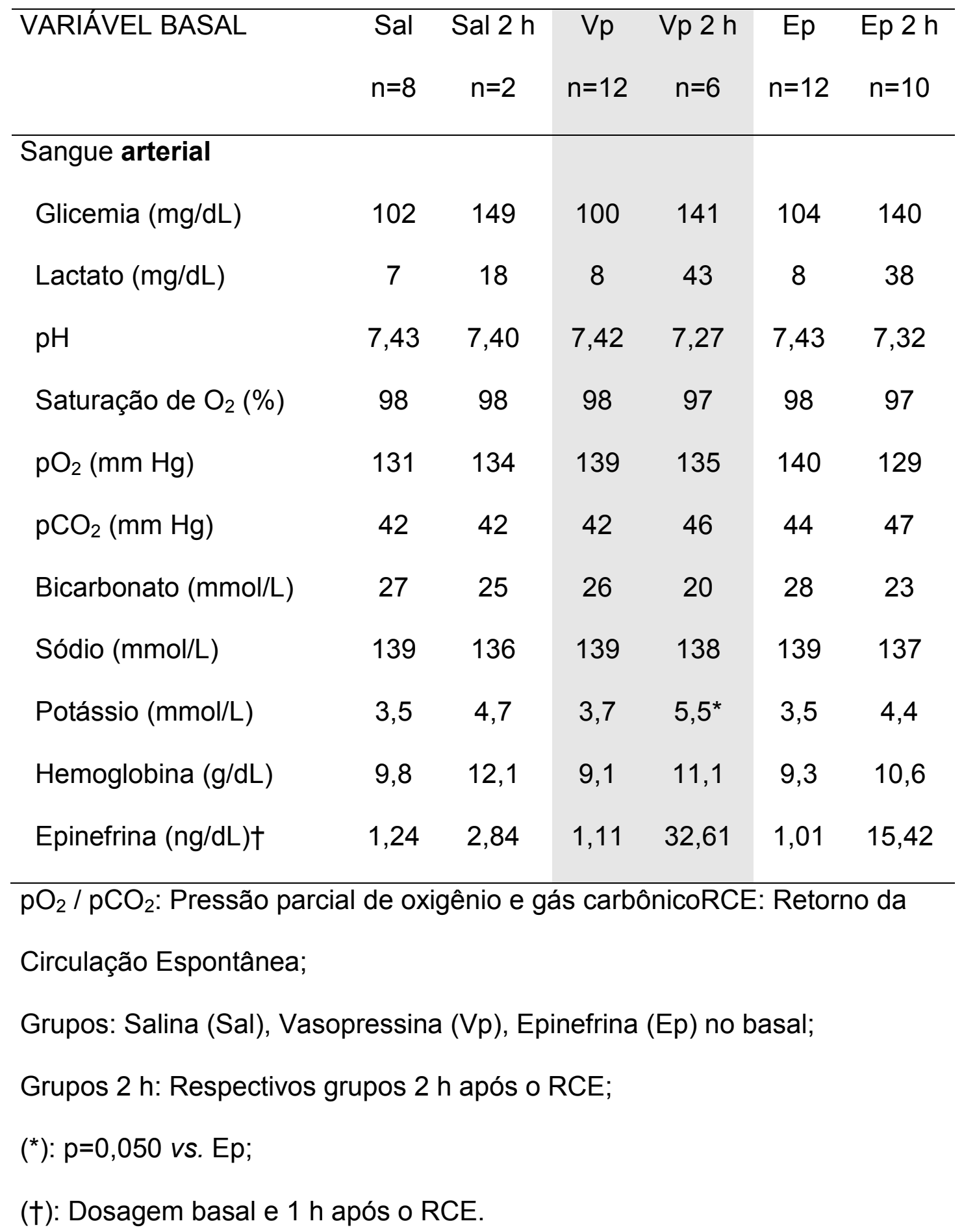




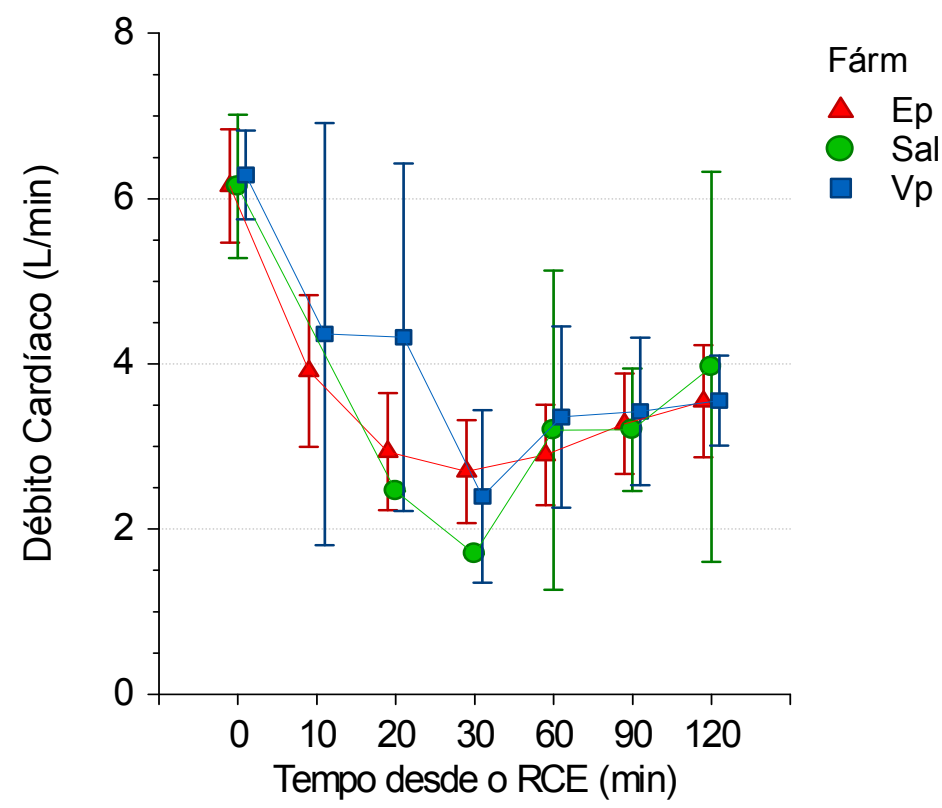

Figura 8 - Evolução do débito cardíaco basal (0) até 2 h após o retorno da circulação espontânea (RCE) conforme os grupos Epinefrina (Ep), Vasopressina (Vp) ou Salina (Sal).

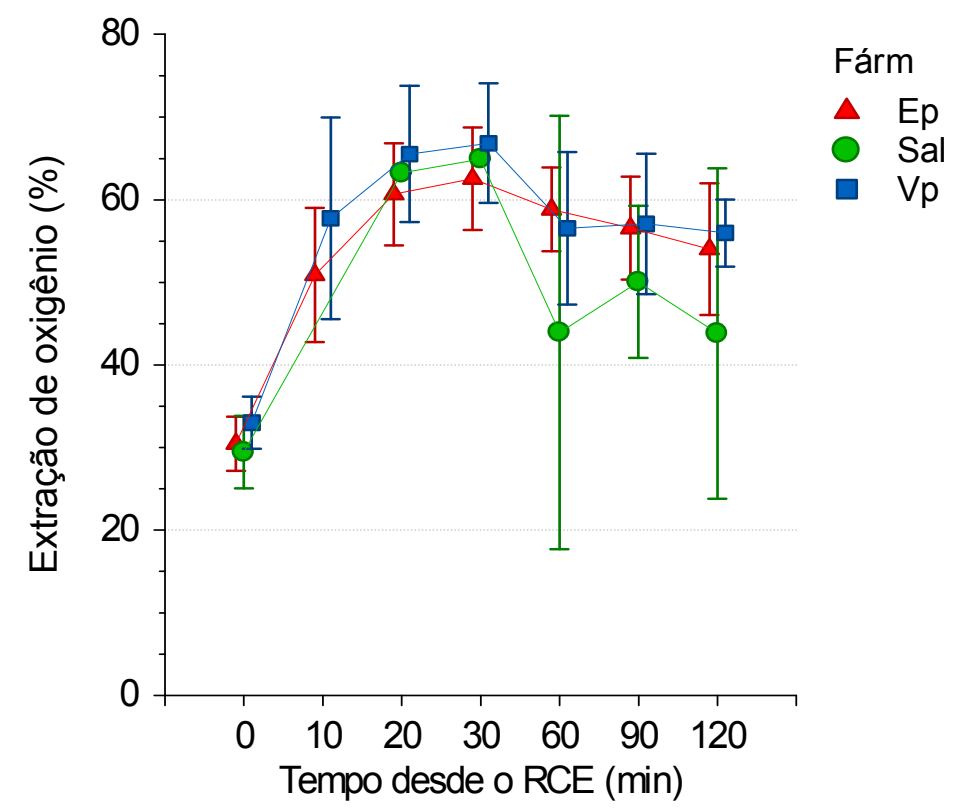

Figura 9 - Evolução da extração de oxigênio basal (0) até 2 h após o retorno da circulação espontânea (RCE) conforme os grupos Epinefrina (Ep), Vasopressina (Vp) ou Salina (Sal). 


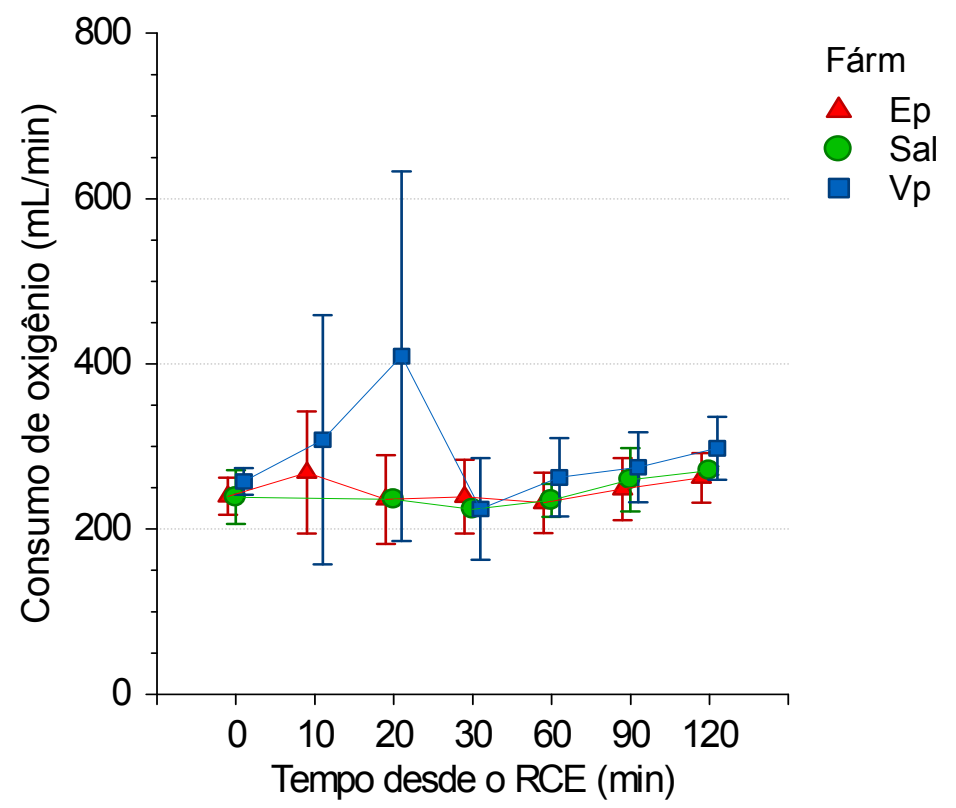

Figura 10 - Evolução do consumo de oxigênio basal (0) até $2 \mathrm{~h}$ após o retorno da circulação espontânea (RCE) conforme os grupos Epinefrina (Ep), Vasopressina (Vp) ou Salina (Sal).

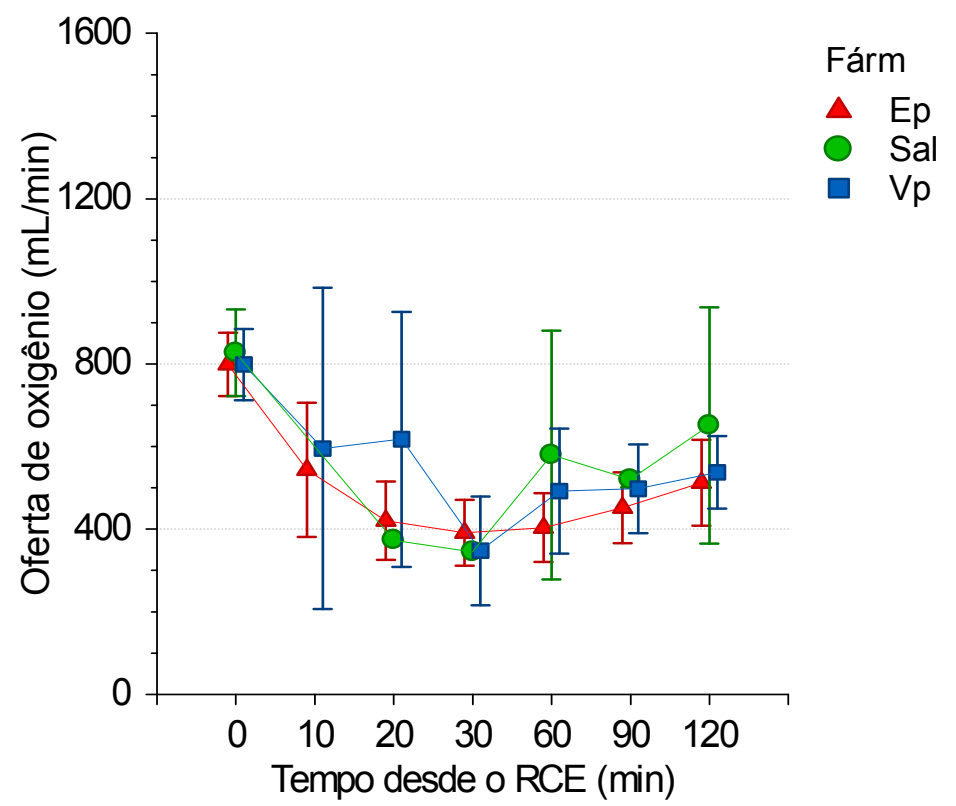

Figura 11 - Evolução da oferta de oxigênio basal (0) até $2 \mathrm{~h}$ após o retorno da circulação espontânea (RCE) conforme os grupos Epinefrina (Ep), Vasopressina (Vp) ou Salina (Sal). 


\section{DISCUSSÃO}

\section{A glicemia observada pode ser a expressão da adaptação conjunta celular e sistêmica constituintes da reação de fuga.}

\section{Aspectos gerais}

A curva típica da glicemia na RCP pode ser a manifestação conjunta de importantes mecanismos de adaptação celular e sistêmica da reação de fuga. Na condição de PCR e RCP ocorrem anóxia, hipóxia e isquemia global. ${ }^{55,121}$ Nesta condição, as células produzem ATP suficiente para manter a integridade funcional e estrutural por alguns minutos. ${ }^{121}$ Neste período, a célula utiliza o glicogênio intracelular que varia de acordo com os estudos, de 10 a $30 \mu \mathrm{mol} / \mathrm{g}$ de músculo cardíaco. ${ }^{179,198,199}$ No sistema nervoso central, os astrócitos podem tolerar até 20 min com o glicogênio de reserva e podem suprir lactato para os neurônios, principalmente nas terminações axonais. ${ }^{186,}$, 200, 201 Um estudo mensurou o glicogênio cerebral de rato em cerca de $20 \mathrm{nmol} / \mathrm{mg}$ de peso seco. ${ }^{202} \mathrm{O}$ cardiócito tem reserva de glicogênio que corresponde a aproximadamente $2 \%$ de seu volume. Em termos clínicos, significa a tolerância de até 15 min de isquemia sem lesão estrutural detectável por meio da troponina sérica ou muito menos tempo, por outros meios, em relação ao SNC. ${ }^{200,203}$ Mas enquanto não houver circulação sanguínea, a célula não tem reserva de oxigênio e produzirá o ATP pela via anaeróbia chamada de glicólise. ${ }^{122}$ Uma circulação sanguínea precária se obtém com o SBV, portanto, antes disso, a célula está sob 
anóxia e ocorrem mecanismos de adaptação celular ao estresse. ${ }^{121,122}$ Os mecanismos primordiais são os mesmos que ocorrem sob hipóxia, ou seja, sob hipoxemia na condição de baixo fluxo sanguíneo sistêmico obtido com as compressões torácicas. ${ }^{121,122}$

\section{Mecanismos de adaptação celular no período de PCR}

\section{sem suporte de vida (sem circulação)}

Estímulos como anóxia, hipóxia ou adrenalina desencadeiam adaptações celulares. Essas adaptações ocorrem muito rapidamente. De imediato, somente pela glicólise a produção de ATP cai para 2 mol por mol de glicose. ${ }^{122}$ Para tentar manter o equilíbrio da relação ATP/ ADP, ocorre "translocação" (do inglês translocation) para a membrana plasmática de proteínas da família dos transportadores de glicose (GLUT), aumento da atividade das hexoquinases e aumento da hidrólise do glicogênio (glicogenólise). ${ }^{175,177,178,180-182,185,187,199,204-208}$ As adaptações ocorrem no sentido de aumentar o rendimento da produção energética, pois são necessárias 18 vezes mais glicose para produzir a mesma quantidade de ATP que o catabolismo completo produziria no ciclo de Krebs e cadeia de transporte de elétrons. ${ }^{122}$ Essas adaptações são reguladas e moduladas pela adrenalina, assim como os demais efeitos locais e sistêmicos associados à clássica reação de fuga ou de luta. ${ }^{119,}{ }^{209}$ Note-se que as adaptações ocorrem sem depender da circulação sanguínea, mas, na fase elétrica da parada cardíaca o nível de ATP cai após alguns minutos sem a oferta de oxigênio e de substrato energético. ${ }^{121}$ 


\section{A reação de fuga durante a PCR}

\section{sem suporte de vida (sem circulação)}

Para ilustrar sobre a complexidade da reação de fuga durante a PCR, pode-se exemplificar com o seguinte caso clínico: um indivíduo que sofre morte súbita, sem pródromos, sem dor, sem elevação de adrenalina sérica, devido à síncope por arritmia. Como não há circulação sanguínea, existe a reação de fuga associada à adrenalina neste caso? Um estudo de isquemia in vivo evidenciou aumento da adrenalina e noradrenalina intersticial do coração liberada pelas terminações nervosas. ${ }^{82}$ A concentração sérica de epinefrina aumenta durante a RCP e nas condições de estresse. ${ }^{209}$ Portanto, durante o período de PCR sem suporte de vida, grande quantidade de adrenalina é liberada nos diversos sistemas, regulando e modulando a reação local de fuga. O sistema nervoso central faz a vez do sistema circulatório que também transporta adrenalina das supra-renais durante reações de fuga secundárias a outros eventos cardiovasculares. No estudo atual, a concentração sérica de adrenalina no período basal foi cerca de 1 $\mathrm{ng} / \mathrm{dL}$ em todos os animais, na amostra coletada da artéria femoral esquerda após todo o estresse eventual ocorrido com o preparo do animal e sua manutenção em anestesia geral. Aumentou dezenas de vezes em todos os grupos, inclusive no grupo controle. 


\section{A glicólise e a glicogenólise}

Tanto a vasopressina quanto a adrenalina aumentam a glicólise e a glicogenólise. A isquemia também promove aumento da glicólise e da glicogenólise, junto com outras adaptações que, em conjunto, tentam manter a produção energética celular. No contexto da parada cardíaca, um dos mais importantes mecanismos de adaptação é o aumento da capacidade de transporte de glicose. ${ }^{175,177, ~ 178, ~ 182, ~ 188, ~ 210-212 ~}$

\section{Os transportadores de glicose}

A isquemia promove o aumento da expressão celular dos transportadores de glicose rapidamente, pois os transportadores não são produzidos e sim translocados do compartimento endossomal para a membrana plasmática. ${ }^{182}$ Diversos estudos in vitro e in vivo já demonstraram o aumento da captação de glicose poucos minutos após o estímulo desencadeante. ${ }^{177-188}$ No contexto da parada cardíaca, significa que os transportadores estão prontos para captar glicose logo no início do suporte de vida. O mais importante é que a captação de glicose depende fundamentalmente da oferta ou da concentração extracelular de glicose. A hiperglicemia observada no estudo atual não é suficiente para saturar o transporte, ao contrário, os animais com maiores glicemias se beneficiaram minuto a minuto com uma maior captação de glicose e possivelmente uma maior produção de energia e melhor preservação das funções celulares. 
As adaptações sistêmicas e a importância da compressão torácica.

A oferta de oxigênio depende da perfusão pulmonar; a oferta de glicose, da perfusão hepática. ${ }^{84,87,123,124,213,214}$ A oferta de oxigênio e de glicose ao coração depende da relação que existe entre pressão e fluxo (perfusão) no sistema cardiovascular, a PPC. A oferta de glicose a todo o organismo depende da perfusão sistêmica e hepática. ${ }^{87,123,125-128,172-174, ~ 213, ~} 214$ Há poucos estudos sobre a perfusão hepática e esplâncnica em modelos de RCP. A primordial importância do SBV é porque promove o transporte de glicose, e não somente de oxigênio. Neste estudo a oferta de glicose promovida pelo SBV, precisamente a concentração de glicose no sangue venoso misto foi elevada em quase todos os animais deste estudo. Isso corrobora com as recomendações atuais de se priorizar a compressão torácica efetiva, sem pausas após as tentativas de desfibrilação e mesmo sem manobras de ventilação. ${ }^{121,131,132,215}$ Alguns estudos já demonstraram iguais taxas de RCE ao comparar modelos de compressão torácica com e sem ventilação ativa, além dos estudos clínicos no contexto do atendimento extra-hospitalar da parada. ${ }^{216}$ Uma razoável saturação arterial de oxigênio se mantém por vários minutos ao longo da RCP, mesmo sem ventilação. ${ }^{216} \mathrm{O}$ foco atual do suporte básico de vida está na circulação obtida com a técnica adequada. Mesmo que não tenha sido o foco e apesar de não se ter estudado a perfusão hepática, a oferta de glicose promovida pela compressão torácica pode ter sido típica na maioria dos estudos de RCP, da mesma forma como ocorreu no estudo atual. O SBV promoveu aumento da 
glicemia na maioria dos animais e, quanto à perfusão hepática, apresenta relação pressão vs. fluxo peculiar, difícil de mensurar com precisão mesmo em condições fisiológicas habituais.

\section{Perfusão hepática}

O fígado apresenta grande capacidade de reserva sanguínea, grande superfície sinusoidal e cerca de $10 \%$ do peso em glicogênio no animal alimentado. $^{122} \mathrm{O}$ catabolismo de todo o glicogênio hepático pode se completar em 12 h a 24 h, sob jejum prolongado. ${ }^{122}$ A relação pressão vs. fluxo dos vasos hepáticos é peculiar e sua perfusão, difícil de mensurar com precisão devido à anatomia vascular. Em condições normais, $80 \%$ do fluxo hepático provêm da drenagem esplâncnica, apenas $20 \%$ provém da artéria hepática. ${ }^{123,124} \mathrm{O}$ fígado é o único órgão com perfusão de sangue arterial e sangue venoso da porta. ${ }^{123,124}$ A comunicação entre os vasos ocorre nos sinusoidais onde a pressão é de $2-4 \mathrm{~mm} \mathrm{Hg}$ maior que na veia cava inferior, em condições normais. ${ }^{123} \mathrm{O}$ fluxo hepático tende a ser constante, com a artéria hepática compensando as alterações do fluxo portal, mecanismo possivelmente mediado pela adenosina, chamado de Buffer Hepático. ${ }^{123-125}$ O fluxo da artéria hepática já foi mensurado durante PCR e RCP em cerca de $50 \mathrm{ml} / \mathrm{min}$, e não foi descrito diferença de fluxo sob influência de adrenalina exógena ou da vasopressina. ${ }^{84}$ Mas os efeitos desses hormônios vasoconstritores são próprios de cada território vascular, podendo ter efeitos particulares ou aditivos quanto à perfusão esplâncnica, além dos efeitos sobre o metabolismo dos carboidratos. ${ }^{87,123-128,172,174,213,214}$ Quaisquer que 
sejam os reais efeitos da adrenalina exógena e da vasopressina sobre a perfusão hepática durante a RCP, o SBV promoveu elevação da glicemia em $91 \%$ da amostra deste estudo e não ocorreram casos de hipoglicemia no grupo controle, como ocorreu uma vez em cada grupo de vasoconstritor.

\section{$\underline{\text { A associação entre PPC e RCE }}$}

O SBV inicia o metabolismo isquêmico ou hipóxico não por falta de oxigenação sanguínea razoável e sim porque a oferta de oxigênio é insuficiente com o precário fluxo sistêmico obtido. ${ }^{121}$ Esse fluxo pode ser inferido por meio da relação que existe entre pressão e fluxo do sistema cardiovascular. A perfusão coronária pode ser inferida pela PPC que, quando acima de $20 \mathrm{~mm} \mathrm{Hg}$, está associada ao RCE. ${ }^{66}$ Os fármacos vasoativos são hormônios que claramente elevaram a PPC neste estudo e a média da PPC foi maior no grupo que alcançou RCE, previamente.

\section{A associação entre glicemia e RCE}

O SBV inicia o metabolismo isquêmico e promove a oferta de glicose e oxigênio para as células. ${ }^{121,217}$ Mas, apesar dos valores elevados da glicemia observados, é possível que a concentração de glicose e a velocidade de sua oferta sejam insuficientes, principalmente durante os primeiros minutos de suporte de vida. ${ }^{217}$ Como a captação de glicose é proporcional à sua concentração, uma oferta de glicose maior a cada instante pode propiciar maior produção de energia e melhores condições celulares para responder bem ao desfibrilador. ${ }^{66,121,217}$ Ocorreu uma maior 
elevação da glicemia nos 2 min iniciais de suporte neste estudo. A cada instante, a diferença entre os grupos aumentou, alcançando $85 \mathrm{mg} / \mathrm{dL}$ a mais no grupo que sobreviveu à parada cardíaca. Esse pode ser o motivo para a concentração mais elevada de glicose no grupo com RCE, ou seja, uma melhor adaptação agudíssima.

\section{$\underline{\text { A PPC e a glicemia são importantes em conjunto }}$}

O SBV de nada adiantaria se promovesse o transporte de oxigênio apenas. ${ }^{217}$ Considerando os 2 min iniciais de suporte de vida, onde ainda não se deram os efeitos dos hormônios exógenos, pode-se analisar a correlação entre PPC e glicemia, com a cautela de que a glicemia depende sim da perfusão e produção hepáticas e de que a perfusão sistêmica depende do SBV. A correlação geral entre as mensurações da PPC aos 4 $\min (\mathrm{PPC}=$ zero), $8 \mathrm{~min}$ e $9 \mathrm{~min}$ com as respectivas glicemias nos mesmos instantes foi de 59\% $(p<0,001)$. A correlação entre a glicemia e a PPC dos sobreviventes foi de $67 \%(p<0,001)$. Essa correlação, nos animais que não sobreviveram foi de $36 \%(p=0,037)$; no grupo Epinefrina foi de $56 \%$ $(p=0,001)$; Vasopressina 79\% $(p<0,001)$; Salina 27\% ( $p=N S)$. Ou seja, houve correlação entre a glicemia e a PPC, nos 2 min iniciais de suporte de vida, com exceção do grupo Salina. A correlação foi fraca e positiva, no geral. Cabe lembrar que nenhum grupo estava sob efeito dos fármacos até 9 min. Ou seja, o suporte de vida promoveu a oferta de glicose para o organismo durante a parada cardíaca. Essa oferta depende da perfusão de cada órgão ou sistema. 


\section{A glicemia da admissão hospitalar}

Em RCP não há estudos clínicos adequados comparando a evolução conforme a glicemia da admissão. Os conceitos a respeito foram, na maioria das vezes, extrapolados de doenças isquêmicas agudas como o infarto do miocárdio e o acidente vascular encefálico. Nessas doenças a chamada "hiperglicemia de estresse" ou "da admissão" hospitalar está associada a mau prognóstico. ${ }^{31,32,36,39,45}$ Por outro lado, a terapia com insulina intensiva diminuiu a mortalidade e a morbidade de pacientes de UTI, principalmente cirúrgicos. ${ }^{48,49}$ Ao inferir sobre o prognóstico, os estudos clínicos de RCP não compararam a glicemia dos sobreviventes com seu grupo complemento, ou seja, os pacientes que não sobreviveram. Os animais deste estudo apresentaram glicemia ainda elevada aos 120 min após o RCE. Em muitos países a glicemia da admissão poderia ser coletada pouco depois do RCE e dentro do período de $2 \mathrm{~h}$ em que a glicemia ainda pode estar bastante elevada, considerando o tempo médio de socorro extra-hospitalar. Portanto, deve-se inferir com cautela sobre o prognóstico e sobre a glicemia da admissão de pacientes recuperados da parada cardíaca. A glicose é o mais importante substrato energético durante a PCR e sua elevação no período pós-parada pode ser apenas o reflexo da adaptação celular e sistêmica da reação de fuga. Novos estudos serão necessários para verificar essa questão e se o controle da glicemia com insulina ou com GIK (glicose, insulina e potássio) no período pós-parada seriam benéficos nos casos de hiperglicemia prolongada ou persistente. Note-se que os pacientes geralmente têm doenças crônicas associadas como o diabetes, 
aterosclerose e insuficiência cardíaca que cursam com modificações vasculares e teciduais secundárias à glicação, à glico-oxidação proteica e alterações na utilização de substratos energéticos bem como alterações no catabolismo oxidativo da glicose..$^{218-220}$ Os animais deste estudo eram supostamente saudáveis.

Limitações do estudo

Alguns pontos do estudo devem ser destacados:

- Quanto aos três animais excluídos, é fato que, com ou sem esses animais na análise, a freqüência de RCE continua maior no grupo Epinefrina, com significância. Dois animais excluídos eram desse grupo e não alcançaram o RCE. O outro animal excluído era do grupo Vasopressina que, com ou sem esse animal, não apresentou significância quanto à freqüência de RCE.

- Os motivos para a exclusão foram de natureza estatística (outlier) e metabólica (hipoglicemia). Caso se exclua apenas o animal que apresentou valor extremo (outlier) de hiperglicemia, a significância da hiperglicemia para o RCE ainda existe a partir de 9 min ou 2 min de suporte de vida.

- Provavelmente os animais que apresentaram hipoglicemia ficaram mais tempo de jejum do que o tempo prescrito. Os animal provém de empresa terceirizada e não se tem controle absoluto sobre essa variável de confusão, nem se os animais estariam com alguma doença. Um deles já estava com 60 mg/dL no exame basal. 
- Sete por cento de todos as coletas de sangue não procederam da artéria pulmonar com o sangue venoso misto das duas cavas e sim do átrio direito, devido à obstrução de cateter em momentos críticos de tempo para a coleta durante o SBV, mesmo com heparina. $\mathrm{Na}$ maioria das vezes, percebeu-se uma queda do valor da glicemia, sem relevância na seqüência de exames apropriados da artéria pulmonar. Outras duas vezes a coleta foi perdida porque passou da hora sem se conseguir. Uma foi na coleta de 4 min, que foi corrigida com o valor basal. Outra foi na coleta de 8 min de outro animal, corrigida com o valor médio entre a coleta de 4 min e a de 9 min.

- Seis dos oito animais do grupo Salina foram experimentados no terço inicial do projeto, apesar do sorteio simples sem reposição e sem o conhecimento dos investigadores. Pode ser que a menor prática no protocolo tenha influenciado o RCE nessa fase.

- Não se coletou sangue arterial durante o suporte de vida. Ao menos na metade inicial da RCP, o sangue arterial permitiria inferir sobre a perfusão pulmonar e a extração de oxigênio, mas não se mensurou o débito cardíaco durante o suporte de vida nem a real oferta de oxigênio.

- Não se coletou sangue para dosagem hormonal no período de SBV. Apesar de ser provável que o perfil hormonal da reação de fuga tenha ocorrido, essas coletas poderiam ao menos corroborar com esse conceito. 
- A mensuração de adrenalina ocorreu 10 min após o RCE e a coleta de 60 min apresentou valores semelhantes. É possível que a concentração de epinefrina imediatamente depois do RCE fosse maior e sem diferença com a concentração imediatamente após o óbito.

- O tamanho da amostra foi insuficiente para analisar seis grupos de acordo com o fármaco e com o RCE ou não. Cabe dizer que a tendência de glicemias maiores entre os sobreviventes da parada cardíaca se manteve nos seis grupos. 


\section{CONCLUSÕES}

A glicemia apresentou uma evolução típica ao longo da ressuscitação cardiopulmonar. Ocorreu hiperglicemia independente do fármaco utilizado e concentrações mais elevadas de glicose se associaram ao retorno da circulação espontânea. A glicemia diminuiu, mas ainda estava elevada $2 \mathrm{~h}$ depois da parada cardíaca.

A freqüência de retorno da circulação espontânea foi maior nos animais que receberam epinefrina do que nos animais que receberam solução salina.

A pressão de perfusão coronária também foi maior nos animais que sobreviveram à parada cardíaca, previamente ao retorno da circulação espontânea, mas somente após a aplicação dos medicamentos vasoativos e não de solução salina.

A epinefrina sérica endógena aumentou dezenas de vezes em todos os grupos depois do suporte de vida, sendo maior depois do óbito do que depois do retorno da circulação espontânea. 
ANEXOS 


\section{Anexo A - Documento da Comissão de Pós-Graduação ao diretor do \\ Instituto de Ensino e Pesquisa do Hospital Sírio-Libanês e ao Comitê de Ética local.}

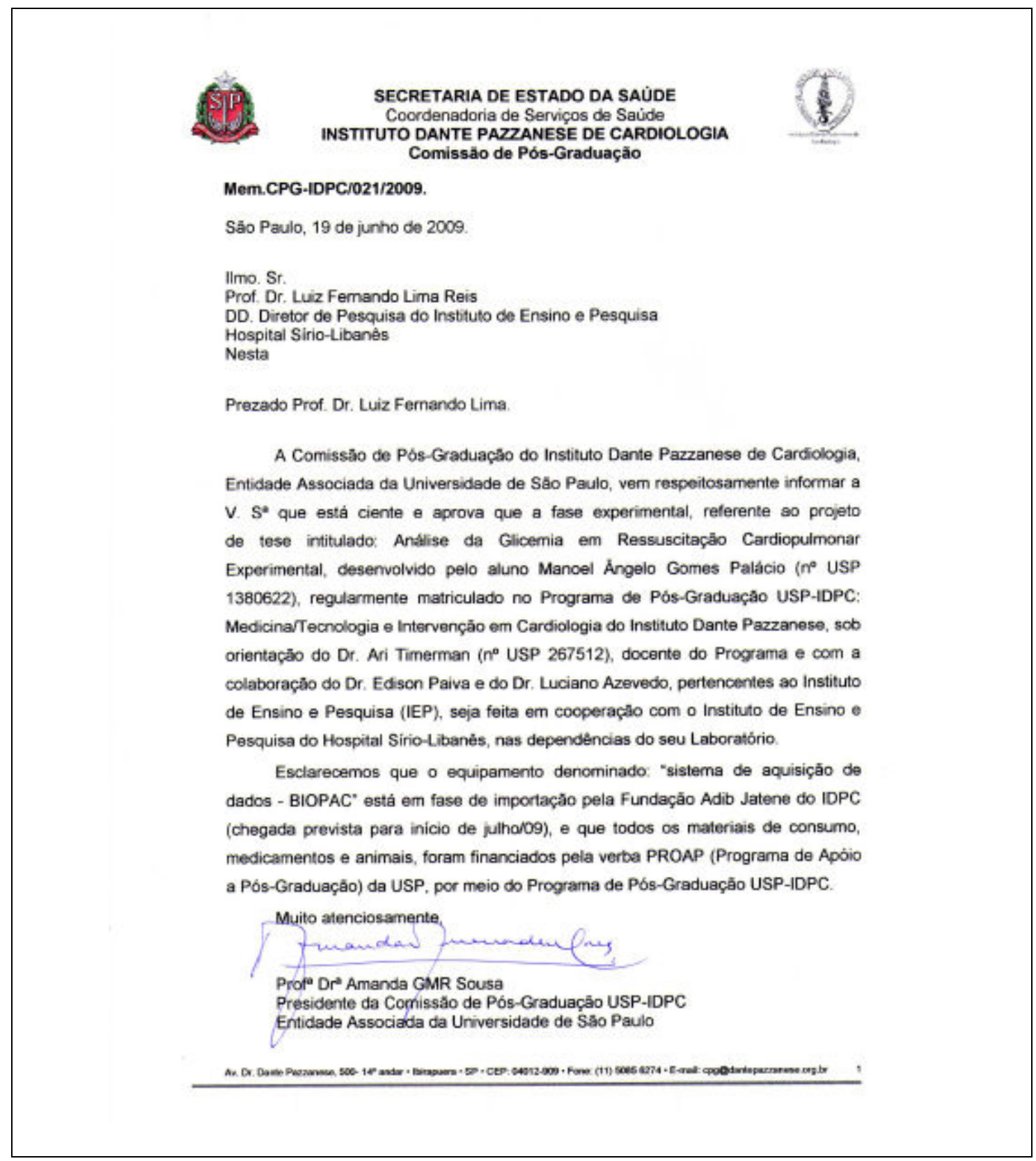


Anexo B - Documento de aprovação do Comitê de Ética no Uso de Animais do Instituto de Ensino e Pesquisa do Hospital Sírio-Libanês.

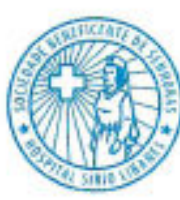

\section{Hospital \\ Sírılibanês \\ INSTITUTO DE ENSINO E PESQUISA}

COMISSÃO DE ÉTICA NO USO DE ANIMAIS - CEUA HOSPITAL SIRIO-LIBANÊS

REGISTRO CEUA: CEUA2009/12

PESQUISADOR PRINCIPAL: Dr. Edson Paiva

PROJETO DE PESQUISA: Análise da glicemia em ressuscitaçào cardiopulmonar experimental.

Prezado Pesquisador,

A Comissåo de Ética no Uso de Animais do instituto de Ensino de Pesquisa do Hospital Sirio-Libanés analisou e APROVOU o protocolo de pesquisa em 13 de julho de 2009.

\section{INFORMACOES IMPORTANTES:}

a) A Comissáo de Ética devera receber relatorios parciais e final scbre a pesquisa,

b) Comunicar ateraçbes no projeto. 
Anexo C - Documento de aprovação do Comitê de Ética no Uso de Animais do Instituto Dante Pazzanese de Cardiologia.

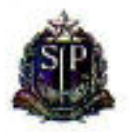

\section{SECRETARIA DE ESTADO DA SAÚDE \\ Coordenadoria de Serviços de Saúde INSTITUTO DANTE PAZZANESE DE CARDIOLOGIA}

Comissão de Ética no Uso de ANIMAIS

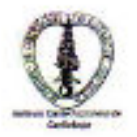

REGISTRO CEUA: PROJETO 2010102

COORDENADOR DO PROJETO: Ari Timerman

PROJETO DE PESQUISA: Análise da glicemia em nessuscitaçăo cardiopulmonar experimental.

Prezado Coordenador

A Comissaio de Ética para o Uso de Animais (CEUA) do Instituto Dante Pazzanese de Cardiologia (IDPC), órgåo responsável pelo acompanhamenta das atividades que envolvam a utilizaçāo de animais, analisou e APROVOU o projeto de pesquisa em 02 de março de 2010.

o Coordenador do Projeto deverá encaminhar ao CEUA, relatórios parciais e final das atividades.

A duração do projeto è de seis meses. Comunicar alterações no projeto.

Sắo Paulo, 02 de março de 2010.

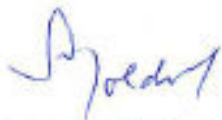

Prof. Dr. Saul Goldenberg

Presidente da CEUA - IDPC 
Anexo D - Fórmulas.

\section{VARIÁVEL}

\section{FÓRMULA}

Conteúdo Arterial de $\mathrm{O}_{2}\left(\mathrm{CaO}_{2}\right) \quad\left(\mathrm{Hb} \times \mathrm{sO}_{2} \times 0,0138\right)+\left(\mathrm{pO}_{2} \times 0,0031\right)$

$(\mathrm{mL} / \mathrm{dL})$

Conteúdo Venoso de $\mathrm{O}_{2}\left(\mathrm{CvO}_{2}\right) \quad\left(\mathrm{Hb} \times \mathrm{sO}_{2} \times 0,0138\right)+\left(\mathrm{pO}_{2} \times 0,0031\right)$

$(\mathrm{mL} / \mathrm{dL})$

$\Delta$ Conteúdo de $\mathrm{O}_{2}\left(\mathrm{Ca}-\mathrm{vO}_{2}\right) \quad \mathrm{CaO}_{2}-\mathrm{CvO}_{2}$

$(\mathrm{mL} / \mathrm{dL})$

Oferta de Oxigênio

$\mathrm{CaO}_{2} \times \mathrm{DC} \times 10$

$(\mathrm{mL} / \mathrm{min})$

Consumo de Oxigênio

$\mathrm{Ca}-\mathrm{vO}_{2} \times \mathrm{DC} \times 10$

$(\mathrm{mL} / \mathrm{min})$

DC: Débito Cardíaco contínuo mensurado;

$\Delta$ : Diferença;

$\mathrm{Hb}$ : Hemoglobina

$\mathrm{sO}_{2}$ : Saturação de oxigênio 
Anexo E - Gráfico para cálculo do tamanho da amostra.

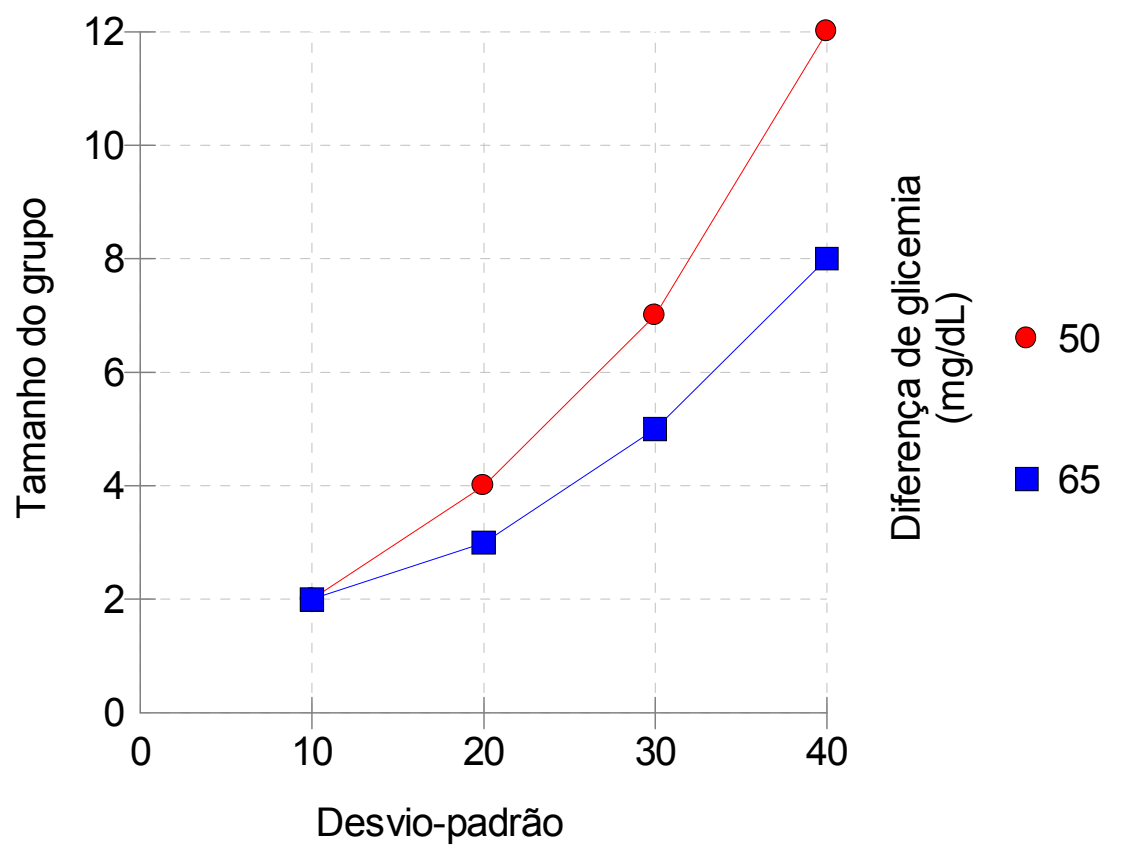

Anexo $\mathrm{E}$ - Por meio de teste $\mathrm{t}$, para se alcançar a significância de uma diferença de $50 \mathrm{mg} / \mathrm{dL}$ entre as glicemias de dois grupos independentes, com desvio-padrão de 40 mg/dL, são necessários 12 animais em cada grupo. Se a diferença for de $65 \mathrm{mg} / \mathrm{dL}$, oito animais são suficientes. 
Anexo F - Evolução de variáveis do sangue venoso misto conforme o retorno da circulação espontânea (RCE).
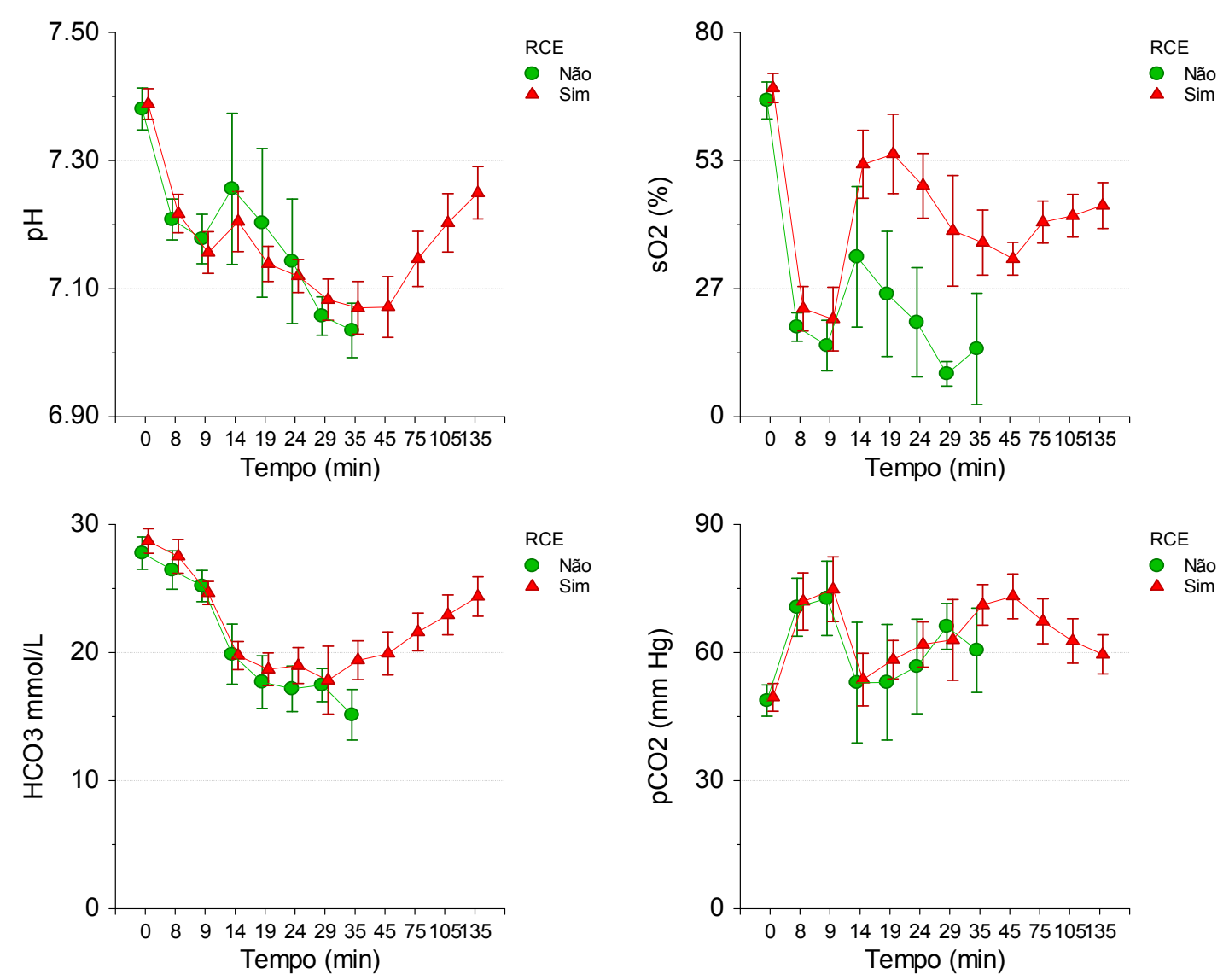

Anexo $\mathrm{F}$ - Bicarbonato e $\mathrm{pH}$ à esquerda, saturação de $\mathrm{O}_{2}$ e pressão parcial de $\mathrm{CO}_{2}$ à direita, conforme o retorno da circulação espontânea (RCE). Média \pm 2 erro-padrão. 
Anexo G - Evolução de variáveis do sangue venoso misto de acordo com o fármaco aplicado.
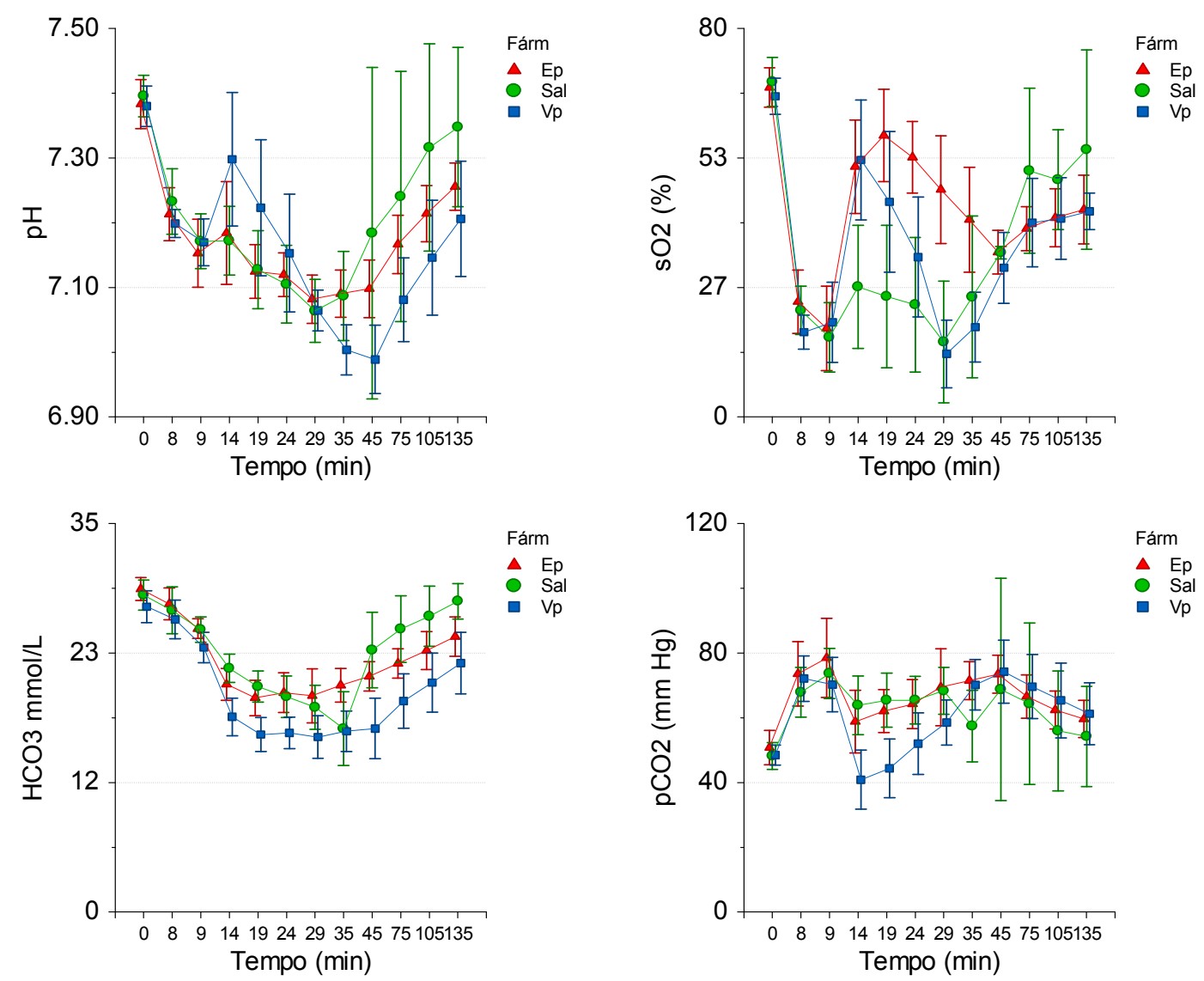

Anexo $\mathrm{G}$ - Bicarbonato e pH à esquerda, saturação de $\mathrm{O}_{2}$ e pressão parcial de $\mathrm{CO}_{2}$ à direita, de acordo com o fármaco Epinefrina (Ep), Vasopressina (Vp) ou Salina (Sal) aplicados aos 9 min. Média \pm 2 erro-padrão. 
Anexo H - Auxílio à pesquisa.

Esta pesquisa recebeu auxílio financeiro e cooperação interinstitucional.

Materiais de consumo e animais

Comissão de Pós-Graduação - Instituto Dante Pazzanese.

PROAP - CAPES

USP DANTE PAZZANESE PROAP 0552008.

Laboratório de Pesquisa de Medicina Intensiva (CT2)

Instituto de Ensino e Pesquisa - Hospital Sírio-Libanês.

\section{Materiais permanentes}

Fundação Adib Jatene - Instituto Dante Pazzanese de Cardiologia. 


\section{REFERÊNCIAS}

1. Opie LH. Metabolic management of acute myocardial infarction comes to the fore and extends beyond control of hyperglycemia. Circulation. 2008;117:2172-2177

2. Yang SW, Zhou YJ, Nie XM, Liu YY, Du J, Hu DY, Jia DA, Gao F, Hu B, Fang Z, Han HY, Liu XL, Yan ZX, Wang JL, Hua Q, Shi YJ, Li HW. Effect of abnormal fasting plasma glucose level on all-cause mortality in older patients with acute myocardial infarction: Results from the beijing elderly acute myocardial infarction study (beamis). Mayo Clinic proceedings. Mayo Clinic. 2011;86:94-104

3. Vora NA, Shook SJ, Schumacher HC, Tievsky AL, Albers GW, Wechsler LR, Gupta R. A 5-item scale to predict stroke outcome after cortical middle cerebral artery territory infarction: Validation from results of the diffusion and perfusion imaging evaluation for understanding stroke evolution (defuse) study. Stroke; a journal of cerebral circulation. 2011;42:645-649

4. Verhoeven JJ, den Brinker M, Hokken-Koelega AC, Hazelzet JA, Joosten KF. Pathophysiological aspects of hyperglycemia in children with meningococcal sepsis and septic shock: A prospective, observational cohort study. Critical Care. 2011;15:R44

5. Sykora M, Diedler J, Poli S, Rizos T, Kellert L, Turcani P, Steiner T. Association of non-diabetic hyperglycemia with autonomic shift in acute ischaemic stroke. European journal of neurology : the official journal of the European Federation of Neurological Societies. 2011

6. Sanjuan R, Nunez J, Blasco ML, Minana G, Martinez-Maicas H, Carbonell N, Palau P, Bodi V, Sanchis J. Prognostic implications of stress hyperglycemia in acute st elevation myocardial infarction. Prospective observational study. Revista Espanola de Cardiologia. 2011;64:201-207

7. Qureshi Al, Palesch YY, Martin R, Novitzke J, Cruz-Flores S, Ehtisham A, Ezzeddine MA, Goldstein JN, Kirmani JF, Hussein HM, Suri MF, Tariq N, Liu Y. Association of serum glucose concentrations during acute hospitalization with hematoma expansion, perihematomal edema, and three month outcome among patients with intracerebral hemorrhage. Neurocrit Care. 2011

8. Putaala J, Sairanen T, Meretoja A, Lindsberg PJ, Tiainen M, Liebkind R, Strbian D, Atula S, Artto V, Rantanen K, Silvonen P, Piironen K, Curtze S, Happola O, Mustanoja S, Pitkaniemi J, Salonen O, Silvennoinen H, Soinne L, Kuisma M, Tatlisumak T, Kaste M. Post-thrombolytic hyperglycemia and 3-month outcome in acute ischemic stroke. Cerebrovascular Diseases. 2011;31:83-92

9. Polito A, Brouland JP, Porcher R, Sonneville R, Siami S, Stevens RD, Guidoux C, Maxime V, Lorin de la Grandmaison G, Chretien F, Gray F, Annane D, Sharshar T. Hyperglycaemia and apoptosis of microglial cells in human septic shock. Critical Care. 2011;15:R131

10. Munoz C, Villanueva G, Fogg L, Johnson T, Hannold K, Agruss J, Baldwin D. Impact of a subcutaneous insulin protocol in the emergency department: Rush emergency department hyperglycemia intervention (redhi). The Journal of emergency medicine. 2011;40:493-498

11. Lazzeri C, Valente S, Attana P, Chiostri M, Picariello C, Gensini GF. Acute hyperglycemia and insulin resistance in acute heart failure syndromes without previously known diabetes. Intern Emerg Med. 2011 
12. Yang SW, Zhou YJ, Hu DY, Nie XM, Liu YY, Hua Q, Wang X, Li HW. Association between admission hypoglycaemia and in-hospital and 3-year mortality in older patients with acute myocardial infarction. Heart. 2010;96:1444-1450

13. Vis MM, Engstrom AE, Sjauw KD, Tjong FV, Baan J, Jr., Koch KT, DeVries JH, Tijssen JG, de Winter RJ, Piek JJ, Henriques JP. Plasma glucose and not hemoglobin or renal function predicts mortality in patients with stemi complicated with cardiogenic shock. J Cardiovasc Med (Hagerstown). 2010;11:827-831

14. Loomba RS, Arora R. Hyperglycemia and acute coronary syndrome: A systematic review of hyperglycemia's impact on acs. Am J Ther. 2010;17:e48-51

15. Leite SA, Locatelli SB, Niece SP, Oliveira AR, Tockus D, Tosin T. Impact of hyperglycemia on morbidity and mortality, length of hospitalization and rates of rehospitalization in a general hospital setting in brazil. Diabetol Metab Syndr. 2010;2:49

16. Issa VS, Amaral AF, Cruz FD, Ayub-Ferreira SM, Guimaraes GV, Chizzola PR, Souza GE, Bocchi EA. Glycemia and prognosis of patients with chronic heart failure-subanalysis of the long-term prospective randomized controlled study using repetitive education at six-month intervals and monitoring for adherence in heart failure outpatients (remadhe) trial. American Heart Journal. 2010;159:90-97

17. Dziewierz A, Giszterowicz D, Siudak Z, Rakowski T, Dubiel JS, Dudek D. Admission glucose level and in-hospital outcomes in diabetic and non-diabetic patients with acute myocardial infarction. Clinical research in cardiology : official journal of the German Cardiac Society. 2010;99:715-721

18. Dziedzic T, Pera J, Trabka-Janik E, Szczudlik A, Slowik A. The impact of postadmission glycemia on stroke outcome: Glucose normalisation is associated with better survival. Atherosclerosis. 2010;211:584-588

19. de Mulder M, Cornel JH, van der Ploeg T, Boersma E, Umans VA. Elevated admission glucose is associated with increased long-term mortality in myocardial infarction patients, irrespective of the initially applied reperfusion strategy. American Heart Journal. 2010;160:412-419

20. Angeli F, Verdecchia P, Karthikeyan G, Mazzotta G, Del Pinto M, Repaci S, Gatteschi C, Gentile G, Cavallini C, Reboldi G. New-onset hyperglycemia and acute coronary syndrome: A systematic overview and meta-analysis. Curr Diabetes Rev. 2010;6:102110

21. Pesaro AE, Nicolau JC, Serrano CV, Jr., Truffa R, Gaz MV, Karbstein R, Giraldez RR, Kalil Filho R, Ramires JA. Influence of leukocytes and glycemia on the prognosis of patients with acute myocardial infarction. Date of Input: 21/3/2011. 2009;92:84-93

22. Kreutziger J, Wenzel V, Kurz A, Constantinescu MA. Admission blood glucose is an independent predictive factor for hospital mortality in polytraumatised patients. Intensive Care Medicine. 2009;35:1234-1239

23. Kreutziger J, Schlaepfer J, Wenzel V, Constantinescu MA. The role of admission blood glucose in outcome prediction of surviving patients with multiple injuries. The Journal of trauma. 2009;67:704-708

24. Kosiborod M, Inzucchi SE, Spertus JA, Wang Y, Masoudi FA, Havranek EP, Krumholz $\mathrm{HM}$. Elevated admission glucose and mortality in elderly patients hospitalized with heart failure. Circulation. 2009;119:1899-1907 
25. Kolman L, Hu YC, Montgomery DG, Gordon K, Eagle KA, Jackson EA. Prognostic value of admission fasting glucose levels in patients with acute coronary syndrome. The American Journal of Cardiology. 2009;104:470-474

26. Ishihara M, Kojima S, Sakamoto T, Kimura K, Kosuge M, Asada Y, Tei C, Miyazaki S, Sonoda M, Tsuchihashi K, Yamagishi M, Shirai M, Hiraoka H, Honda T, Ogata Y, Ogawa $\mathrm{H}$. Comparison of blood glucose values on admission for acute myocardial infarction in patients with versus without diabetes mellitus. The American Journal of Cardiology. 2009;104:769-774

27. Griesdale DE, Tremblay MH, McEwen J, Chittock DR. Glucose control and mortality in patients with severe traumatic brain injury. Neurocrit Care. 2009;11:311-316

28. Goyal A, Mehta SR, Diaz R, Gerstein HC, Afzal R, Xavier D, Liu L, Pais P, Yusuf S. Differential clinical outcomes associated with hypoglycemia and hyperglycemia in acute myocardial infarction. Circulation. 2009;120:2429-2437

29. Falciglia M, Freyberg RW, Almenoff PL, D'Alessio DA, Render ML. Hyperglycemiarelated mortality in critically ill patients varies with admission diagnosis. Critical Care Medicine. 2009;37:3001-3009

30. Kosiborod M, Inzucchi SE, Krumholz HM, Xiao L, Jones PG, Fiske S, Masoudi FA, Marso SP, Spertus JA. Glucometrics in patients hospitalized with acute myocardial infarction: Defining the optimal outcomes-based measure of risk. Circulation. 2008;117:1018-1027

31. Pesaro AEP, Nicolau JC, Serrano Jr CV, Truffa R, Gaz MVB, Karbstein R, Giraldez RR, Kalil Filho R, Ramires JA. Influence of leukocytes and glycemia on the prognosis of patients with acute myocardial infarction. Date of Input: 21/3/2011. 2009;92:88-93

32. Zarich SW, Nesto RW. Implications and treatment of acute hyperglycemia in the setting of acute myocardial infarction. Circulation. 2007;115:e436-e439

33. Baker EH, Wood DM, Brennan AL, Clark N, Baines DL, Philips BJ. Hyperglycaemia and pulmonary infection. Proceedings of the Nutrition Society. 2007;65

34. Bader MS. Hyperglycemia and mortality in elderly patients with staphylococcus aureus bacteremia. Southern Medical Journal. 2007;100:252-256 210.1097/1001.smj.0000257383.0000266288.0000257368

35. Ali NA, O'Brien JM, Blum W, Byrd JC, Klisovic RB, Marcucci G, Phillips G, Marsh CB, Lemeshow S, Grever MR. Hyperglycemia in patients with acute myeloid leukemia is associated with increased hospital mortality. Cancer. 2007;110:96-102

36. Schiele F, Descotes-Genon V, Seronde MF, Blonde MC, Legalery P, Meneveau N, Ecarnot F, Mercier M, Penfornis A, Thebault L, Boumal D, Bassand JP. Predictive value of admission hyperglycaemia on mortality in patients with acute myocardial infarction. Diabet Med. 2006;23:1370-1376

37. Paiboonpol S. Hyperglycemia in acute cerebral infarction. J Med Assoc Thai. 2006;89:614-618

38. Baker EH. Hyperglycaemia is associated with poor outcomes in patients admitted to hospital with acute exacerbations of chronic obstructive pulmonary disease. Thorax. 2006;61:284-289 
39. Whitcomb BW, Pradhan EK, Pittas AG, Roghmann M-C, Perencevich EN. Impact of admission hyperglycemia on hospital mortality in various intensive care unit populations*. Critical Care Medicine. 2005;33:2772-2777

40. Sung J, Bochicchio GV, Joshi M, Bochicchio K, Tracy K, Scalea TM. Admission hyperglycemia is predictive of outcome in critically ill trauma patients. The Journal of Trauma: Injury, Infection, and Critical Care. 2005;59:80-83

41. Wasmuth HE, Kunz D, Graf Jr, Stanzel S, Purucker EA, Koch A, Gartung C, Heintz B, Gressner AM, Matern S, Lammert F. Hyperglycemia at admission to the intensive care unit is associated with elevated serum concentrations of interleukin- 6 and reduced ex vivo secretion of tumor necrosis factor-??*. Critical Care Medicine. 2004;32:1109-1114

42. Baird TA. Persistent poststroke hyperglycemia is independently associated with infarct expansion and worse clinical outcome. Stroke. 2003;34:2208-2214

43. Parsons MW, Barber PA, Desmond PM, Baird TA, Darby DG, Byrnes G, Tress BM, Davis SM. Acute hyperglycemia adversely affects stroke outcome: A magnetic resonance imaging and spectroscopy study. Annals of Neurology. 2002;52:20-28

44. Scott J, Robinson G, French J, Oconnell J, Alberti K, Gray C. Prevalence of admission hyperglycaemia across clinical subtypes of acute stroke. The Lancet. 1999;353:376377

45. Norhammar AM, Ryden L, Malmberg K. Admission plasma glucose. Independent risk factor for long-term prognosis after myocardial infarction even in nondiabetic patients. Diabetes Care. 1999;22:1827-1831

46. Intensive versus conventional glucose control in critically ill patients. New England Journal of Medicine. 2009;360:1283-1297

47. Read JL, Cheng EY. Intensive insulin therapy for acute hyperglycemia. AACN Advanced Critical Care. 2007;18:200-212

210.1097/1001.AACN.0000269264.0000222041.0000269261c

48. Van den Berghe G, Schoonheydt K, Becx P, Bruyninckx F, Wouters PJ. Insulin therapy protects the central and peripheral nervous system of intensive care patients. Neurology. 2005;64:1348-1353

49. Van den Berghe G, Wouters P, Weekers F, Verwaest C, Bruyninckx F, Schetz M, Vlasselaers D, Ferdinande P, Lauwers P, Bouillon R. Intensive insulin therapy in critically ill patients. New England Journal of Medicine. 2001;345:1359-1367

50. Kansagara D, Fu R, Freeman M, Wolf F, Helfand M. Intensive insulin therapy in hospitalized patients: A systematic review. Annals of Internal Medicine. 2011;154:268282

51. D'Ancona G, Bertuzzi F, Sacchi L, Pirone F, Stringi V, Arcadipane A, Bellazzi R, Pilato $M$. latrogenic hypoglycemia secondary to tight glucose control is an independent determinant for mortality and cardiac morbidity. Eur J Cardiothorac Surg. 2011

52. Krinsley J, Preiser JC. Intensive insulin therapy to control hyperglycemia in the critically ill: A look back at the evidence shapes the challenges ahead. Critical Care. 2010;14:330

53. Honiden S, Inzucchi SE. Glucose controversies in the icu. J Intensive Care Med. 2010 
54. Dokun AO. Lessons learned from glycemia control studies. Curr Diab Rep. 2010;10:133-138

55. Wiklund L. Circulatory arrest as a model for studies of global ischemic injury and neuroprotection. Annals of the New York Academy of Sciences. 2005;1053:205-219

56. Spöhr F, Wenzel V, Böttiger BW. Drug treatment and thrombolytics during cardiopulmonary resuscitation. Current Opinion in Anesthesiology. 2006;19:157-165 110.1097/1001.aco.0000192797.0000110420.a0000192791

57. Wiklund L, Sharma HS, Basu S. Circulatory arrest as a model for studies of global ischemic injury and neuroprotection. Annals of the New York Academy of Sciences. 2005;1053:205-219

58. Nolan JP, Neumar RW, Adrie C, Aibiki M, Berg RA, Böttiger BW, Callaway C, Clark RSB, Geocadin RG, Jauch EC. Post-cardiac arrest syndrome: Epidemiology, pathophysiology, treatment, and prognostication international liaison committee on resuscitation; the american heart association emergency cardiovascular care committee; the council on cardiovascular surgery and anesthesia; the council on cardiopulmonary, perioperative, and critical care; the council on clinical cardiology; the council on stroke. Resuscitation. 2008;79:350-379

59. Neumar RW, Nolan JP, Adrie C, Aibiki M, Berg RA, Bottiger BW, Callaway C, Clark RSB, Geocadin RG, Jauch EC, Kern KB, Laurent I, Longstreth WT, Jr, Merchant RM, Morley P, Morrison LJ, Nadkarni V, Peberdy MA, Rivers EP, Rodriguez-Nunez A, Sellke FW, Spaulding C, Sunde K, Vanden Hoek T. Post-cardiac arrest syndrome: Epidemiology, pathophysiology, treatment, and prognostication a consensus statement from the international liaison committee on resuscitation (american heart association, australian and new zealand council on resuscitation, european resuscitation council, heart and stroke foundation of canada, interamerican heart foundation, resuscitation council of asia, and the resuscitation council of southern africa); the american heart association emergency cardiovascular care committee; the council on cardiovascular surgery and anesthesia; the council on cardiopulmonary, perioperative, and critical care; the council on clinical cardiology; and the stroke council. Circulation. 2008;118:2452-2483

60. Verma S, Fedak PWM, Weisel RD, Butany J, Rao V, Maitland A, Li R-K, Dhillon B, Yau TM. Fundamentals of reperfusion injury for the clinical cardiologist. Circulation. 2002;105:2332-2336

61. Adrie C, Adib-Conquy M, Laurent I, Monchi M, Vinsonneau C, Fitting C, Fraisse F, Dinh-Xuan AT, Carli P, Spaulding C, Dhainaut J-F, Cavaillon J-M. Successful cardiopulmonary resuscitation after cardiac arrest as a "sepsis-like" syndrome. Circulation. 2002;106:562-568

62. Nolan JP, Neumar RW, Adrie C, Aibiki M, Berg RA, Bbttiger BW, Callaway C, Clark RS, Geocadin RG, Jauch EC, Kern KB, Laurent I, Longstreth WT, Merchant RM, Morley P, Morrison LJ, Nadkarni V, Peberdy MA, Rivers EP, Rodriguez-Nunez A, Sellke FW, Spaulding C, Sunde K, Vanden Hoek T. Post-cardiac arrest syndrome: Epidemiology, pathophysiology, treatment, and prognostication: A scientific statement from the international liaison committee on resuscitation; the american heart association emergency cardiovascular care committee; the council on cardiovascular surgery and anesthesia; the council on cardiopulmonary, perioperative, and critical care; the council on clinical cardiology; the council on stroke (part ii). Int Emerg Nurs. 2010;18:8-28

63. Neumar RW, Nolan JP, Adrie C, Aibiki M, Berg RA, Bottiger BW, Callaway C, Clark RS, Geocadin RG, Jauch EC, Kern KB, Laurent I, Longstreth WT, Jr., Merchant RM, 
Morley P, Morrison LJ, Nadkarni V, Peberdy MA, Rivers EP, Rodriguez-Nunez A, Sellke FW, Spaulding C, Sunde K, Vanden Hoek T. Post-cardiac arrest syndrome: Epidemiology, pathophysiology, treatment, and prognostication. A consensus statement from the international liaison committee on resuscitation (american heart association, australian and new zealand council on resuscitation, european resuscitation council, heart and stroke foundation of canada, interamerican heart foundation, resuscitation council of asia, and the resuscitation council of southern africa); the american heart association emergency cardiovascular care committee; the council on cardiovascular surgery and anesthesia; the council on cardiopulmonary, perioperative, and critical care; the council on clinical cardiology; and the stroke council. Circulation. 2008;118:2452-2483

64. Gonzalez MM, Berg RA, Nadkarni VM, Vianna CB, Kern KB, Timerman S, Ramires JA. Left ventricular systolic function and outcome after in-hospital cardiac arrest. Circulation. 2008;117:1864-1872

65. Andreka P, Frenneaux MP. Haemodynamics of cardiac arrest and resuscitation. Curr Opin Crit Care. 2006;12:198-203

66. Reynolds JC, Salcido DD, Menegazzi JJ. Coronary perfusion pressure and return of spontaneous circulation after prolonged cardiac arrest. Prehospital emergency care : official journal of the National Association of EMS Physicians and the National Association of State EMS Directors. 2010;14:78-84

67. Betz AE, Menegazzi JJ, Logue ES, Callaway CW, Wang HE. A randomized comparison of manual, mechanical and high-impulse chest compression in a porcine model of prolonged ventricular fibrillation. Resuscitation. 2006;69:495-501

68. Paradis NA, Martin GB, Rivers EP, Goetting MG, Appleton TJ, Feingold M, Nowak RM. Coronary perfusion pressure and the return of spontaneous circulation in human cardiopulmonary resuscitation. JAMA : the journal of the American Medical Association. 1990;263:1106-1113

69. Reynolds JC, Salcido DD, Menegazzi JJ. Coronary perfusion pressure and return of spontaneous circulation after prolonged cardiac arrest. Prehosp Emerg Care. 2010;14:78-84

70. Paradis N. Pressor drugs in the treatment of cardiac arrest. Cardiology Clinics. 2002;20:61-78

71. Nolan JP, De Latorre FJ, Steen PA, Chamberlain DA, Bossaert LL. Advanced life support drugs: Do they really work? Curr Opin Crit Care. 2002;8:212-218

72. Overgaard CB, Dzavik V. Inotropes and vasopressors: Review of physiology and clinical use in cardiovascular disease. Circulation. 2008;118:1047-1056

73. Weil M, Sun S. Clinical review: Devices and drugs for cardiopulmonary resuscitation opportunities and restraints. Critical Care. 2005;9:287

74. Morley PT. Drugs during cardiopulmonary resuscitation. Current Opinion in Critical Care. 2011;17:214-218

75. Penson PE, Ford WR, Broadley KJ. Vasopressors for cardiopulmonary resuscitation. Does pharmacological evidence support clinical practice? Date of Input: 20/4/2011. 2007;115:37-55 
76. Dager WE, Sanoski CA, Wiggins BS, Tisdale JE. Pharmacotherapy considerations in advanced cardiac life support. Pharmacotherapy. 2006;26:1703-1729

77. Zhong JQ, Dorian P. Epinephrine and vasopressin during cardiopulmonary resuscitation. Resuscitation. 2005;66:263-269

78. Nolan JP, De Latorre FJ, Steen PA, Chamberlain DA, Bossaert LL. Advanced life support drugs: Do they really work? Current Opinion in Critical Care. 2002;8:212-218

79. Paradis NA, Wenzel V, Southall J. Pressor drugs in the treatment of cardiac arrest. Cardiology Clinics. 2002;20:61-78, viii

80. Aung K, Htay T. Vasopressin for cardiac arrest: A systematic review and metaanalysis. Arch Intern Med. 2005;165:17-24

81. Wenzel V, Krismer AC, Arntz HR, Sitter H, Stadlbauer KH, Lindner KH. A comparison of vasopressin and epinephrine for out-of-hospital cardiopulmonary resuscitation. New England Journal of Medicine. 2004;350:105-113

82. Killingsworth CR, Wei C-C, Dell'Italia LJ, Ardell JL, Kingsley MA, Smith WM, Ideker $\mathrm{RE}$, Walcott GP. Short-acting \{beta\}-adrenergic antagonist esmolol given at reperfusion improves survival after prolonged ventricular fibrillation. Circulation. 2004;109:2469-2474

83. Nozari A, Rubertsson S, Wiklund L. Differences in the pharmacodynamics of epinephrine and vasopressin during and after experimental cardiopulmonary resuscitation. Resuscitation. 2001;49:59-72

84. Voelckel WG, Lindner KH, Wenzel V, Bonatti J, Hangler H, Frimmel C, Kunszberg E, Lingnau W. Effects of vasopressin and epinephrine on splanchnic blood flow and renal function during and after cardiopulmonary resuscitation in pigs. Crit Care Med. 2000;28:1083-1088

85. Poullis DM, Wenzel V, Lindner KH, Krismer AC, Miller EA, G. Voelckel W, Lingnau W. Repeated administration of vasopressin but not epinephrine maintains coronary perfusion pressure after early and late administration during prolonged cardiopulmonary resuscitation in pigs response. Circulation. 2000;101:e174-175

86. Achleitner U, Wenzel V, Strohmenger HU, Krismer AC, Lurie KG, Lindner KH, Amann A. The effects of repeated doses of vasopressin or epinephrine on ventricular fibrillation in a porcine model of prolonged cardiopulmonary resuscitation. Anesth Analg. 2000;90:1067-1075

87. Prengel AW, Lindner KH, Wenzel V, Tugtekin I, Anhäupl T. Splanchnic and renal blood flow after cardiopulmonary resuscitation with epinephrine and vasopressin in pigs. Resuscitation. 1998;38:19-24

88. BERG RA, OTTO CW, KERN KB, SANDERS AB, HILWIG RW, HANSEN KK, EWY GA. High-dose epinephrine results in greater early mortality after resuscitation from prolonged cardiac arrest in pigs: A prospective, randomized study. Critical Care Medicine. 1994;22:282-290

89. Wenzel V, Raab H, Dunser MW. Role of arginine vasopressin in the setting of cardiopulmonary resuscitation. Best Pract Res Clin Anaesthesiol. 2008;22:287-297

90. Wenzel V, Lindner $\mathrm{KH}$. Vasopressin combined with epinephrine during cardiac resuscitation: A solution for the future? Critical Care. 2006;10:125 
91. Krismer AC, Dunser MW, Lindner KH, Stadlbauer KH, Mayr VD, Lienhart HG, Arntz $\mathrm{RH}$, Wenzel V. Vasopressin during cardiopulmonary resuscitation and different shock states: A review of the literature. Am J Cardiovasc Drugs. 2006;6:51-68

92. Aung K, Htay T. Vasopressin for cardiac arrest: A systematic review and metaanalysis. Archives of internal medicine. 2005;165:17-24

93. Krismer AC, Wenzel V, Stadlbauer KH, Mayr VD, Lienhart HG, Arntz HR, Lindner KH. Vasopressin during cardiopulmonary resuscitation: A progress report. Critical Care Medicine. 2004;32:S432-435

94. Hatlestad D. Vasopressin: Improving resuscitation? Emerg Med Serv. 2004;33:85-89

95. Wenzel V, Lindner KH. Arginine vasopressin during cardiopulmonary resuscitation: Laboratory evidence, clinical experience and recommendations, and a view to the future. Critical Care Medicine. 2002;30:S157-161

96. Stiell I, Hebert P, Wells G, Vandemheen K, Tang A, Higginson L, Dreyer J, Clement C, Battram E, Watpool I. Vasopressin versus epinephrine for inhospital cardiac arrest: A randomised controlled trial. The Lancet. 2001;358:105-109

97. Lindner KH, Prengel AW, Pfenninger EG, Lindner IM, Strohmenger H-U, Georgieff M, Lurie KG. Vasopressin improves vital organ blood flow during closed-chest cardiopulmonary resuscitation in pigs. Circulation. 1995;91:215-221

98. Wenzel V, Raab H, Dünser MW. Role of arginine vasopressin in the setting of cardiopulmonary resuscitation. Best Practice \& Research Clinical Anaesthesiology. 2008;22:287-297

99. Babar SI, Berg RA, Hilwig RW, Kern KB, Ewy GA. Vasopressin versus epinephrine during cardiopulmonary resuscitation: A randomized swine outcome study. Resuscitation. 1999;41:185-192

100. Lindner KH, Brinkmann A, Pfenninger EG, Lurie KG, Goertz A, Lindner IM. Effect of vasopressin on hemodynamic variables, organ blood flow, and acid $\square$ base status in a pig model of cardiopulmonary resuscitation. Anesthesia \& Analgesia. 1993;77:427-435

101. Jochberger S, Wenzel V, Dunser MW. Arginine vasopressin as a rescue vasopressor agent in the operating room. Current opinion in anaesthesiology. 2005;18:396-404

102. Pellis $T$, Weil MH, Tang W, Sun S, Xie J, Song L, Checchia P. Evidence favoring the use of an \{alpha\}2-selective vasopressor agent for cardiopulmonary resuscitation. Circulation. 2003;108:2716-2721

103. Berg RA, Otto CW, Kern KB, Sanders AB, Hilwig RW, Hansen KK, Ewy GA. Highdose epinephrine results in greater early mortality after resuscitation from prolonged cardiac arrest in pigs: A prospective, randomized study. Crit Care Med. 1994;22:282290

104. Postma AV, Denjoy I, Hoorntje TM, Lupoglazoff J-M, Da Costa A, Sebillon P, Mannens MMAM, Wilde AAM, Guicheney P. Absence of calsequestrin 2 causes severe forms of catecholaminergic polymorphic ventricular tachycardia. Circ Res. 2002;91:e21-26

105. Nielsen TT, Støttrup NB, Løfgren B, Bøtker HE. Metabolic fingerprint of ischaemic cardioprotection: Importance of the malate-aspartate shuttle. Cardiovascular Research. 2011 
106. Loukogeorgakis SP, van den Berg MJ, Sofat R, Nitsch D, Charakida M, Haiyee BH, de Groot E, MacAllister RJ, Kuijpers TW, Deanfield JE. Role of nadph oxidase in endothelial ischemia/reperfusion injury in humans. Circulation. 2010;121:2310-2316

107. Youngquist S, Niemann J, Heyming T, Rosborough J. The central nervous system cytokine response to global ischemia following resuscitation from ventricular fibrillation in a porcine model thists. Resuscitation. 2009;80:249-252

108. Minamishima S, Bougaki M, Sips PY, De Yu J, Minamishima YA, Elrod JW, Lefer DJ, Bloch KD, Ichinose F. Hydrogen sulfide improves survival after cardiac arrest and cardiopulmonary resuscitation via a nitric oxide synthase 3-dependent mechanism in mice. Circulation. 2009;120:888-896

109. Dezfulian C, Shiva S, Alekseyenko A, Pendyal A, Beiser DG, Munasinghe JP, Anderson SA, Chesley CF, Vanden Hoek TL, Gladwin MT. Nitrite therapy after cardiac arrest reduces reactive oxygen species generation, improves cardiac and neurological function, and enhances survival via reversible inhibition of mitochondrial complex i. Circulation. 2009;120:897-905

110. Wu D, Bassuk J, Arias J, Kurlansky P, Lozano H, Lamas G, Adams JA. Different roles of nitric oxide synthase isoforms in cardiopulmonary resuscitation in pigs Resuscitation. 2007;73:144-153

111. Wu D, Bassuk J, Arias J, Peschiera I, Lamet A, Kurlansky P, Adams JA. Postresuscitation reperfusion injury: Comparison of periodic gz acceleration versus thumper cpris. Resuscitation. 2006;70:454-462

112. Oliver JA, Landry DW. Potassium channels and septic shock. Crit Care Med. 2006;34:1255-1257

113. Anderson TC, Li C-Q, Shao Z-H, Hoang T, Chan KC, Hamann KJ, Becker LB, Vanden Hoek TL. Transient and partial mitochondrial inhibition for the treatment of postresuscitation injury: Getting it just right. Critical Care Medicine. 2006;34:S474S482

114. Bolli R, Becker L, Gross G, Mentzer R, Jr, Balshaw D, Lathrop DA. Myocardial protection at a crossroads: The need for translation into clinical therapy. Circ Res. 2004;95:125-134

115. HWANG YC, SATO S, TSAI J-Y, YAN S, BAKR S, ZHANG H, OATES PJ, RAMASAMY R. Aldose reductase activation is a key component of myocardial response to ischemia. The FASEB Journal. 2002;16:243-245

116. Gazmuri RJ, Ayoub IM, Hoffner E, Kolarova JD. Successful ventricular defibrillation by the selective sodium-hydrogen exchanger isoform-1 inhibitor cariporide. Circulation. 2001;104:234-239

117. Nakamura M, Thourani VH, Ronson RS, Velez DA, Ma X-L, Katzmark S, Robinson J, Schmarkey LS, Zhao Z-Q, Wang N-P, Guyton RA, Vinten-Johansen J. Glutathione reverses endothelial damage from peroxynitrite, the byproduct of nitric oxide degradation, in crystalloid cardioplegia. Circulation. 2000;102:III-332-338

118. Cooper JA, Cooper JD, Cooper JM. Cardiopulmonary resuscitation: History, current practice, and future direction. Circulation. 2006;114:2839-2849

119. Weisfeldt ML, Sugarman J, Bandeen-Roche K. Toward definitive trials and improved outcomes of cardiac arrest. Circulation. 2010;121:1586-1588 
120. Gazmuri RJ, Nadkarni VM, Nolan JP, Arntz H-R, Billi JE, Bossaert L, Deakin CD, Finn J, Hammill WW, Handley AJ, Hazinski MF, Hickey RW, Jacobs I, Jauch EC, Kloeck WGJ, Mattes MH, Montgomery WH, Morley P, Morrison LJ, Nichol G, O'Connor RE, Perlman J, Richmond S, Sayre M, Shuster M, Timerman S, Weil MH, Weisfeldt ML, Zaritsky A, Zideman DA. Scientific knowledge gaps and clinical research priorities for cardiopulmonary resuscitation and emergency cardiovascular care identified during the 2005 international consensus conference on ecc and cpr science with treatment recommendations: A consensus statement from the international liaison committee on resuscitation (american heart association, australian resuscitation council, european resuscitation council, heart and stroke foundation of canada, interamerican heart foundation, resuscitation council of southern africa, and the new zealand resuscitation council); the american heart association emergency cardiovascular care committee; the stroke council; and the cardiovascular nursing council. Circulation. 2007;116:25012512

121. Ornato JP, Peberdy MA. Measuring progress in resuscitation: It's time for a better tool. Circulation. 2006;114:2754-2756

122. Nelson DL, Cox MM. Lehninger principles of biochemistry. 2008

123. Eipel C, Abshagen K, Vollmar B. Regulation of hepatic blood flow: The hepatic arterial buffer response revisited. World journal of gastroenterology : WJG. 2010;16:60466057

124. Takala J. Determinants of splanchnic blood flow. British journal of anaesthesia. 1996;77:50-58

125. Ayuse T, Brienza N, O'Donnell CP, Robotham JL. Pressure-flow analysis of portal vein and hepatic artery interactions in porcine liver. The American journal of physiology. 1994;267:H1233-1242

126. Wood CL, Babcock CJ, Blum JJ. Effects of vasopressin on carbohydrate metabolism in hepatocytes from dehydrated rats. Proc Soc Exp Biol Med. 1981;167:129-136

127. Jakob A. Hormonal and metabolic control of hepatic carbohydrate metabolism. Molecular Aspects of Medicine. 1981;4:369-455

128. Kirk CJ, Hems DA. The control by vasopressin of carbohydrate and lipid metabolism in the perfused rat liver. Biochim Biophys Acta. 1979;583:474-482

129. Travers AH, Rea TD, Bobrow BJ, Edelson DP, Berg RA, Sayre MR, Berg MD, Chameides L, O'Connor RE, Swor RA. Part 4: Cpr overview: 2010 american heart association guidelines for cardiopulmonary resuscitation and emergency cardiovascular care. Circulation. 2010;122:S676-684

130. Khalid U, Juma AA. Paradigm shift: 'Abc' to 'cab' for cardiac arrests. Scand J Trauma Resusc Emerg Med. 2010;18:59

131. Valenzuela TD, Kern KB, Clark LL, Berg RA, Berg MD, Berg DD, Hilwig RW, Otto CW, Newburn D, Ewy GA. Interruptions of chest compressions during emergency medical systems resuscitation. Circulation. 2005;112:1259-1265

132. Kern KB, Hilwig RW, Berg RA, Sanders AB, Ewy GA. Importance of continuous chest compressions during cardiopulmonary resuscitation: Improved outcome during a simulated single lay-rescuer scenario. Circulation. 2002;105:645-649 
133. Berg RA, Sanders AB, Kern KB, Hilwig RW, Heidenreich JW, Porter ME, Ewy GA. Adverse hemodynamic effects of interrupting chest compressions for rescue breathing during cardiopulmonary resuscitation for ventricular fibrillation cardiac arrest. Circulation. 2001;104:2465-2470

134. Andreas N, Jon N, Jo K-J, Joar E, Peter P, Helge M, Volker W, Karl HL, Werner S, Morten P, Petter AS, Hans-Ulrich S. Comparison of mechanical characteristics of the human and porcine chest during cardiopulmonary resuscitation. Resuscitation. 2009;80:463-469

135. Sattur S, Kern KB. Increasing cpr duration prior to first defibrillation does not improve return of spontaneous circulation or survival in a swine model of prolonged ventricular fibrillation. Resuscitation. 2009;80:382-382

136. Paal P, Neurauter A, Loedl M, Pehböck D, Herff H, von Goedecke A, Lindner KH, Wenzel $\mathrm{V}$. Effects of stomach inflation on haemodynamic and pulmonary function during cardiopulmonary resuscitation in pigs 2 . Resuscitation. 2009;80:365-371

137. Osipov RM, Robich MP, Feng J, Clements RT, Liu Y, Glazer HP, Wagstaff J, Bianchi $\mathrm{C}$, Sellke FW. Effect of thrombin fragment (tp508) on myocardial ischemia-reperfusion injury in hypercholesterolemic pigs. J App/ Physiol. 2009;106:1993-2001

138. Xu T, Tang W, Ristagno G, Sun S, Weil MH. Myocardial performance index following electrically induced or ischemically induced cardiac arrest 2 . Resuscitation. 2008;76:103-107

139. Vanmeter K, Sheps S, Kriedt F, Moises J, Barratt D, Murphylavoie H, Harch P, Bazan $\mathrm{N}$. Hyperbaric oxygen improves rate of return of spontaneous circulation after prolonged normothermic porcine cardiopulmonary arrest ț. Resuscitation. 2008;78:200-214

140. Xanthos T, Tsirikos-Karapanos N, Papadimitriou D, Vlachos IS, Tsiftsi K, Ekmektzoglou KA, Papadimitriou L. Resuscitation outcomes comparing year 2000 with

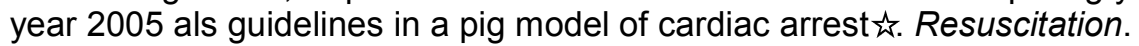
2007;73:459-466

141. Wang J, Weil M, Tang W, Chang Y, Huang L. A comparison of electrically induced cardiac arrest with cardiac arrest produced by coronary occlusion 2 . Resuscitation. 2007;72:477-483

142. Sullivan JL, Melnick SB, Chapman FW, Walcott GP. Porcine defibrillation thresholds with chopped biphasic truncated exponential waveforms 2 . Resuscitation.

2007;74:325-331

143. Ristagno G, Tang W, Xu TY, Sun S, Weil MH. Outcomes of cpr in the presence of partial occlusion of left anterior descending coronary artery 2 . Resuscitation. 2007;75:357-365

144. Tang W, Snyder D, Wang J, Huang L, Chang YT, Sun S, Weil MH. One-shock versus three-shock defibrillation protocol significantly improves outcome in a porcine model of prolonged ventricular fibrillation cardiac arrest. Circulation. 2006;113:2683-2689

145. Sigurdsson G, Yannopoulos D, McKnite SH, Sondeen JL, Benditt DG, Lurie KG. Effects of an inspiratory impedance threshold device on blood pressure and short term survival in spontaneously breathing hypovolemic pigs th. Resuscitation. 2006;68:399404 
146. Pytte M, Kramer-Johansen J, Eilevstjønn J, Eriksen M, Strømme TA, Godang K, Wik L, Steen PA, Sunde K. Haemodynamic effects of adrenaline (epinephrine) depend on chest compression quality during cardiopulmonary resuscitation in pigs 2 . Resuscitation. 2006;71:369-378

147. Zhang Y, Boddicker KA, Rhee BJ, Davies LR, Kerber RE. Effect of nitric oxide synthase modulation on resuscitation success in a swine ventricular fibrillation cardiac arrest model ㄴ. Resuscitation. 2005;67:127-134

148. Rubertsson S, Karlsten R. Increased cortical cerebral blood flow with lucas; a new device for mechanical chest compressions compared to standard external compressions during experimental cardiopulmonary resuscitation. Resuscitation. 2005;65:357-363

149. Rhee BJ, Zhang Y, Boddicker KA, Davies LR, Kerber RE. Effect of hypothermia on transthoracic defibrillation in a swine model 2 . Resuscitation. 2005;65:79-85

150. Nordmark J, Rubertsson S. Induction of mild hypothermia with infusion of cold $\left(4^{\circ} \mathrm{C}\right)$ fluid during ongoing experimental cprit. Resuscitation. 2005;66:357-365

151. Anastasiou-Nana MI, Tsagalou EP, Mavrikakis EM, Siafakas KX, Tsolakis EJ, Drakos SG, Dalianis A, Karelas J, Terrovitis JV, Nanas JN. Myocardial ischaemic preconditioning in the pig has no effect on the ventricular fibrillation and defibrillation thresholds 谞. Resuscitation. 2005;64:373-376

152. Tsagalou E. Time course of fibrillation and defibrillation thresholds after an intravenous bolus of amiodarone?An experimental study. Resuscitation. 2004;61:83-89

153. Prado AMdRBd. Hematimetrical normal values in sus scrofa dom. Lineu, 1758 swines, of races landrace and large white in parana, brazil. Revista Acadêmica: ciências agrárias e ambientais. 2004;2:65-80

154. Niemann JT. A model of ischemically induced ventricular fibrillation for comparison of fixed-dose and escalating-dose defibrillation strategies. Academic Emergency Medicine. 2004;11:619-624

155. Wu, D. Calcitonin gene-related peptide protects against whole body ischemia in a porcine model of cardiopulmonary resuscitation. Resuscitation. 2003;59:139-145

156. Steen, S. The critical importance of minimal delay between chest compressions and subsequent defibrillation: A haemodynamic explanation. Resuscitation. 2003;58:249258

157. Ayoub IM. Sodium-hydrogen exchange inhibition during ventricular fibrillation: Beneficial effects on ischemic contracture, action potential duration, reperfusion arrhythmias, myocardial function, and resuscitability. Circulation. 2003;107:1804-1809

158. Parker SJ, Brown D, Kenward CE, Watkins PE. Pentoxifylline fails to improve organ dysfunction and survival when used in the resuscitation of a porcine model of haemorrhage and abdominal sepsis. Resuscitation. 2000;44:61-69

159. Niemann JT, Burian D, Garner D, Lewis RJ. Monophasic versus biphasic transthoracic countershock after prolonged ventricular fibrillation in a swine model. Journal of the American College of Cardiology. 2000;36:932-938 
160. Niemann JT, Burian D, Garner D, Lewis RJ. Transthoracic monophasic and biphasic defibrillation in a swine model: A comparison of efficacy, st segment changes, and postshock hemodynamics. Resuscitation. 2000;47:51-58

161. Tang W, Weil MH, Sun S, Yamaguchi H, Povoas HP, Pernat AM, Bisera J. The effects of biphasic and conventional monophasic defibrillation on postresuscitation myocardial function. Journal of the American College of Cardiology. 1999;34:815-822

162. Baron BJ, Sinert RH, Sinha AK, Buckley MC, Shaftan GW, Scalea TM. Effects of traditional versus delayed resuscitation on serum lactate and base deficit. Resuscitation. 1999;43:39-46

163. Wenzel V, Lindner KH, Mayer H, Lurie KG, Prengel AW. Vasopressin combined with nitroglycerin increases endocardial perfusion during cardiopulmonary resuscitation in pigs. Resuscitation. 1998;38:13-17

164. Behringer W, Sterz F, Domanovits H, Hohenberger B, Schorkhuber W, Frass M, Losert U, Laggner AN. Effects of manual high-impulse cpr on myocardial perfusion during cardiac arrest in pigs. Resuscitation. 1997;34:271-279

165. Wik L, Naess PA, llebekk A, Nicolaysen G, Steen PA. Effects of various degrees of compression and active decompression on haemodynamics, end-tidal co2, and ventilation during cardiopulmonary resuscitation of pigs. Resuscitation. 1996;31:45-57

166. Traverso LW. Effectiveness of aprotinin in blocking a hypotensive factor of pancreatic origin from the pig, dog and monkey. Resuscitation. 1985;12:271-277

167. Reineke H, Dick W, Ahnefeld FW, Milewski P, Steinhardt B. Pulmonary compliance and gas exchange in newborn pigs during artificial ventilation. Resuscitation. 1974;3:69-79

168. Fricker J. The pig: A new model of diabetic atherosclerosis. Drug Discov Today. 2001;6:921-922

169. Nielsen HB, Clemmesen JO, Skak C, Ott P, Secher NH. Attenuated hepatosplanchnic uptake of lactate during intense exercise in humans. Journal of Applied Physiology. 2002;92:1677-1683

170. Bergeron R, Kjaer M, Simonsen L, Bulow J, Galbo H. Glucose production during exercise in humans: A-hv balance and isotopic-tracer measurements compared. $J$ Appl Physiol. 1999;87:111-115

171. Vanoverschelde JL, Janier MF, Bakke JE, Marshall DR, Bergmann SR. Rate of glycolysis during ischemia determines extent of ischemic injury and functional recovery after reperfusion. American Journal of Physiology - Heart and Circulatory Physiology. 1994;267:H1785-H1794

172. Krismer AC, Wenzel V, Voelckel WG, Stadlbauer K-H, Wagner-Berger H, Schaefer A, Lindner $\mathrm{KH}$. Effects of vasopressin on adrenal gland regional perfusion during experimental cardiopulmonary resuscitation. Resuscitation. 2003;56:223-228

173. Kuster J, Beuers $\mathrm{U}$, Jungermann $\mathrm{K}$. Modulation of the sympathetic nerve action on carbohydrate and ketone body metabolism by fatty acids, glucagon und insulin in perfused rat liver. Biological chemistry Hoppe-Seyler. 1989;370:1035-1044

174. Oviasu OA, Whitton PD. Hormonal control of pyruvate dehydrogenase activity in rat liver. The Biochemical journal. 1984;224:181-186 
175. Depre C, Vanoverschelde JLJ, Taegtmeyer H. Glucose for the heart. Circulation. 1999;99:578

176. Taegtmeyer H. Metabolism--the lost child of cardiology. Journal of the American College of Cardiology. 2000;36:1386

177. Cura AJ, Carruthers A. Acute modulation of sugar transport in brain capillary endothelial cell cultures during activation of the metabolic stress pathway. Journal of Biological Chemistry. 2010;285:15430-15439

178. Carruthers A, DeZutter J, Ganguly A, Devaskar SU. Will the original glucose transporter isoform please stand up! American Journal of Physiology - Endocrinology And Metabolism. 2009;297:E836-E848

179. Liang GY, Cai QY, Niu YM, Zheng H, Gao ZY, Liu DX, Xu G. Cardiac glucose uptake and suppressed expression/translocation of myocardium glucose transport-4 in dogs undergoing ischemia-reperfusion. Experimental biology and medicine. 2008;233:11421148

180. Katherine A. B. Davey PBG, Alice Warley, Richard Southworth. Immunogold labeling study of the distribution of glut-1 and glut-4 in cardiac tissue following stimulation by insulin or ischemia. Am J Physiol Heart Circ Physiol. 2007;292:H2009-H2019

181. Barros LF, Bittner CX, Loaiza A, Porras $\mathrm{OH}$. A quantitative overview of glucose dynamics in the gliovascular unit. Glia. 2007;55:1222-1237

182. Becker $\mathrm{C}$, Sevilla L, Tomàs E, Palacin M, Zorzano A, Fischer Y. The endosomal compartment is an insulin-sensitive recruitment site for glut4 and glut1 glucose transporters in cardiac myocytes. Endocrinology. 2001;142:5267-5276

183. Fillenz M, Lowry JP, Boutelle MG, Fray AE. The role of astrocytes and noradrenaline in neuronal glucose metabolism. Acta Physiol Scand. 1999;167:275-284

184. Egert S, Nguyen N, Schwaiger M. Contribution of a-adrenergic and b-adrenergic stimulation to ischemia-induced glucose transporter (glut) 4 and glut1 translocation in the isolated perfused. Circ Res. 1999;84:1407-1415

185. Young LH, Renfu Y, Russell R, Hu X, Caplan M, Ren J, Shulman GI, Sinusas AJ. Low-flow ischemia leads to translocation of canine heart glut- 4 and glut-1 glucose transporters to the sarcolemma in vivo. Circulation. 1997;95:415-422

186. Vannucci SJ, Maher F, Simpson IA. Glucose transporter proteins in brain: Delivery of glucose to neurons and glia. Glia. 1997;21:2-21

187. Li WM. In vivo glut4 translocation in lean and fatty zucker rat hearts effect of insulin dose and time. 1996

188. Wheeler TJ, Fell RD, Hauck MA. Translocation of two glucose transporters in heart: Effects of rotenone, uncouplers, workload, palmitate, insulin and anoxia. Date of Input: 12/4/2011. 1994;1196:191-200

189. Seki Y, Berggren JR, Houmard JA, Charron MJ. Glucose transporter expression in skeletal muscle of endurance-trained individuals. Medicine \& Science in Sports \& Exercise. 2006;38:1088-1092 
190. Nishimura H, Pallardo FV, Seidner GA, Vannucci S, Simpson IA, Birnbaum MJ. Kinetics of glut1 and glut4 glucose transporters expressed in xenopus oocytes. Journal of Biological Chemistry. 1993;268:8514-8520

191. Yang YM, Zhu J, Tan HQ, Liang Y, Zhang Y, Li Y, Li JD, Liu LS. [effect of high dose glucose-insulin-potassium infusion in patients with acute st-segment elevation myocardial infarction: Analysis of 7510 patients in china as part of create-ecla study]. Zhonghua Yi Xue Za Zhi. 2008;88:1806-1810

192. Kloner RA, Nesto RW. Glucose-insulin-potassium for acute myocardial infarction: Continuing controversy over cardioprotection. Circulation. 2008;117:2523-2533

193. Watanabe K, Yaoita H, Ogawa K, Oikawa M, Maehara K, Maruyama Y. Attenuated cardioprotection by ischemic preconditioning in coronary stenosed heart and its restoration by carvedilol. Cardiovasc Res. 2006;71:537-547

194. Uyttenboogaart M, Koch MW, Stewart RE, Vroomen PC, Luijckx GJ, De Keyser J. Moderate hyperglycaemia is associated with favourable outcome in acute lacunar stroke. Brain. 2007;130:1626-1630

195. Al-Bermani A, Desha YH, Morgan J, Soobrah R, Symonds CS, Taylor R. Management of incidental hyperglycaemia in acute medical emergencies. Diabet Med. 2005;22:937941

196. Nolan JP, Soar J. Postresuscitation care: Entering a new era. Current Opinion in Critical Care. 2010;16:216-222

197. Palácio MAG, Santos ES, Timerman A. A glicemia da admissão de 216 diabéticos internados por síndrome coronária aguda (sca) foi maior no infarto com supradesnivelamento de st e foi maior nos pacientes sob tratamento farmacológico do diabetes. Poster. Rev Soc Cardiol Estado de São Paulo. 2007;17:103

198. McFalls EO, Murad B, Liow JS, Gannon MC, Haspel HC, Lange A, Marx D, Sikora J, Ward HB. Glucose uptake and glycogen levels are increased in pig heart after repetitive ischemia. American journal of physiology. Heart and circulatory physiology. 2002;282:H205-211

199. Tian R, Abel ED. Responses of glut4-deficient hearts to ischemia underscore the importance of glycolysis. Circulation. 2001;103:2961

200. Brown AM, Ransom BR. Astrocyte glycogen and brain energy metabolism. Glia. 2007;55:1263-1271

201. Dienel GA, Hertz L. Astrocytic contributions to bioenergetics of cerebral ischemia. Glia. 2005;50:362-388

202. Hoxworth JM, Xu K, Zhou Y, Lust WD, LaManna JC. Cerebral metabolic profile, selective neuron loss, and survival of acute and chronic hyperglycemic rats following cardiac arrest and resuscitation. Brain Research. 1999;821:467-479

203. Snyder-Ramos SA, Bottiger BW. Molecular markers of brain damage--clinical and ethical implications with particular focus on cardiac arrest. Restor Neurol Neurosci. 2003;21:123-139

204. Simoes MV, Egert S, Ziegler S, Miyagawa M, Reder S, Lehner T, Nguyen N, Charron MJ, Schwaiger M. Delayed response of insulin-stimulated fluorine-18 deoxyglucose 
uptake in glucose transporter-4-null mice hearts. Journal of the American College of Cardiology. 2004;43:1690-1697

205. Southworth R, Dearling JL, Medina RA, Flynn AA, Pedley RB, Garlick PB. Dissociation of glucose tracer uptake and glucose transporter distribution in the regionally ischaemic isolated rat heart: Application of a new autoradiographic technique. European journal of nuclear medicine and molecular imaging. 2002;29:1334-1341

206. Ramasamy R, Hwang YC, Whang J, Bergmann SR. Protection of ischemic hearts by high glucose is mediated, in part, by glut-4. American Journal of Physiology-Heart and Circulatory Physiology. 2001;281:H290

207. Egert S, Nguyen N, Schwaiger M. Contribution of alpha-adrenergic and betaadrenergic stimulation to ischemia-induced glucose transporter (glut) 4 and glut1 translocation in the isolated perfused rat heart. Circ Res. 1999;84:1407-1415

208. Egert S, Nguyen N, Schwaiger M. Myocardial glucose transporter glut1: Translocation induced by insulin and ischemia. Journal of molecular and cellular cardiology. 1999;31:1337-1344

209. Lathers CM, Tumer N, Schoffstall JM. Plasma catecholamines, ph, and blood pressure during cardiac arrest in pigs. Resuscitation. 1989;18:59-74

210. Stanley WC. Myocardial energy metabolism during ischemia and the mechanisms of metabolic therapies. Journal of Cardiovascular Pharmacology and Therapeutics. 2004;9:S31-S45

211. Olson AL, Pessin JE. Structure, function, and regulation of the mammalian facilitative glucose transporter gene family. Annual Review of Nutrition. 1996;16:235-256

212. Mueckler M. Facilitative glucose transporters. European Journal of Biochemistry. 1994;219:713-725

213. Farand $P$, Hamel M, Lauzier F, Plante GE, Lesur O. Review article: Organ perfusion/permeability-related effects of norepinephrine and vasopressin in sepsis. Can J Anaesth. 2006;53:934-946

214. Studer W, Wu X, Siegemund M, Seeberger M. Resuscitation from cardiac arrest with adrenaline/epinephrine or vasopressin: Effects on intestinal mucosal tonometer pco2 during the postresuscitation period in rats. Resuscitation. 2002;53:201-207

215. Yannopoulos D, McKnite S, Aufderheide TP, Sigurdsson G, Pirrallo RG, Benditt D, Lurie KG. Effects of incomplete chest wall decompression during cardiopulmonary resuscitation on coronary and cerebral perfusion pressures in a porcine model of cardiac arrest 次. Resuscitation. 2005;64:363-372

216. Kern KB. Cardiopulmonary resuscitation without ventilation. Critical Care Medicine. 2000;28:N186-189

217. King LM, Opie LH. Glucose delivery is a major determinant of glucose utilisation in the ischemic myocardium with a residual coronary flow. Cardiovascular Research. 1998;39:381

218. Schwenk RW, Luiken JJ, Bonen A, Glatz JF. Regulation of sarcolemmal glucose and fatty acid transporters in cardiac disease. Cardiovascular Research. 2008;79:249-258 
219. Lei B, Lionetti V, Young ME, Chandler MP, d'Agostino C, Kang E, Altarejos M, Matsuo K, Hintze TH, Stanley WC, Recchia FA. Paradoxical downregulation of the glucose oxidation pathway despite enhanced flux in severe heart failure. Journal of molecular and cellular cardiology. 2004;36:567-576

220. Ramasamy R, Vannucci SJ, Yan SS, Herold K, Yan SF, Schmidt AM. Advanced glycation end products and rage: A common thread in aging, diabetes, neurodegeneration, and inflammation. Glycobiology. 2005;15:16R-28R 